\title{
Fluctuation Solution Theory Properties from Molecular Simulation
}

\author{
Abildskov, Jens; Wedberg, R.; O’Connell, John P.
}

Published in:

Fluctuation Theory of Solutions

Publication date:

2013

Link back to DTU Orbit

Citation (APA):

Abildskov, J., Wedberg, R., \& O'Connell, J. P. (2013). Fluctuation Solution Theory Properties from Molecular Simulation. In E. Matteoli, J. P. O'Connell, \& P. E. Smith (Eds.), Fluctuation Theory of Solutions: Applications in Chemistry, Chemical Engineering and Biophysics CRC Press.

\section{General rights}

Copyright and moral rights for the publications made accessible in the public portal are retained by the authors and/or other copyright owners and it is a condition of accessing publications that users recognise and abide by the legal requirements associated with these rights.

- Users may download and print one copy of any publication from the public portal for the purpose of private study or research.

- You may not further distribute the material or use it for any profit-making activity or commercial gain

- You may freely distribute the URL identifying the publication in the public portal

If you believe that this document breaches copyright please contact us providing details, and we will remove access to the work immediately and investigate your claim 


\title{
6. Fluctuation Solution Theory Properties from Molecular
}

\section{Simulation}

\author{
Jens Abildskov, ${ }^{1}$ R. Wedberg, ${ }^{2}$ and John P. O’Connell ${ }^{3}$ \\ ${ }^{1}$ CAPEC, Department of Chemical and Biochemical Engineering Building 229, Technical \\ University of Denmark, 2800 Kgs. Lyngby, Denmark \\ ${ }^{2}$ FOI-Swedish Defense Research Agency, Division of Defense and Security, Systems and \\ Technology, 14725 Tumba, Sweden \\ ${ }^{3}$ Department of Chemical Engineering, University of Virginia, \\ Charlottesville, VA 22904-4741 USA
}




\begin{abstract}
The thermodynamic properties obtained in the Fluctuation Solution Theory are based on spatial integrals of molecular TCFs between component pairs in the mixture. Molecular simulation, via either MD or MC calculations, can yield these correlation functions for model inter- and intramolecular potential functions. However, system-size limitations and statistical noise cause uncertainties in the functions at long range, and thus uncertainties or errors in the integrals. A number of methods such as truncation, distance shifting, long-range modeling, transforms, DCF matching, finite-size scaling and adaptive resolution, have been explored to overcome these problems. This chapter reviews the issues and published work associated with using molecular simulation to obtain FST properties. The results suggest that molecular simulation should now be more fully utilized for obtaining quantitative FST thermodynamic properties of solutions.
\end{abstract}




\subsection{Introduction}

Although FST integrals may be obtained from simulations, most modeling has been done with empirical expressions for the integrals which appear in the final exact expressions. These are described in Chapter 9 for both pure and mixed systems. However, since the RDFs for the three molecular pairs of a binary mixture can be directly obtained from MD simulations, in principle these may be integrated numerically to yield TCFIs. With force fields capable of representing real behavior, real FST property variations can be computed. However, this task has proven to be more difficult than might have been expected. We are not aware of a fully reliable method for obtaining TCFIs from RDFs for polyatomic molecules. However, recent progress in calculating RDFs, as described in this chapter, should eventually lead to direct applications for real systems of interest, significantly expanding the knowledge and application of fluctuation solution theory. The focus here is on smaller molecules; simulations of proteins and larger substances have been described in Chapter 5.

\subsection{Basics}

Unlike the atomic TCFs and pair RDFs introduced in Chapter 1, which are functions of only the spatial distance $r$ between the centers of mass of the two molecules, molecular correlation functions depend on orientations, $\omega_{1}$ and $\omega_{2}$. The TCF can be resolved into isotropic and anisotropic parts (Gray and Gubbins 1984),

$$
h_{i j}\left(r_{12}, \omega_{1}, \omega_{2}\right)=h_{i j}\left(r_{12}\right)+h_{i j}^{(a)}\left(r_{12}, \omega_{1}, \omega_{2}\right)
$$

where the isotropic part $h_{i j}\left(r_{12}\right)=g_{i j}\left(r_{12}\right)-1$ is obtained by averaging over angles, 


$$
h_{i j}\left(r_{12}\right) \equiv\left\langle h_{i j}\left(r_{12}, \omega_{1}, \omega_{2}\right)\right\rangle_{\omega_{1}, \omega_{2}}
$$

with,

$$
\langle\cdot\rangle_{\omega_{1}} \equiv \frac{1}{8 \pi^{2}} \int d \omega_{1} \equiv \frac{1}{8 \pi^{2}} \int_{0}^{2 \pi} d \phi \int_{-1}^{1} d\left(\cos \theta_{1}\right) \int_{0}^{2 \pi} d \chi_{1}
$$

Thus, the anisotropic part is constructed to vanish upon averaging over orientations,

$$
\left\langle h_{i j}^{(a)}\left(r_{12}, \omega_{1}, \omega_{2}\right)\right\rangle_{\omega_{1}, \omega_{2}}=0
$$

For flexible molecules, the correlation functions are also functions of the molecular conformation. We consider small substances those for which conformation effects can be ignored. The molecular OZ equation defines the molecular DCF, $c_{i j}\left(r_{12}, \omega_{1}, \omega_{2}\right)$ (Gray and Gubbins 1984),

$$
h_{i j}\left(\boldsymbol{r}_{12}, \omega_{1}, \omega_{2}\right)=c_{i j}\left(\boldsymbol{r}_{12}, \omega_{1}, \omega_{2}\right)+\rho \sum_{l} x_{l} \int\left\langle h_{i l}\left(\boldsymbol{r}_{13}, \omega_{1}, \omega_{3}\right) c_{l j}\left(\boldsymbol{r}_{32}, \omega_{3}, \omega_{2}\right)\right\rangle_{\omega_{3}} d \boldsymbol{r}_{3}
$$

where $\rho$ denotes the overall number density of the fluid and $x_{i}$ is the number fraction of component $i$. In analogy with Equations 6.1, 6.2, and 6.4 the DCF can be written as a sum of isotropic and anisotropic parts,

$$
c_{i j}\left(\boldsymbol{r}_{12}, \omega_{1}, \omega_{2}\right)=c_{i j}\left(r_{12}\right)+c_{i j}^{(a)}\left(\boldsymbol{r}_{12}, \omega_{1}, \omega_{2}\right)
$$

Substituting Equations 6.1 and 6.6 into Equation 6.5 and angle-averaging leads to,

$$
\begin{aligned}
h_{i j}(r)= & c_{i j}(r)+\rho \sum_{l} x_{l} \int h_{i l}\left(r_{13}\right) c_{l j}\left(r_{32}\right) d \boldsymbol{r}_{3}+ \\
& \rho \sum_{l} x_{l} \int\left\langle\left\langle h_{i l}^{(a)}\left(\boldsymbol{r}_{13}, \omega_{1}, \omega_{3}\right)\right\rangle_{\omega_{1}}\left\langle c_{l j}^{(a)}\left(\boldsymbol{r}_{32}, \omega_{3}, \omega_{2}\right)\right\rangle_{\omega_{2}}\right\rangle_{\omega_{3}} d \boldsymbol{r}_{3}
\end{aligned}
$$

Neglecting the last term in Equation 6.7 gives a simplified version of the OZ equation, in which the isotropic DCFs and TCFs are related without the anisotropic terms, 


$$
h_{i j}(r)=c_{i j}(r)+\rho \sum_{l} x_{l} \int h_{i l}\left(\left|\boldsymbol{r}-\boldsymbol{r}^{\prime}\right|\right) c_{l j}\left(r^{\prime}\right) d \boldsymbol{r}^{\prime}
$$

The various approaches to spatial integration of molecular simulation data described in section 6.3 use this equation instead of the full $\mathrm{OZ}$ equation. While this may not be fully rigorous, it is supported by several different analyses. First, Equation 6.8 is exact in some integral equation theories of fluids with anisotropic interactions, such as the mean-spherical approximation and the generalized mean field theory (Gray and Gubbins 1984). Second, Wang et al. showed from MC simulations of LJ particles with significant dipole and quadrupole moments, that anisotropic forces have limited effects on $h_{i j}(r)$ (Wang et al. 1973). Also, Gubbins and O'Connell showed that, for dense fluids, compressibility data for water and argon could be scaled with only two parameters, meaning that the anisotropic effects were not apparent in the water data (Gubbins and O'Connell 1974). In addition, several studies show successful corresponding-states scaling for the DCFIs (Brelvi and O'Connell 1972, 1975a, 1975b; Campanella, Mathias, and O'Connell 1987; Huang and O'Connell 1987; Abildskov, Ellegaard, and O'Connell 2009, 2010a, 2010b), as described in detail by O'Connell (O’Connell 1994). Finally, the approximation of Equation 6.8 is the first term of the spherical harmonic expansions of the molecular correlation functions. It is worth noting that Equation Equation 6.8 can be systematically improved by considering the spherical harmonic expansions of the orientation-dependent TCFs and DCFs (Gray and Gubbins 1984). The significance of this improvement is currently unknown, and probably depends on the system.

\subsubsection{Equivalence of Ensembles}

FST is based on the $\mu V T$ ensemble, so the KBIs are integrals over RDFs for an open system. However, simulations are most conveniently performed in the $N p T, N V T$, or $N V E$ ensembles. 
MD simulations in the $\mu V T$ ensemble are possible (Cagin and Pettitt 1991), but nontrivial due to the problems associated with inserting new particles (Beutler et al. 1994). For this and other reasons, simulations are normally done on closed systems, though rigorously, the corresponding KBIs are equal to 0 for unlike pairs and -1 for like pairs, $\mu V T$ and $N p T$ RDFs differ by a term of the order of $1 / N$, and the principle that $g_{i j}(r \rightarrow \infty)=1$ is violated for closed systems (Ben-Naim 1990a). Fortunately, as illustrated in previous computational studies, RDFs in open and closed systems are extremely similar (Weerasinghe and Pettitt 1994). This means that while the original KB theory cannot be rigorously applied to a closed system, calculations converge to correct results with increasing $N$. Thus, it has become standard to use the equivalence of ensembles and to determine TCFIs using the MD simulations in the (NpT/NVT) ensembles rather than the $\mu V T$ ensemble.

\subsubsection{Integration}

The usual approach to determine the function $g_{a b}(r)$ between the centers of mass of particle 1 of species $a$ and particle 2 of species $b$ separated by the distance $r$, is the accumulation of the number of particles b lying in the interval $[r, r+d r]$ from a given particle $a$, and for all available values of $r$ within the central box. Numerical integration of the RDFs from molecular simulation is less straightforward. Theoretically, $h_{i j}(r)$ goes to zero when $r$ goes to infinity. However, because the integral is evaluated numerically, convergence requires that $h_{i j}(r)$ goes faster to zero than $r^{2}$ goes to infinity. For practicality, since the upper limit of the integral is infinite, for a convergent integral, there must be some upper separation distance, $R_{\text {lim }}$, beyond which the integrand no longer contributes significantly to the value of the integral. Thus, one defines 


$$
H_{i j}\left(R_{\lim }\right)=\rho \int_{0}^{R_{\lim }} r^{2} h_{i j}(r) d r
$$

with $R_{\lim }$ is chosen sufficiently large that the integral is converged. This means that $H_{i j}\left(R_{\lim }\right)$ should be insensitive to larger values of $R_{\lim }$. Experience shows, however, that $H_{i j}\left(R_{\lim }\right)$ frequently does not include all of the nonzero values of $r^{2} h_{i j}(r)$ from an MD simulation (Salacuse, Denton, and Egelstaff 1996). An example of this is shown in Figure 6.1 (Wedberg 2011).

[Insert Figure 6.1]

The lack of convergence is mainly due to the RDFs retaining subtle structure over relatively long distances that contribute to the integral. While using a larger system might minimize the effects of omitting such contributions, the result would be significantly increased computational time without necessarily ensuring accuracy or reliable extrapolation. There are techniques (Theodorou and Suter 1985; Nichols, Moore, and Wheeler 2009) to allow calculation of pair correlation functions for distances up to $\sqrt{3} / 2$ times the box dimension. However, convergence may not be obtained with the RDFs exhibiting substantial noise as the upper limit is approached (Salacuse, Denton, and Egelstaff 1996).

\subsubsection{Asymptotic Properties of RDFs and Potential Truncations}

One clever approach to obtaining better convergence is to include asymptotic properties of the pair correlation functions (Lebowitz and Percus 1963). In particular, exact asymptotic expressions have been obtained by Attard and co-workers (Attard 1990; Attard et al. 1991) such as for dipolar fluids. Other work has extended simulation results for a system with a truncated potential to give those for the full potential (Lado 1964). The effects on pair distribution 
functions of potential truncations are important, for example, when the long-range tail of a potential must be truncated at some finite distance and the effect of the neglected part of the potential must be determined.

\subsection{Methods}

The task of extending the pair distribution function based on theoretical considerations has been addressed many times (Verlet 1968; Galam and Hansen 1976; Jolly, Freasier, and Bearman 1976; Ceperley and Chester 1977; Dixon and Hutchinson 1977; Foiles, Ashcroft, and Reatto 1984). Often the goal has been to study the correlation functions themselves or to calculate structure factors, not to obtain properties. Here we will emphasize applications aimed toward representing thermodynamic properties of molecular fluids that do not have conformational variations. While many publications have been confined to atomic model fluids, such as LJ particles, we focus here on applications for real molecular systems and their mixtures.

\subsubsection{Direct correlation function matching}

The method of Verlet (Verlet 1968) is intended to correct correlation functions from simulation for the effects of finite-sized systems, such as those summarized by Salacuse et al., and to extend computed correlation functions to long range (Salacuse, Denton, and Egelstaff 1996). The method was originally used for a pure LJ fluid in a study of the DCF and the structure factor. Later it was extended to a LJ mixture (Jolly, Freasier, and Bearman 1976). With the method, pair TCFs are extended by forcing the corresponding DCF at large separations to be consistent with the result, 


$$
\left(\begin{array}{l}
h(r) \\
c(r)
\end{array}\right)=\left(\begin{array}{cc}
h_{\mathrm{MD}}(r) & , r \leq R \\
a(u(r), h(r)), & r>R
\end{array}\right)
$$

Here $h_{\mathrm{MD}}(r)$ is given by the simulation result and $a$ is a closure relation giving the DCF in terms of the TCF, $h(r)$, and the potential, $u(r)$, evaluated at the same $r$. Verlet's method utilizes the simple structure and short range of $c$ compared to $h$. The approach can use either the Mayer $f$ function or the Percus-Yevick relation to extend pair distribution functions obtained from simulations of the pure $\mathrm{LJ}$ fluid. For the LJ fluid, three different relations $a(u, h)$ have been commonly used: the Mayer function,

$$
a(u(r), h(r))=f(r)=\exp (-\beta u)-1
$$

the PY relation,

$$
a(u(r), h(r))=f(r)(1+h)(1-\exp (-\beta u))
$$

and the first-order virial expansion of $c$ (Wedberg et al. 2010),

$$
a(u(r), h(r))=f(r)\left[1+\rho \int f\left(\left|\boldsymbol{r}-\boldsymbol{r}^{\prime}\right|\right) f\left(r^{\prime}\right) d r^{\prime}\right]
$$

Note that these theories for $c$ are all consistent with the asymptotic result $c(r) \rightarrow u(r) / k T$, when $r \rightarrow \infty$ (Lebowitz and Percus 1963). As shown in Foiles, et al. , Equations 6.11-6.13 usually yield similar results and there is no rigorous basis for selecting one over another (Foiles, Ashcroft, and Reatto 1984). Calculations of isothermal compressibilities by integration of the extended pair correlation functions were reported only for three state conditions by Verlet (Verlet 1968), and the statistical uncertainties were large. It is not clear whether these uncertainties were due to the quality of the simulations and their analysis or to the assumptions made by the extension method. Furthermore, while the compressibilities were fairly reasonable for noble gases, agreement with experiment was not reported in quantitative terms, due to the focus of the paper being on other properties of the correlation functions. 
For some time, the numerical solution of the liquid structure integral equations remained a challenge. Progress along these lines was made by the numerical implementation of Verlet's method, based on the Newton-Raphson method, known as the Gillan scheme for solving the OZ equation (Gillan 1979; Abernethy and Gillan 1980; Enciso 1985). Also a factorization approach to the OZ equation was demonstrated by Jolly et al. (Jolly, Freasier, and Bearman 1976). Before describing applications of our variant of the Verlet method to systems resembling real molecular mixtures in Section 6.4, we review other approaches designed to improve convergence.

\subsubsection{Truncation}

One of the simplest strategies is called truncation (Weerasinghe and Smith 2003b). With this method, the $\mu V T$ RDF is approximated by the $N p T$ RDF truncated at a specific distance chosen

for $R_{\mathrm{lim}}$. This distance is chosen to be, "The range over which the intermolecular forces dominate the distribution of particles." Ideally, the truncated NpT RDF captures the major features of the $\mu V T$ RDF, and its integral provides a good approximation to the desired KBIs. Truncated RDFs obtained from $N p T$ simulations have been obtained for several different mixtures, and used to obtain properties, such as partial molar volumes (Lin and Wood 1996), and to express the KB equation in terms of local compositions (Mansoori and Ely 1985).

As described in Chapter 5, Smith and co-workers have employed the truncation method in order to develop accurate force fields for solutions, especially those with biochemicals and proteins. Over the past decade, a series of force-field development and validation studies have been published using KBIs (Chitra and Smith 2001a; Weerasinghe and Smith 2003d, 2004; Gee et al. 
2011). The truncation approach can be successful if the TCFIs converge within the range of distance sampled by simulation. If not, the results will depend sensitively on the choice of $R_{\text {lim. }}$. It is therefore common to average $H\left(R_{\lim }\right)$ with $R_{\lim }$ varying over a selected interval. There seem to be no general rules for selecting the interval, other than suggesting that it should cover one oscillation of the TCF.

\subsubsection{Distance-Shifting}

Distance-shifting is another method employed with data on systems resembling real molecules. Both Perera and Sokolić (Perera and Sokolic 2004) and Hess and van der Vegt (Hess and van der Vegt 2009) attempt to correct the RDFs obtained from simulation by rescaling according to

$$
g_{i j}(r)=\alpha_{i j}(r) g_{i j}^{(0)}(r)
$$

Here $\alpha_{i j}$ is chosen in order to enforce that $g_{i j}(r)$ approaches unity at long distances. Perera and Sokolić (Perera and Sokolic 2004) presented NpT simulations of the water + acetone binary mixture. Although a correction of the order $1 / N$ is required, the result $g_{a b}(r) \rightarrow 1$ (for $r \rightarrow \infty$ ) is often valid for simple fluids after a few molecular diameters. This can be realistic in simulation boxes with a few hundred particles. However, for systems characterized by microscopic aggregation, the RDFs decay in irregular fashions with the range of correlations in the RDF differing from that of pair interactions, even at conditions remote from a critical point. The apparent problem in evaluating these quantities is the upper bound of the integral relative to the range of the correlations described by the simulations. If the system is large enough, one may consider that the correct asymptotic behavior is attained at some cutoff $R_{\text {lim }}$ smaller than the halfbox length $L_{\text {box }} / 2$. Accordingly, the KBI can be computed by replacing the infinite upper bound by $R_{\text {lim }}$, as in truncation methods. Though this may be satisfactory for simple fluids, it is 
probably incorrect for fluids with long-range correlations. If the upper bound is not large enough to capture the correct asymptotic behavior, it will lead to incorrect estimation of the KBIs. For water/solute systems, these correlations probably extend over five to six water diameters, which is too large even for a system with $N=1024$.

Since the $L_{\mathrm{box}} / 2$ values of all partial $g_{i j}\left(L_{\mathrm{box}} / 2\right)$ are always close to unity, Perera and Sokolić (Perera and Sokolic 2004) restored the correct asymptotic value at the natural half-box cutoff by shifting the value to unity. The expression used is,

$$
g_{i j}(r)=\alpha_{i j}(r) g_{i j}^{(0)}(r), \quad \alpha_{i j}(r)=\frac{1}{1+r /\left(L_{\mathrm{box}} / 2\right)\left[g_{i j}^{(0)}\left(L_{\mathrm{box}} / 2\right)-1\right]}
$$

where $g_{i j}{ }^{(0)}(r)$ is the uncorrected RDF. This procedure leaves values of the RDF at contact nearly unchanged if $g_{i j}{ }^{(0)}\left(L_{\mathrm{box}} / 2\right)$ is close to unity. Perera and Sokolić (Perera and Sokolic 2004) found that $N=864$ is just enough to satisfy this condition, though $N=2048$ is much better. The merit of this equation is the use of all $r<L_{\mathrm{box}} / 2$ values in the calculation of the KBI, and, in particular, avoiding artifacts in the evaluations of the canonical ensemble KBIs.

Hess and van der Vegt (Hess and van der Vegt 2009) studied cation binding affinity with carboxylate ions. They computed the excess coordination numbers, $N_{\mathrm{ij}}$, defined in Section 1.1.5, for water $(w)$ or cations $(c)$ about cations,

$$
N_{j c}=\rho_{c} 4 \pi \int_{0}^{\infty}\left(g_{j c}(r)-1\right) r^{2} d r
$$

where $j=w, c$ and computed the chemical potential derivatives of Equation 1.49 from closed system $N p T$ simulations. The finite-size correction is accounted for in a novel way. The idea is to consider a small part of a large system, such that this small part can be considered as open, and 
then evaluate the integral up to a finite distance where it has converged within the larger system. Since the RDFs can not converge exactly to unity, the Hess/van der Vegt approach employs a scaling factor to account for the fact that the fluid composition far from a given molecule is different from the overall composition. The scaling factor is chosen, "Such that the RDF becomes exactly 1." Assuming that $N_{j c}(R)$ is constant beyond a distance $R_{\text {lim }}$, the RDF can be normalized to 1 by dividing it by the 'observed' number of particles and multiplying by the 'expected' number,

$$
g_{j c}^{*}=\frac{N_{j}\left(1-V\left(R_{\mathrm{lim}}\right) / V_{\mathrm{box}}\right)}{N_{j}\left(1-V\left(R_{\mathrm{lim}}\right) / V_{\mathrm{box}}\right)-\Delta N_{j c}\left(R_{\mathrm{lim}}\right)-\delta_{j c}} g_{j c}
$$

where $N_{j}$ is the number of particles of species $j, V(R)$ is the volume of a sphere with radius $R$ and $V_{\text {box }}$ is the volume of the simulation box, $\delta_{c c}=1$ and $\delta_{w c}=0$. For a system with 100 ion pairs, the scaling factor is around 1.005 (or one particle in 200). The correction for $g_{w c}$ is two orders of magnitude smaller. Although the methods are straightforward to implement, they still require selecting an appropriate truncation distance, and there seems to be no systematic way to choose the value of $R_{\text {lim }}$. This aspect can be a limitation, since in our experience the results are very sensitive to the selection of this value (Wedberg 2011).

\subsubsection{Long Range Modeling}

To avoid searching for an $R_{\lim }$ that gives the value of a converged, KBI, an alternative is to find a model, and its parameters, for the long-range tail of the RDF to effectively extend the simulation results to infinite separation. The intention is to minimize sensitivity to the location where the simulation results are considered unreliable. 
Matteoli and Mansoori (Matteoli and Mansoori 1995) gave a parametric expression for the RDFs of LJ fluids and their mixtures. That work arrived at a final form of the RDF based on the asymptotic conditions for zero density and infinite distance, as required by statistical thermodynamics, rather than rigorous geometrical and spatial considerations. Seven adjustable parameters were fitted to literature data on RDFs for each LJ fluid at different temperatures and densities. These were in turn expressed as functions of reduced temperature and density, so the complete parameterization used a total of 21 parameters. The capability of the expression to fit to RDFs of mixtures was checked against literature simulations of binary LJ mixtures with different diameters, molar fractions and $\varepsilon_{\mathrm{AA}} / \varepsilon_{\mathrm{BB}}$ ratios. The agreement between calculated and simulation curves was satisfactory. The values of the reduced pressure and internal energy calculated by numerical integration of the completely parameterized equation compared reasonably well with literature MD simulations. This approach allows calculation by integration of related quantities such as compressibility, internal energy, pressure and, using FST, the chemical potentials and partial molar volumes of the LJ mixture components for which RDF results are available. The works of Christensen et al. (Christensen et al. 2007a; Christensen et al. 2007b; Christensen et al. 2007c) addressed molecular simulations of systems resembling real molecules.

As shown in Figure 6.2 (a) for the benzene(1)/ethanol(2) binary mixture, the solid line is $g_{22}(r)$ which deviates much less than $1 \%$ from unity near $r_{\max }$. However, divergence is clearly seen in Figure $6.2 \mathrm{~b}$, starting at $r \approx 15 \AA$, where a local maximum in the integrand, $d G_{22}$, has a negative value. This is magnified in the TCFI because $r^{2}$ is a factor in the integrand, $d G_{22}$. To overcome this issue, a data reduction procedure based on tail modeling, in the sense of Matteoli/Mansoori 
(Matteoli and Mansoori 1995) was tried. Unfortunately, the assumptions underlying the Matteoli/Mansoori RDF are not valid in the direct correlation range (first peak) for the kinds of substances frequently encountered in chemical engineering applications, such as hydrogen bonding species. For example, the Matteoli correlation assumes that the variations of the RDF from unity decrease from peak to peak so a combination of the exponential and cosine functions can be used. However, this is not always the case with real molecules. For example, the ethanolethanol RDF at high concentrations of benzene shows an irregular multi-peak behavior not seen in LJ mixtures. This reflects dilute solution association effects of the ethanol molecules. As a result, Christensen et al. abandoned the LJ expression and integrated the simulation results numerically for the range of direct interactions. Then, since the indirect part of the RDF does not change dramatically when different interaction potentials are used, especially when averaging over angles, the long-range shape of $g_{i j}(r)$ is simple and similar to that of hard spheres. Further, when a model expression is used, it is possible to analytically integrate the indirect $g_{i j}$ out to $r_{\max }$, and ultimately to $r_{n c}$, beyond which there is no contribution to the TCFI. The model expression selected was,

$$
g_{i j}^{\text {indirect }}(r)=1+a \cdot \exp ^{[-b(r-c)]} \sin (d(r-e))
$$

The five-parameters are determined by regression with the objective to reproduce $g_{i j}(r)$ from the third unity, $r_{u 3}$, to $r_{\max }$, with initial guesses found from,

$$
\begin{aligned}
& a_{\text {init }}=g_{i j}\left(r_{\text {max }, 2}\right)-1, \quad b_{\text {init }}=\frac{-1}{r_{\text {min }, 2}-r_{\text {max }, 2}} \ln \frac{1-g_{i j}\left(r_{\min , 2}\right)}{g_{i j}\left(r_{\max , 2}\right)-1} \\
& c_{\text {init }}=r_{\text {max }, 2}, \quad d_{\text {init }}=\frac{\pi}{r_{u 4}-r_{u 3}}, \quad e_{\text {init }}=r_{u 3}
\end{aligned}
$$

Here $r_{u 3}$ and $r_{u 4}$ are the radii of the third and fourth zeros of $h_{i j}(r)$, respectively, while $r_{\max , 2}$ is the 
radius of the second maximum of $g_{i j}(r)$, or the first maximum of the indirect interaction, located between the third and fourth zeros of $h_{i j}(r)$. The quantities $g_{i j}\left(r_{\max , 2}\right)$ and $g_{i j}\left(r_{\min , 2}\right)$ are the values of the second maximum and minimum, respectively. The dashed curve in Figure 6.2 is the result of such a regression. The contribution to $H_{i j}$ from integration from $r_{\max }$ to $r_{n c}$ is viewed as a long distance correction term.

\section{[Insert Figure 6.2]}

Thus, the final form for TCFIs has three contributions as shown in Figure 6.3:1) the direct interaction part of the RDF, $H_{i j}{ }^{\text {direct }}$, integrated numerically; 2$)$ the integral of a trial function from the end of the direct interaction to the maximum distance determined by the box size, $H_{i j}$ box; and 3) the long distance contribution, $H_{i j}$, ,

$$
H_{i j}=\underbrace{\rho \int_{0}^{r_{u 3}} r^{2}\left(g_{i j}(r)-1\right) d r}_{=H_{i j}^{\text {direct }}}+\rho \underbrace{\int_{r_{u 3}}^{\infty} r^{2}\left(g_{i j}(r)-1\right) d r}_{=H_{i j}^{\text {indirect }}+H_{i j}^{\mathrm{ld}}}=H_{i j}^{\mathrm{direct}}+H_{i j}^{\mathrm{indirect}}+H_{i j}^{\mathrm{ld}}
$$

The statistical uncertainty of the direct interaction part of the RDFs is normally negligible.

Uncertainties are small for the first portion of the indirect part, though they could be significant at greater distances. Finally, the contribution of $H_{i j}^{\text {ld }}$ to $H_{i j}$ is the least, so its uncertainty can be ignored.

\section{[Insert Figure 6.3]}

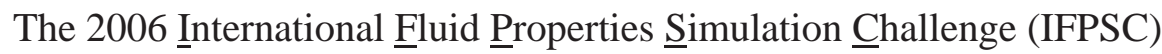
(http://fluidproperties.org/) competitions were initiated in 2001 to stimulate and assess prediction methods for properties of industrially important fluids, by comparing methods, assessing the 
state of the art in simulation, and enhancing alignment of academic efforts with industrial needs. The $3^{\text {rd }}$ IFPSC was held from March to September 2006. The focus of this contest was on the transferability of force fields and simulation methods for bubble pressures of mixtures of 1,1,1,2,3,3,3-heptafluoropropane (HFC-227ea refrigerant) and ethanol, based on limited data. In addition to their interesting pure component chemical properties, HFCs are often mixed with other fluids to be replacements for environmentally damaging chlorofluorocarbon refrigerants, and for cleaning-solutions, fire-retardants, and propellants. In the system of interest, hydrogen bonding interactions could occur between the HFC-227ea proton and the ethanol hydroxyl, leading to attractive unlike interactions. It was expected that this system would not be wellmodeled by simple EoS mixing rules.

Entrants were provided with the experimental bubble points for 15 mixture compositions of 1,1,1,2,3,3,3-heptafluoropropane (HFC-227ea) and ethanol at $283.17 \mathrm{~K}$, and properties of the pure materials at $343.13 \mathrm{~K}$. The challenge was to compute bubble points for seven mixture compositions at $343.13 \mathrm{~K}$, using any experimental data for the pure components but the only mixture points were those at $283.17 \mathrm{~K}$. Entries using any theory/modeling/simulation method were accepted. Entries were judged based on the criterion,

$$
\text { SCORE }=\frac{100}{7} \sum_{i=1}^{7}\left|\frac{P_{i, \text { exp }}-P_{i, \text { calc }}}{P_{i, \text { calc }}}\right|
$$

The experimental data for the mixtures at $343.13 \mathrm{~K}$, measured at DuPont, were not released until all entries had been received. The four contestants used a range of different techniques including statistical-mechanical and molecular-simulation approaches that gave significantly more accurate predictions than from the semi-empirical NRTL model (Prausnitz, Lichtenthaler, and Gomes de Azevedo 1999). The entry provided by Christensen, et al. (Christensen et al. 2007a) was based 
on an NPT-MD simulation of the liquid phase at each mixture composition with FST linking the predicted microscopic structure (from the calculated RDF), to parameters that optimized a $G^{E}$ model for the liquid phase. It was assumed that the vapor phase was an ideal gas. For this contest the CHARMM force field was modified by revising the LJ parameters for the -CHF- part of the HFC-227ea molecule to fit experimental densities. The long-range modeling method of Christensen et al. (Christensen et al. 2007a) was sufficiently accurate to win (Case et al. 2007) in the 'State Conditions Transferability' category. Their predictions of VLE behavior shown in Figure 6.4 gave a SCORE of 1.52. Activity coefficients found for this system are unusual in behavior, as shown in Figure 6.5. The total pressures show positive deviations from Raoult's law, but the activity coefficients have a maximum for HFC-227ae and a minimum for ethanol near $x_{1}=0.45$.

[Insert Figures 6.4 and 6.5]

The approach of Christensen was later modified by Wedberg et al. (Wedberg, Peters, and Abildskov 2008). First, the 5-parameter form of Equation 6.18 was changed to a 4-parameter form,

$$
g_{i j}^{\text {indirect }}(r)=1+a \cdot \exp ^{[-b(r-c)]} \sin (d(r-c))
$$

Next, a tail model corresponding to the anti-derivative of the trial expression for $g(r)$ was fitted to the truncated numerical integral of $g(r)$ as a function of the upper integration limit. This tail model was then used to extrapolate $H\left(R_{\lim }\right)$ to $R_{\text {lim }}=\infty$ which yielded the value of the TCFI. Defining the running integrals of the RDF, $G(r)$,

$$
G(r)=4 \pi \int_{0}^{r} r^{\prime 2}\left[g\left(r^{\prime}\right)-1\right] d r^{\prime}, \quad H=\lim _{r \rightarrow \infty} \rho G
$$


the anti-derivative of Equation 6.23 used is,

$$
\begin{aligned}
& G_{\text {smooth }}(r)=-4 \pi a[p(r) \cos (d(r-c))+q(r) \sin (d(r-c))] e^{-b(r-c)}+f \\
& p(r)=\frac{d}{b^{2}+d^{2}} r^{2}+\frac{4 b d}{\left(b^{2}+d^{2}\right)^{2}} r-2 \frac{d^{3}-3 b^{2} d}{\left(b^{2}+d^{2}\right)^{3}} \\
& q(r)=\frac{b}{b^{2}+d^{2}} r^{2}+\frac{2\left(b^{2}-d^{2}\right)}{\left(b^{2}+d^{2}\right)^{2}} r-2 \frac{3 d^{2} b-b^{3}}{\left(b^{2}+d^{2}\right)^{3}}
\end{aligned}
$$

The parameters for $G_{\text {smooth }}(r)$ were fitted to the sampled $G(r)$ for $r$ ranging from $r_{u 3}$ to $r_{\max }$, as defined above. The method was used to obtain isothermal compressibilities of five pure alkanes at three different state points and these were compared to the values derived from simulated overall density fluctuations. Results showed that the two approaches were fully consistent in values and uncertainties. Further, the computations converged in approximately the same simulation times. This suggests that computation of TCFIs is a route to isothermal compressibility, as accurate and fast as well-established benchmark techniques, with the advantage that it can be used in any ensemble (Puliti, Paolucci, and Sen 2011). Note that this approach has only been successfully tested on pure fluids. The main limitation of both methods (Christensen et al. 2007a; Christensen et al. 2007b; Christensen et al. 2007c; Wedberg, Peters, and Abildskov 2008) is that they apply only to systems where the TCF tails can be approximated by the model equations, which may not be true in general.

\subsubsection{Transforms}

Nichols et al. developed a method using finite-Fourier-series expansions of molecular concentration fluctuations in order to reduce systematic errors from the simulation boundary conditions (Nichols, Moore, and Wheeler 2009). The procedure was validated and compared to a truncation method for a non-ideal binary liquid mixture of LJ particles tuned to imitate the 
system $\mathrm{CF}_{4}$ and $\mathrm{CH}_{4}$. A fluctuation expression is applied to a portion of the total volume within a closed simulation such as NVT. Rather than the sampling volume being spherical and centered on a single moving molecule, the sampling volume is one or more rectangular-slab regions that are stationary with respect to the simulation cell. This leads to two alternative expressions,

$$
S_{i j}(q)=x_{i} \delta_{i j}+x_{i} x_{j} \rho \int_{0}^{\infty} \frac{\sin (q r)}{q r}\left[g_{i j}(r)-1\right] 4 \pi r^{2} d r
$$

and,

$$
S_{i j}(\boldsymbol{q})=\frac{1}{N}\left\langle\delta N_{i}(\boldsymbol{q}, t) \cdot \delta N_{i}(-\boldsymbol{q}, t)\right\rangle=N\left\langle\psi_{i}(\boldsymbol{q}, t) \cdot \psi_{j}(-\boldsymbol{q}, t)\right\rangle
$$

where $\psi_{i}(q, t)$ is the Fourier mass coefficient at the time $t$ of the component $i$, and the wave vector $\boldsymbol{q}$ has components that are integer multiples of $2 \pi / L_{\mathrm{box}}$. The TCFIs are found from the structure factors via $\rho G_{i j}=S_{i j}(0)-1$.

For an infinite system, the definitions of $S_{i j}$ in Equations 6.25 and 6.26 are equivalent. However, for finite systems, truncation of the integrals can lead to errors in the integral of Equation 6.25. The advantage of Equation 6.26 relative to Equation 6.25 is that the structure factor can be based on a discrete Cartesian-based Fourier transform, rather than a continuous, spherically symmetric Fourier transform, Equation 6.26, is evaluated at various values of $q$ which are most accurate at larger values. The $q$-dependent $S_{i j}$ are then extrapolated to $q=0$ by fitting them to polynomials, the range of $q$ and the polynomial order being selected empirically. Thus, it is not $g_{i j}(r)$ that is corrected; it is done via the structure factors related to the RDFs using the radial Fourier transform. The sampling volumes of the method do not truncate intermolecular correlations at a particular radial distance and no assumption is made that $g_{i j} \rightarrow 1$ at large intermolecular 
separations. In effect, this approach is consistent with periodic boundary conditions, but immune to long-range truncation effects. The inaccuracies in simulation RDFs at large $r$ become unreliable $S_{i j}(0)$ because of the system size but extrapolation to $q=0$ provides the correction. Good results are obtained for LJ mixtures, but the method has apparently not yet been tested for molecular fluids.

\subsubsection{Finite-size scaling}

The approach of Schnell et al. is to sample small non-periodic systems in a (periodic) simulation box (reservoir) and then scale the results (Schnell et al. 2011). The simulation system has sides of $L_{t}$ in each dimension. Small systems are randomly selected sub-volumes, denoted by $L_{n-1}, L_{n}$,

and $L_{n+1}$, and can exchange energy and particles with the rest of the system. While the reservoir may not be a grand-canonical ensemble, the small systems will be when $L_{n} \ll L_{t}$. Finite-size scaling of KBIs determined from different-sized small systems is done by fitting and extrapolating them to the thermodynamic limit using essentially straight lines. The values compare well with those from integrating the RDF using a truncation method. In all cases, visual inspection is needed to identify where the subvolume results follow straight lines, but this is straightforward. While this approach has not been extensively tested, there is promise for such computations for practical applications with relative insensitivity to system size.

\subsubsection{Adaptive Resolution}

Quite recently, Mukherji et al. (Mukherji et al. 2012) have proposed an adaptive resolution simulation method ('AdResS'). In a way resembling the distance-shifting method of Hess and 
van der Vegt (Hess and van der Vegt 2009), the 'AdResS' method divides the simulation domain into a small region of high resolution (atomistic) molecules and a large region of (coarsegrained) lower resolution. Mukherji et al. analyze their method with a mixture resembling methanol and water by comparing the results with all-atom simulations and existing experimental results. Excellent agreement is found with the much larger and computationally more expensive all-atom simulations as well as with data. As with other methods that need to select an integration limit such that the integral converges to a plateau value or oscillates in a well-controlled way around a mean value, the 'AdResS' method also selects a high resolution region width. The results indicate that a radius of $2 \mathrm{~nm}$ is adequate for the specific system of methanol and water, but a general approach to selecting the radius is uncertain.

\subsection{DCF Matching - Mixtures of Polyatomic Molecules}

Recently we (Wedberg et al. 2010; Wedberg 2011; Wedberg et al. 2011a, 2011b) have investigated more thoroughly the extension method of Verlet (Verlet 1968) for mixtures with polyatomic molecules. This section gives a more complete description of our implementation, including some results not previously published. We have analyzed MD simulations of both pure (Wedberg et al. 2010) and mixed (Wedberg et al. 2011a, 2011b) LJ and Stockmayer fluids for wide ranges of state conditions and compared the results with the truncation method of Weerasinghe and Smith (Weerasinghe and Smith 2003b) and the distance-shifting method of Hess and van der Vegt (Hess and van der Vegt 2009). 


\subsubsection{Method}

For potentials that decay faster than $r^{-3}$, the asymptotic behavior of the DCF is (Lebowitz and Percus 1963),

$$
c(r)=-\beta u(r)+O\left\{[\beta u(r)]^{2}\right\}
$$

Here $u$ is the pair intermolecular potential. In order to extend the TCF obtained from simulation, one chooses a value $R$ within the range for which $h(r)$ is sampled, and determines $h$ and $c$ according to Equation 6.10. These requirements, together with the OZ equation, define a closedform integral equation, which can be solved in order to obtain $h(r)$ for $r>R$. Simultaneously, $c(r)$ is obtained for all $r$. In our implementation, $h$ and $c$ are discretized as linear splines and both functions are assumed to be zero beyond a finite distance $R_{c}$. For example, in the cases of LJ and Stockmayer particles $R_{c}=15 \sigma$, where $\sigma$ is the LJ diameter. For "real" fluids, other values are used. Selecting this truncation radius is straightforward since the integrals generally converge, as can be checked by plotting the running integral versus $r$. If not converged, one repeats the calculation with a larger $R_{c}$. The Fourier-transformed OZ equation (Lebowitz and Percus 1963) is employed to express $c$ explicitly in terms of $h$. This transforms the integral equation into a system of nonlinear equations for which a numerical solution is found using Newton's method (Wedberg et al. 2011a). The Jacobian is evaluated analytically and 5-15 iterations are normally required for convergence. Commonly, the Wiener-Hopf factorization technique is applied when the DCF is computed numerically from the TCF or vice versa (Jolly, Freasier, and Bearman 1976; Gray and Gubbins 1984; Press et al. 1992; Ramirez, Mareschal, and Borgis 2005). For the present application, the three-dimensional Fourier-transformed OZ equation can be employed. Applying the Fourier transform to Equation 6.6 gives a product, 


$$
\hat{h}_{i j}(k)=\hat{c}_{i j}(k)+\rho \sum_{l=1} \hat{h}_{i l}(k) x_{l} \hat{c}_{l j}(k)
$$

where $\hat{h}_{i j}(k)$ denotes the Fourier transformation of $h_{i j}(r)$. Due to radial symmetry, this is the zeroth-order Hankel transform, defined by,

$$
\hat{h}_{i j}(k)=4 \pi \int_{0}^{\infty} d r r^{2} \frac{\sin (k r)}{k r} h_{i j}(r)
$$

This same formulation holds for $\hat{c}_{i j}(k)$. The function $h_{i j}(r)$ is recovered from the inverse Hankel transform and is given by,

$$
h_{i j}(r)=\frac{4 \pi}{(2 \pi)^{3}} \int_{0}^{\infty} d k k^{2} \frac{\sin (k r)}{k r} \hat{h}_{i j}(k)
$$

Utilizing that $\hat{h}_{12}(k)=\hat{h}_{21}(k)$ and $\hat{c}_{12}(k)=\hat{c}_{21}(k)$, Equation 6.28 can be written as a linear system,

$$
\tilde{\boldsymbol{h}}(k)=[\boldsymbol{I}+\rho \boldsymbol{H}(k)] \tilde{\boldsymbol{c}}(k)
$$

with,

$$
\tilde{\boldsymbol{h}}(k)=\left[\begin{array}{c}
\hat{h}_{11}(k) \\
\hat{h}_{12}(k) \\
\hat{h}_{22}(k)
\end{array}\right], \quad \tilde{\boldsymbol{c}}(k)=\left[\begin{array}{c}
\hat{c}_{11}(k) \\
\hat{c}_{12}(k) \\
\hat{c}_{22}(k)
\end{array}\right] \quad, \quad \boldsymbol{H}(k)=\left[\begin{array}{ccc}
x_{1} \hat{h}_{11}(k) & x_{2} \hat{h}_{12}(k) & 0 \\
0 & x_{1} \hat{h}_{11}(k) & x_{2} \hat{h}_{12}(k) \\
0 & x_{1} \hat{h}_{12}(k) & x_{2} \hat{h}_{22}(k)
\end{array}\right]
$$

where $I$ denotes the identity matrix. Equations 6.32 assume that the fluid mixture has at most two components. Equations 6.29-6.31 provide a route for computing $c_{i j}(r)$ given $h_{i j}(r)$. The function $h_{i j}(r)$ is Hankel-transformed to yield $\hat{h}_{i j}(k)$. The linear system in Equation 6.31 is then solved for $\hat{c}_{i j}(k)$ at each $k$, followed by applying the inverse Hankel transform to obtain $c_{i j}(r)$. Solution of the problem of Equation 6.10 requires that the long-range part of $h_{i j}(r)$ is adjusted until the longrange part of $c_{i j}(r)$ matches a trial function $t_{i j}(r)$. This is accomplished by a Newton iteration scheme for which grids in $r$ and $k$ space are introduced, 


$$
\begin{array}{ll}
r_{\alpha} \equiv \alpha \cdot \Delta r, & \alpha=0, \ldots, N \\
k_{\beta} \equiv \beta \cdot \Delta k, & \beta=0, \ldots, N
\end{array}
$$

The upper cutoffs are $R_{c}=N \cdot \Delta r$ and $K_{c}=N \cdot \Delta k$ for the integrals in Equations 6.29 and 6.30, respectively. Note that $R_{c}$ is not the sampling limit set by the simulation box dimensions, but is typically much larger. The TCFs, DCFs, and their Hankel transforms at an iteration step $t$ are represented by discrete vectors,

$$
\begin{array}{lll}
h_{i j, \alpha}^{(t)} \equiv h_{i j}^{(t)}\left(r_{\alpha}\right), & c_{i j, \alpha}^{(t)} \equiv c_{i j}^{(t)}\left(r_{\alpha}\right), & \alpha=1, \ldots, N \\
\tilde{h}_{i j, \beta}^{(t)} \equiv \tilde{h}_{i j}^{(t)}\left(k_{\beta}\right), & \tilde{c}_{i j, \beta}^{(t)} \equiv \tilde{c}_{i j}^{(t)}\left(k_{\beta}\right), & \beta=1, \ldots, N
\end{array}
$$

Equation 6.29 for the TCF is approximated by truncating the integral at $R_{c}$ and using the trapezoidal rule,

$$
\tilde{\boldsymbol{h}}_{i j}^{(t)}=\boldsymbol{T} \cdot \boldsymbol{h}_{i j}^{(t)}
$$

Elements of the matrix $\boldsymbol{T}$ are,

$$
T_{\beta \alpha}=4 \pi \cdot \Delta r \cdot r_{\alpha}^{2} \cdot \frac{\sin k_{\beta} r_{\alpha}}{k_{\beta} r_{\alpha}}\left(1-\frac{\delta_{0 \alpha}+\delta_{N \alpha}}{2}\right)
$$

with $\alpha=1, \ldots, N, \beta=1, \ldots, N$, with $\sin (k r) /(k r)$ being unity if either $k$ or $r$ is zero. Equation 6.30 for the DCF is approximated in a similar way by truncating the integral at $K_{c}$,

$$
\tilde{\boldsymbol{c}}_{i j}^{(t)}=\boldsymbol{U} \cdot \boldsymbol{c}_{i j}^{(t)}
$$

with,

$$
U_{\beta \alpha}=\frac{4 \pi}{(2 \pi)^{3}} \cdot \Delta k \cdot k_{\alpha}^{2} \cdot \frac{\sin k_{\beta} r_{\alpha}}{k_{\beta} r_{\alpha}}\left(1-\frac{\delta_{0 \beta}+\delta_{N \beta}}{2}\right)
$$

with $\alpha$ and $\beta$ as in Equation 6.36. As stated above, the middle step of converting $\hat{h}_{i j}^{(t)}$ to $\hat{c}_{i j}^{(t)}$ is carried out by solving the linear system of Equation 6.31 for each value of $\beta$. If $n_{i j}$ denotes 
indexing such that $r_{n_{i j}} \leq R_{i j} \leq r_{n_{i j}+1}$, and $h_{i j}{ }^{(t)}$ and $c_{i j}{ }^{(t)}$ denote vectors containing the elements of $h_{i j}{ }^{(t)}$ and $c_{i j}{ }^{(t)}$, respectively, with $n_{i j}+1 \leq \alpha \leq N, h_{i j}{ }^{(t)}$ is updated at each iteration step according to,

$$
\boldsymbol{h}_{i j}^{(t+1)}=\boldsymbol{h}_{i j}^{(t)}+\Delta \boldsymbol{h}_{i j}^{(t)}
$$

Here, $\Delta \boldsymbol{h}_{i j}{ }^{(t)}$ in Newton's method is found by solution of the linear system,

$$
\left[\begin{array}{lll}
\boldsymbol{J}_{11}^{11} & \boldsymbol{J}_{12}^{11} & \boldsymbol{J}_{22}^{11} \\
\boldsymbol{J}_{11}^{12} & \boldsymbol{J}_{12}^{12} & \boldsymbol{J}_{22}^{12} \\
\boldsymbol{J}_{11}^{22} & \boldsymbol{J}_{12}^{22} & \boldsymbol{J}_{22}^{22}
\end{array}\right]\left[\begin{array}{c}
\Delta \boldsymbol{h}_{11}^{(t)} \\
\Delta \boldsymbol{h}_{12}^{(t)} \\
\Delta \boldsymbol{h}_{22}^{(t)}
\end{array}\right]=\left[\begin{array}{c}
\Delta \boldsymbol{c}_{11}^{(t)} \\
\Delta \boldsymbol{c}_{12}^{(t)} \\
\Delta \boldsymbol{c}_{22}^{(t)}
\end{array}\right]
$$

where the right-hand side represents the difference between the approximation of the long-range DCF to be enforced and the currently computed DCF,

$$
\Delta \boldsymbol{c}_{i j, \alpha}^{(t)}=t_{i j}\left(r_{\alpha}\right)-\boldsymbol{c}_{i j, \alpha}^{(t)}, \quad \alpha=n_{i j}+1, \ldots . ., N
$$

The Jacobian has the elements,

$$
\boldsymbol{J}_{\alpha \beta}^{i j} \equiv\left[\begin{array}{ccc}
\frac{\partial c_{i j, n_{i j}+1}^{(t)}}{\partial h_{\alpha \beta, n_{\alpha \beta}+1}^{(t)}} & \cdots & \frac{\partial c_{i j, n_{i j}+1}^{(t)}}{\partial h_{\alpha \beta, N}^{(t)}} \\
\ldots & \cdots & \ldots \\
\frac{\partial c_{i j, N}^{(t)}}{\partial h_{\alpha \beta, n_{\alpha \beta}+1}^{(t)}} & \cdots & \frac{\partial c_{i j, N}^{(t)}}{\partial h_{\alpha \beta, N}^{(t)}}
\end{array}\right]
$$

These are partial derivatives that can be expanded by the chain rule to,

$$
\frac{\partial c_{i j, \alpha}}{\partial h_{a b, \alpha^{\prime}}}=\sum_{\beta=0, \beta^{\prime}=0}^{N} \frac{\partial c_{i j, \alpha}}{\partial \tilde{c}_{i j, \beta}} \frac{\partial \tilde{c}_{i j, \beta}}{\partial \tilde{h}_{a b, \beta^{\prime}}} \frac{\partial \tilde{h}_{a b, \beta^{\prime}}}{\partial h_{a b, \alpha^{\prime}}}=\sum_{\beta=0, \beta^{\prime}=0}^{N} U_{\alpha \beta} \frac{\partial \tilde{c}_{i j, \beta}}{\partial \tilde{h}_{a b, \beta}} T_{\beta^{\prime} \alpha^{\prime}}
$$

The last equality is due to the result,

$$
\frac{\partial \tilde{c}_{i j, \beta}}{\partial \tilde{h}_{a b, \beta^{\prime}}}=\delta_{\beta \beta^{\prime}} \frac{\partial \tilde{c}_{i j, \beta}}{\partial \tilde{h}_{a b, \beta}}
$$

a consequence of Equations 6.31, 6.39, and 6.41. The partial derivatives are obtained from three linear systems derived from Equation 6.31 by differentiation with respect to $\hat{h}_{11, \beta}, \hat{h}_{12, \beta}$ and $\hat{h}_{22, \beta}$. 
The results are,

$$
\left[\begin{array}{l}
\frac{\partial \tilde{c}_{11, \beta}}{\partial \tilde{h}_{11, \beta}} \frac{\partial \tilde{c}_{11, \beta}}{\partial \tilde{h}_{12, \beta}} \frac{\partial \tilde{c}_{11, \beta}}{\partial \tilde{h}_{22, \beta}} \\
\frac{\partial \tilde{c}_{12, \beta}}{\partial \tilde{h}_{11, \beta}} \frac{\partial \tilde{c}_{12, \beta}}{\partial \tilde{h}_{12, \beta}} \frac{\partial \tilde{c}_{12, \beta}}{\partial \tilde{h}_{22, \beta}} \\
\frac{\partial \tilde{c}_{22, \beta}}{\partial \tilde{h}_{11, \beta}} \frac{\partial \tilde{c}_{22, \beta}}{\partial \tilde{h}_{12, \beta}} \frac{\partial \tilde{c}_{22, \beta}}{\partial \tilde{h}_{22, \beta}}
\end{array}\right]=[\boldsymbol{I}+\rho \boldsymbol{H}(\beta \cdot \Delta k)]^{-1}\left[\begin{array}{ccc}
1-x_{1} \rho \tilde{c}_{11, \beta} & -x_{2} \rho \tilde{c}_{12, \beta} & 0 \\
-x_{1} \rho \tilde{c}_{12, \beta} & 1-x_{2} \rho \tilde{c}_{22, \beta} & 0 \\
0 & -x_{1} \rho \tilde{c}_{12, \beta} & 1-x_{2} \rho \tilde{c}_{22, \beta}
\end{array}\right]
$$

At each iteration step, these systems are solved for the partial derivatives which then are used to evaluate the Jacobians in Equation 6.44.

The short-range parts of the calculated DCFs are not used within the iteration scheme though the short-range part of the DCF obtained from the final iteration is considered in selecting the parameters $R_{i j}$ Initially, the discretized TCFs are set to $h_{i j, \alpha}^{(0)}=h_{M D, i j}\left(r_{\alpha}\right)$ for all $r_{\alpha}$ within the sampling range for $h_{\mathrm{MD}, i j}(r)$, and $h_{i j, \alpha}^{(0)}=0$ for larger $\alpha$. The iteration is carried out until,

$$
\sum_{i, j} \sum_{\alpha=n_{i j}+1}^{N}\left[\Delta \boldsymbol{c}_{i j, \alpha}^{(t)} r_{\alpha}^{2}\right]^{2}<\eta
$$

with $\eta=10^{-4}$ or less. Typically, this is achieved after 5-15 iterations. For some systems, in particular those at high density where the functions $h_{i j}(r)$ have significant structure beyond the sampling range, the tail model by Christensen et al. (Christensen et al. 2007a; Christensen et al. 2007b; Christensen et al. 2007c) was used to estimate the long-range behavior for the initial guess $h_{i j, \alpha}^{(0)}$. Using this approach, the Newton iterations have converged for all systems we have studied to date. Issues of how to select the matching distance, and the angle-averaging of potentials are discussed in detail by Wedberg (Wedberg 2011). 


\subsubsection{Results}

We now discuss results from MD simulations that test the capabilities of the method. The KBIs are primarily verified by comparing the derivative properties obtained from the integration procedure with the same properties obtained from alternative analyses, or from simulation results in the literature. For the simulations of water/organic solvent mixtures, the derivative properties obtained by integration are also compared against values derived from correlations of experimental data. In this last case, consistency depends not only on the accuracy of the integration procedure, but also on the accuracy of the force field.

\subsubsection{Model Fluids}

The methodology was first tested on pure and mixed LJ and Stockmayer fluids (Wedberg et al. 2010) for several reasons. First, these fluids are well-defined, so simulation results over wide temperature and density ranges could be acquired with limited computational effort. Second, the thermodynamic derivative properties obtained from the extended pair-distribution function can be validated against data derived from correlations of previous simulations. Third, the simple form of the inter-atomic potentials allows a basic test of the assumption that the OZ equation can be resolved into isotropic and anisotropic parts. For the Stockmayer fluid, this form of the OZ relation is inexact, becoming less accurate as the (reduced squared) dipole moment, $\mu^{*^{2}}$, increases. The accuracy of the properties obtained for large $\mu^{*^{2}}$ could indicate validity of the isotropic OZ equation. In what follows, the physical quantities are in dimensionless values, where the quantities marked with an asterisk (*) have been reduced with respect to the LJ parameters $\varepsilon$ (energy), $\sigma$ (length) and the atomic mass. Here we give here later developments (Wedberg 2011; Wedberg et al. 2011b) than described by Wedberg et al. (Wedberg et al. 2010), 
which has less reliable approximations for the DCF tail.

\subsubsection{LJ Fluids}

Figure 6.6 compares the isothermal compressibilities obtained from the method with those obtained from the EOS of Mecke et al. for LJ fluids (Mecke et al. 1996). At all four temperatures, our results are qualitatively consistent with the EOS, with differences in the range of $1-5 \%$. The comparisons are not as good at the two lowest temperatures, where the differences are as high as $6 \%$.

\section{[Insert Figure 6.6]}

The greatest disagreement is seen when $T^{*}=1.5$ and $\rho^{*}$ is 0.3 or 0.4 , which are the state points closest to the critical point of $\rho_{c}^{*}=0.304$ and $T_{c}^{*}=1.316$ (Smit 1992). At those conditions, the differences are $7 \%$ and $8 \%$, respectively. This disagreement is not surprising considering that the reduced bulk modulus $\left(\rho k_{\mathrm{B}} T \kappa_{T}=1-C\right)$ can be very small in this region. We conclude that our method is best suited for systems at liquid density $\left(\rho>2 \rho_{c}\right)$. For $\rho^{*}=0.7$ and $\rho^{*}=0.8$, the agreement with the EOS was better at higher temperature $\left(1 \%\right.$ at $\left.T^{*}=2.5\right)$ than at lower temperature $\left(6 \%\right.$ at $\left.T^{*}=0.85\right)$. It is possible that derivatives of the Mecke EOS are less accurate at lower temperatures since the EOS does not reproduce the simulation pressures very well under these conditions and at higher temperatures. Nevertheless, though low temperatures seem to offer more of a challenge, the results obtained under those conditions may still be considered satisfactory. The standard error in $T$ was less than $0.5 \%$, indicating that the calculations were well converged. 


\subsubsection{LJ/Stockmayer Mixtures}

LJ/Stockmayer mixtures include "Stockmayer" atoms (2) with finite dipole moments and "LJ" atoms (1) with zero dipole moment. LJ-LJ and LJ-Stockmayer interactions thus follow the LJ potential, while Stockmayer-Stockmayer interactions include dipole-dipole interactions. The EOS of Gross and Vrabec (Gross and Vrabec 2006) describes mixtures of fluid particles with different dipole moments and thus can be used to obtain the isothermal compressibility. Values of the reduced bulk modulus obtained from our method are compared in Figure 6.7 with the Gross/Vrabec EOS. For $\mu^{*^{2}}=1$ (a), the Verlet values agrees very well with the EOS; the differences are $1-1.5 \%$. For the higher dipole moments, the agreement is still good when $x_{2}$ is small but deteriorates as $x_{2}$ increases (b) and(c). This becomes more pronounced for $\mu^{*^{2}}=3$ where the discrepancies are as large as $11 \%$ at Stockmayer-rich compositions. Since the Gross/Vrabec EOS did not reproduce simulation pressures very well (Wedberg 2011) with errors increasing with larger $\mu^{* 2}$ and $x_{2}$, the discrepancy may not be only in the simulation results.

[Insert Figure 6.7]

\subsubsection{Comparison with existing approaches}

The truncation (Weerasinghe and Smith 2003b) and distance-shifting (Hess and van der Vegt 2009) methods were also employed to calculate $\rho k_{\mathrm{B}} T \kappa_{T}$. Simple truncation requires averaging $H\left(R_{\text {lim }}\right)$ over a specific interval, where $H\left(R_{\text {lim }}\right)$ is the numerical TCFI as a function of the upper integration limit $R_{\text {lim }}$. It is not obvious how to choose these values. Here, the TCFIs have been

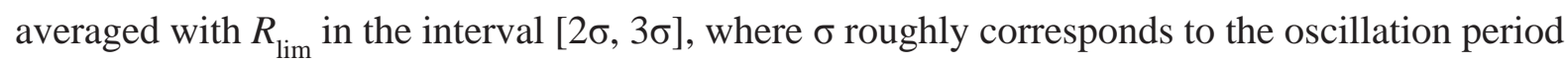
of $h_{i j}(r)$. With the Hess method, the scaling factor $\alpha_{i j}$ was evaluated with $R=4 \sigma$. The RDFs were 
re-scaled, but the integrals still did not converge within the sampled range. The integration of the re-scaled RDFs was thus carried out as with the truncation method, but using larger truncation radii, based on the idea that corrected RDFs are more reliable at large separations. The TCFIs were averaged using truncation radii in the interval $[3.5 \sigma, 4.5 \sigma]$. The values obtained for the isothermal compressibility (Figure 6.7) demonstrates the limitations on simple truncation and distance-shifting methods. Truncation overestimates the compressibility by $10-15 \%$ while distance-shifting underestimates it by $10-40 \%$. These are sensitive to the choice of truncation radii, so it is possible that better results could have been obtained with other radii. The methods should also perform better with significantly larger simulation systems, but this was not tried here. The Verlet method yielded accurate results for LJ/Stockmayer mixtures as indicated by comparisons with benchmark values. While the method achieves better accuracy than simpler integration approaches, caution is advised regarding activity coefficient derivatives when a system is nearly ideal or when the mole fraction of a component is less than approximately $15 \%$, as discussed by Wedberg et al (Wedberg et al. 2011a).

\subsubsection{Aqueous Alcohol Mixtures}

The major goal is to establish an integration method that accurately predicts activity coefficient derivatives, partial molar volumes, and isothermal compressibilities from simulations of molecular mixtures with atom-atom interaction models. This section focuses on such applications with results compared to values derived from correlations of experimental data. It should be noted that the accuracy also depends on the validity of the molecular force fields and reliability of experimental data. As with the analysis of the LJ/Stockmayer mixtures, the simple 
truncation (Weerasinghe and Smith 2003b) and distance-shifting methods (Hess and van der Vegt 2009) were employed to evaluate the same properties. Simple truncation averaging of the integral varied in the interval for $R_{\text {lim }}$ from 1.0 to $1.5 \mathrm{~nm}$. With the distance-shifting method, the scaling factors $\alpha_{i j}$ were evaluated from the calculated RDFs with the parameter $R=2.0 \mathrm{~nm}$. Numerical integration of the re-scaled RDFs did not converge within the sampling range, so the integrals of the rescaled TCFs were evaluated by truncation using intervals of $1.4-1.9 \mathrm{~nm}$. The truncation radii employed for integration of the re-scaled TCFs were larger than those used with the simple truncation approach since the rescaled TCFs probably were more accurate than the original TCFs for large $r$, as discussed in Section 6.3. For comparison, isothermal compressibilities were evaluated via the fluctuations of the simulation box volume. The results are shown in Figure 6.8. The Verlet method reproduced the fluctuation formula results to within $5 \%$, while the simple truncation and distance-shifting methods were greatly in error. In fact, distance-shifting yielded negative compressibilities. It is likely that reliable results by these methods require simulations of larger systems.

[Insert Figure 6.8]

In order to validate the partial molar volumes obtained by the different integration methods, the excess molecular volume, $V^{E}$, was evaluated for the simulations at each composition according to,

$$
V_{m}^{E}\left(x_{1}\right)=V_{m}\left(x_{1}\right)-x_{1} V_{1}^{o}-x_{2} V_{2}^{o}
$$

where $V_{m}\left(x_{1}\right)$ denotes the average molecular volume obtained at the composition $x_{1}$, the mole fraction of water. Also, $V_{1}^{o}$ and $V_{2}^{o}$ denote the average molar volumes of the corresponding pure 
components, obtained from separate simulations. The polynomial model of Handa and Benson (Handa and Benson 1979),

$$
V_{m}^{E}(\text { model })=x_{1} x_{2}\left[a_{0}+a_{1}\left(x_{2}-x_{1}\right)+a_{2}\left(x_{2}-x_{1}\right)^{2}\right]
$$

was fitted to the calculated values of the excess molar volume. Reduced partial molar volumes were evaluated by analytical differentiation of the model according to,

$$
\rho \bar{V}_{1}=\rho V_{m}^{E}+\rho\left[\partial\left(N V_{m}^{E}\right) / \partial N_{1}\right]_{T, p, N_{2}}
$$

In Figure 6.9, the results for $\rho \bar{V}_{1}$ are compared with TCFIs calculated by our Verlet, simple truncation, and distance-shifting methods. The partial molar volumes obtained from the correlations of simulation volumes are in very good agreement with those obtained from experimental correlations (Handa and Benson 1979). The results obtained via the three TCFI calculation methods agreed very well with both correlations. Furthermore, the three methods yielded similar results, though for dilute water systems, simple truncation underestimates the values relative to the other methods and experimental data.

[Insert Figure 6.9]

Figure 6.10 shows activity coefficient derivatives over the whole composition range for experiment from three correlations, and the Verlet method. A procedure for experimental data analysis was described by Wooley and O'Connell (Wooley and O'Connell 1991), in which one extracts the isothermal compressibility, partial molar volumes, and activity coefficient derivatives from experimental data. The activity coefficient derivatives are obtained by fitting mixture vapor-liquid equilibrium data to obtain parameters for at least two different $G^{E}$ models. Wooley and O'Connell employed the Wilson, non-random two liquid (NRTL) and modified Margules (mM) models. Partial molar volumes are obtained from correlations of mixture 
densities (Handa and Benson 1979). Isothermal compressibilities are either taken from measurements or estimated with the correlation of Huang and O'Connell (Huang and O'Connell 1987). Figure 6.10 also shows the relation $y=-1 / x_{1}$; for complete miscibility, the activity coefficient derivative must always lie above this curve. The simulation value at $x_{1}=0.1$ may be unreliable due to diluteness. The results from the NRTL and $\mathrm{mM}$ correlations show immiscibility, which is not observed, while the simulations suggest complete miscibility. The Wilson correlation cannot give two liquid phases so it is more consistent with the simulations at dilute alcohol concentrations.

[Insert Figure 6.10]

As described in Chapter 1, neither TCFIs nor DCFIs can be measured directly in experiments, though they can be derived from correlations of experimental data for other thermodynamic properties or integrals of x-ray or neutron scattering measurements. Figure 6.11 shows TCFIs from the correlated results of Figures 6.9 and 6.10 along with results from our Verlet method.

[Insert Figure 6.11]

The TCFIs obtained by our Verlet method apparently converged at all compositions, indicating phase stability over the whole composition. They compare favorably with those from simple truncation (Weerasinghe and Smith 2003b), and the distance-shifting (Hess and van der Vegt 2009) methods. When a simulated system is sufficiently large, the three methods can be expected to yield similar results, but the Verlet method is superior for smaller systems and when the RDFs have significant structure beyond the sampling limit. This is an important result, since the Verlet method might allow thermodynamic derivative properties to be accurately obtained from 
simulations of complex systems with relatively low computational effort.

\subsection{Future Applications}

Classical thermodynamics can only provide relations among properties; values must be found by experiment or computation. Given our current techniques, future applications of TCFintegrations for properties may be achieved in the following areas.

\subsubsection{Enzyme solutions}

Water activity is an important element of non-aqueous biocatalytic systems. Recently, we have explored different approaches to this property via MD simulation (Wedberg, Abildskov, and Peters 2012). Two main strategies to study how protein properties depend on water activity are termed "real-time" control and "a posteriori" analysis. The former comprises simulations of the protein in a non-aqueous medium in which the number of water molecules is adjusted to maintain a desired water activity. In the latter strategy, conventional MD simulations are carried out, but the water activity is calculated through post-analysis of the simulations. The study of Branco et al. (Branco et al. 2009) is apparently the only work that explicitly considers water activity as a variable. However, their medium was assumed to be an ideal mixture. The greater challenge of nonideal media, such as aqueous organic solutions, has been addressed (Wedberg, Abildskov, and Peters 2012). Much more work needs to be done before establishing a standard method. 


\subsubsection{Diffusion and Reaction}

The current works on properties have involved only equilibrium properties. Computed RDFs for homogeneous, but non-equilibrium, states could lead to local chemical potential gradients for diffusional driving forces and chemical reaction driving forces. Such computations would be unique and powerful for both thermodynamic and transport phenomena.

In particular, the Stefan-Maxwell constitutive equation for multicomponent diffusion in nonideal solutions (Curtiss and Bird 1999; Wheeler and Newman 2004a, 2004b) has driving forces derived from chemical potential gradients of all but one component. The non-ideality adjustment has been obtained for mutual diffusion in binary mixtures using FST (Jolly and Bearman 1980; Schoen and Hoheisel 1984; Chitra and Smith 2001c). Simulations based on the methods described here could describe higher multicomponent systems, which are of significant interest.

\subsection{Conclusions}

The successes described in this Chapter for both model and real mixtures indicate that molecular simulation methods for FST should now be ready for greater implementation and extension. Investigations to refine the various methods to compute KBIs are still ongoing. At this point, our extended Verlet method appears to be the most general and reliable for obtaining thermodynamic properties, especially for dense systems. Its advantages of minimal computational effort and limited need for case-by-case judgment in analysis indicate its efficiency and robustness. 
Figure 6.1 (left) RDFs from simulation of water (1) + t-butanol (2) at $x_{1}=0.65$, at $323 \mathrm{~K}$ and 1 atm; (right) Numerically evaluated (non-converged) integrals $H_{i j}\left(R_{\lim }\right)$ from Equation 6.9.

Figure 6.2. (a) Distribution function of benzene (1) / ethanol (2), $g_{22}(\mathrm{r})$, at $x_{2}=0.5$; (b)

Differential contributions to the $G_{22}$ integral, $d G_{22}$, at $x_{2}=0.5$. (Reprinted with permission from

S. Christensen, G. H. Peters, F. Y. Hansen, J. P. O’Connell, and J. Abildskov. 2007. Generation of thermodynamic data for organic liquid mixtures from molecular simulations. Molecular Simulation. 33, 449.)

Figure 6.3. Spatial RDF - Blocks for integrating $h(r)$. Direct from simulation; End-of-Box for matching simulation to fitted function such as Equation 6.18; Long Distance from fitted function.

Figure 6.4. Ethanol/HFC-227ea pressure-composition diagram at 343 K. -- -- Experiment (Case et al. 2007), — from simulation, —•- - Ideal solution. Modified from S. Christensen, G. H. Peters, F. Y. Hansen, J. P. O'connell, and J. Abildskov. 2007. State conditions transferability of vapor-liquid equilibria via fluctuation solution theory with correlation function integrals from molecular dynamics simulation. Fluid Phase Equilibria. 260, 169.

Figure 6.5. Activity coefficients (based on simulations) of (1) ethanol ( $\square, \mathbf{\square}) /(2)$ HFC-227ea $(\Delta, \boldsymbol{\Delta})$ at $283.17 \mathrm{~K}(-)$ and $343.13 \mathrm{~K} \mathrm{(--).} \mathrm{(Reprinted} \mathrm{with} \mathrm{permission} \mathrm{from} \mathrm{Modified} \mathrm{from} \mathrm{S.}$ Christensen, G. H. Peters, F. Y. Hansen, J. P. O'connell, and J. Abildskov. 2007. State conditions 
transferability of vapor-liquid equilibria via fluctuation solution theory with correlation function integrals from molecular dynamics simulation. Fluid Phase Equilibria. 260, 169)

Figure 6.6. Values (x) for results (left) and relative residuals (right) from calculations of the reduced bulk modulus, $\rho k_{B} T \kappa_{T}$, for the pure LJ fluid at the reduced temperatures $T^{*}=0.85, T^{*}=$ $1.0, T^{*}=1.5$ and $T^{*}=2.5$. Lines derived from EOS of Mecke, et al. (Mecke et al. 1996) are also shown.

Figure 6.7. Values of $\rho k_{B} T \kappa_{T}$ for LJ/Stockmayer mixtures $v s$. the mole fraction of Stockmayer particles, $x_{2}$, for dipole moments of (a) $\mu^{*^{2}}=1$, (b) $\mu^{*^{2}}=2$ and (c) $\mu^{*^{2}}=3$, derived from the Gross/Vrabec EOS (Gross and Vrabec 2006) (-), compared with results from our MD-Verlet ( $\square$ ), truncation (Weerasinghe and Smith 2003b) (o), and distance-shifting (Hess and van Der Vegt 2009) ( $\Delta$ ) methods.

Figure 6.8. Isothermal compressibilities for the mixture water (1) / t-butanol (2). Results from our Verlet ( $\square$ ), truncation (Weerasinghe and Smith 2003b) (o), and distance-shifting (Hess and van Der Vegt 2009) $(\Delta)$, methods compared with values obtained from the fluctuation formula $(-\mathrm{x}-)$ 
Figure 6.9. Relative partial molar volumes $\left(\rho \bar{V}_{1}\right)$ for water (1) / t-butanol (2). The results from the Verlet (ם), truncation (Weerasinghe and Smith 2003b) (o), and distance-shifting (Hess and van Der Vegt 2009) ( $\Delta$ ) methods for obtaining the TCFIs compared with results from full simulations smoothed with a quadratic polynomial (- - -) and with smoothed experimental data

Figure 6.10. Composition derivative of the activity coefficient for water $v s$. the water mole fraction $x_{1}$ of water (1) / t-butanol (2). The Verlet method (A) is compared with experimental data smoothed using the Wilson (- - , NRTL (---) and mM (-•-) models. For phase stability, activity coefficient derivatives must everywhere lie above the curve $y=-1 / x_{1}(\cdots)$.

Figure 6.11. TCFIs vs. mole fraction, $x_{1}$, for water (1) / t-butanol (2): (a) $H_{11}$, (b) $H_{12}$, and (c) $H_{22}$, obtained from simulations using the Verlet method (+), compared with TCFIs obtained from experimental data using the procedure of Wooley and O'Connell (Wooley and O'Connell 1991), based on the Wilson (- $(-)$, NRTL (---) or mM (-•-) models. The NRTL and mM models approach infinity since they falsely predict a phase split. 

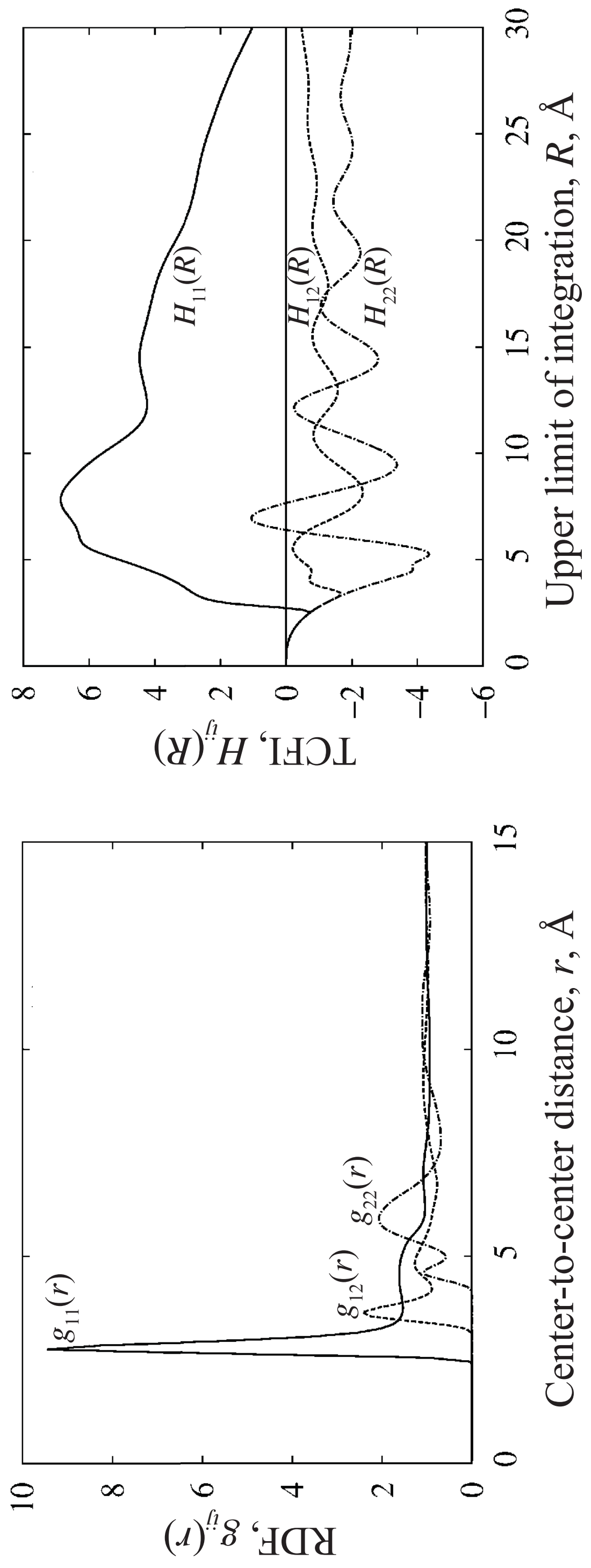


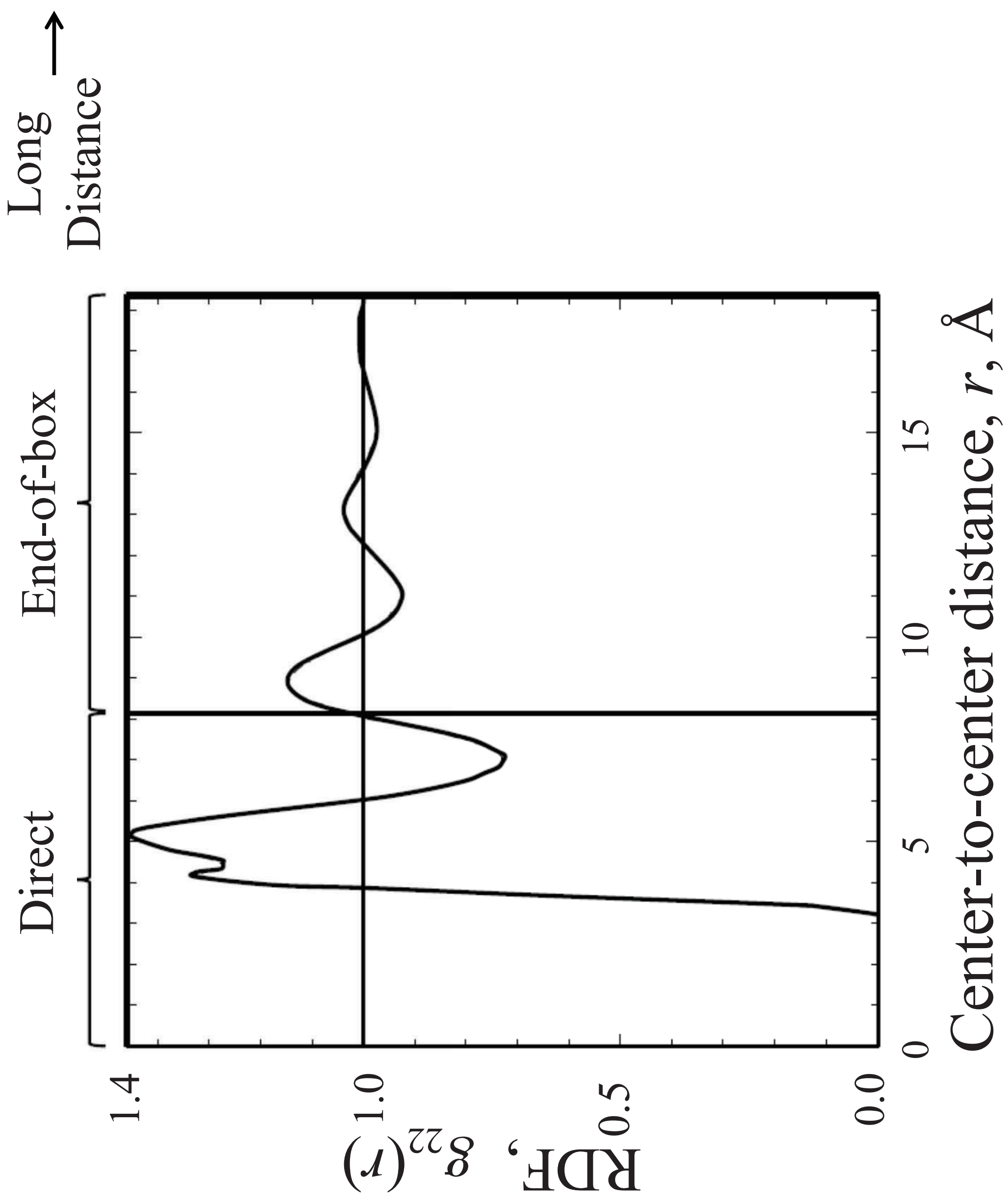




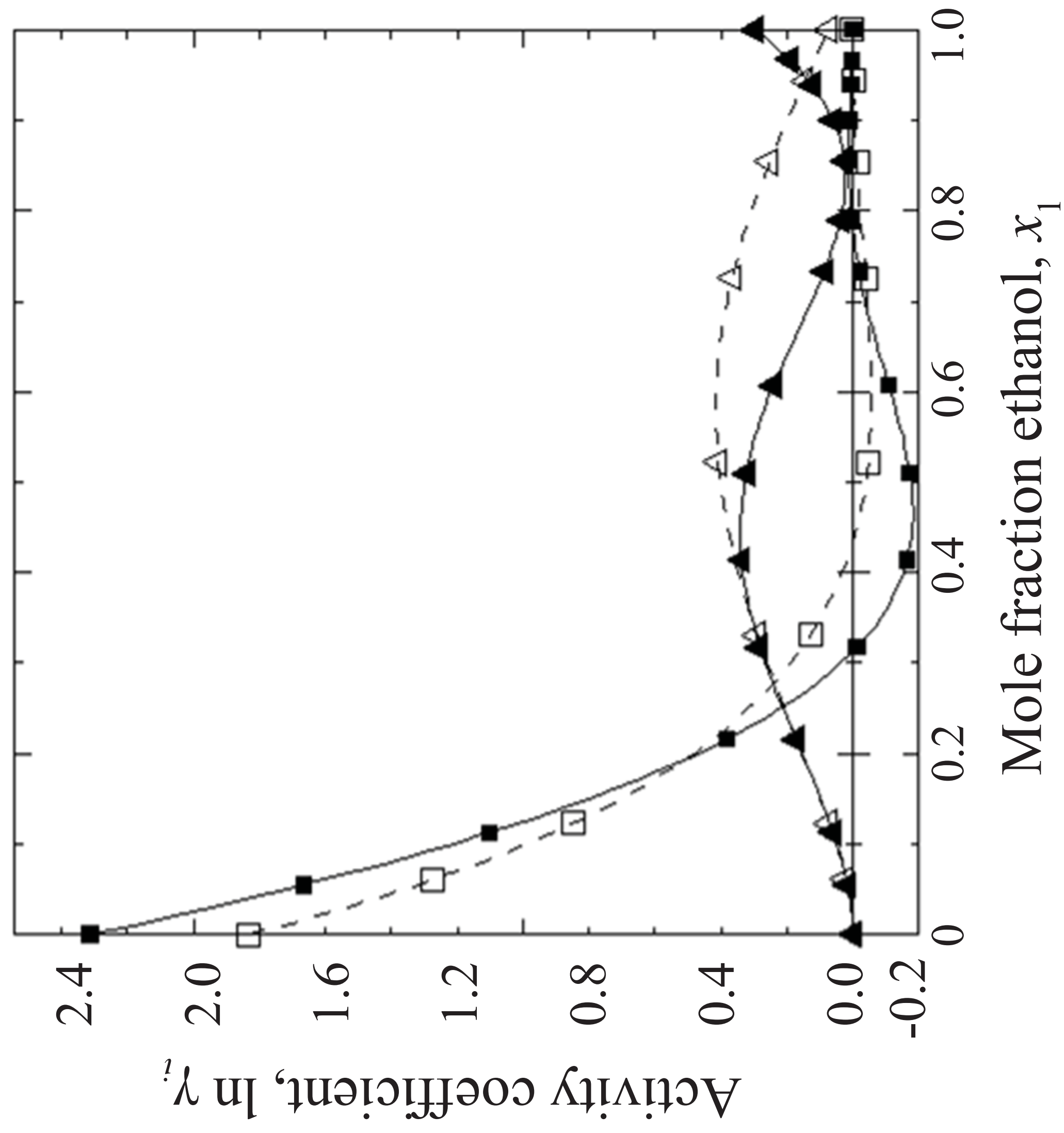



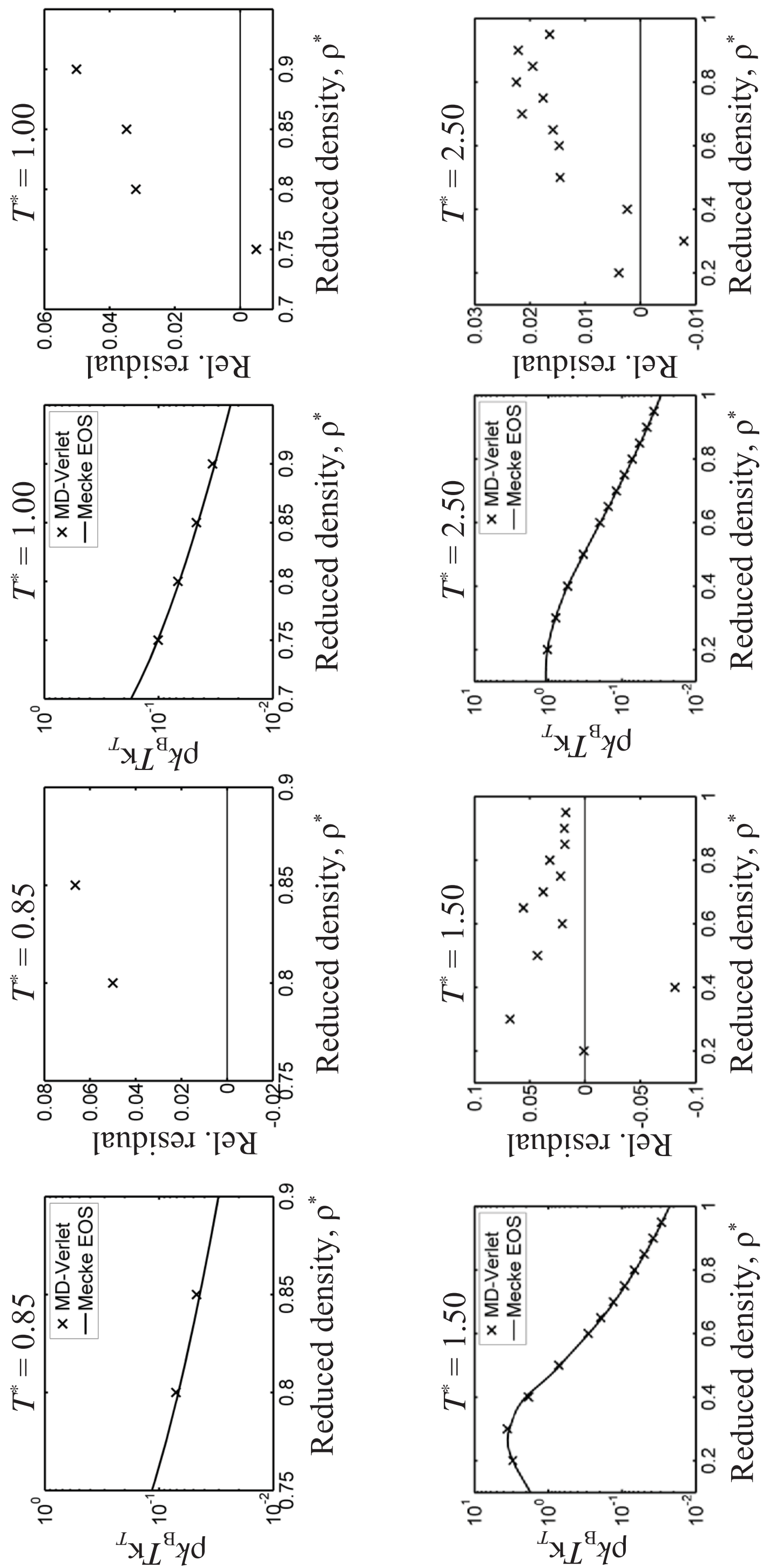

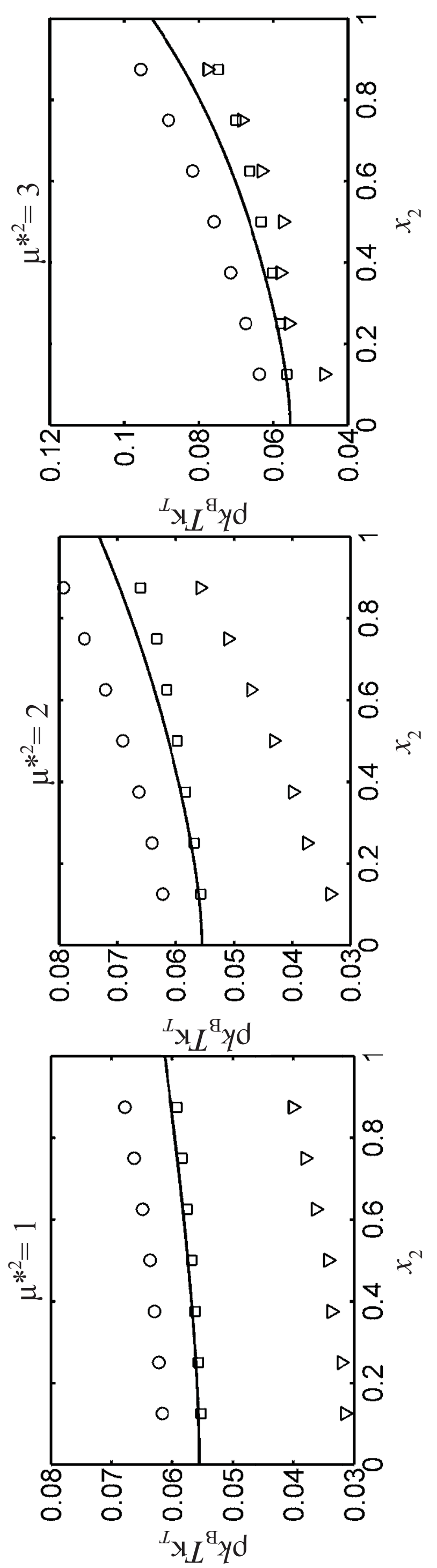


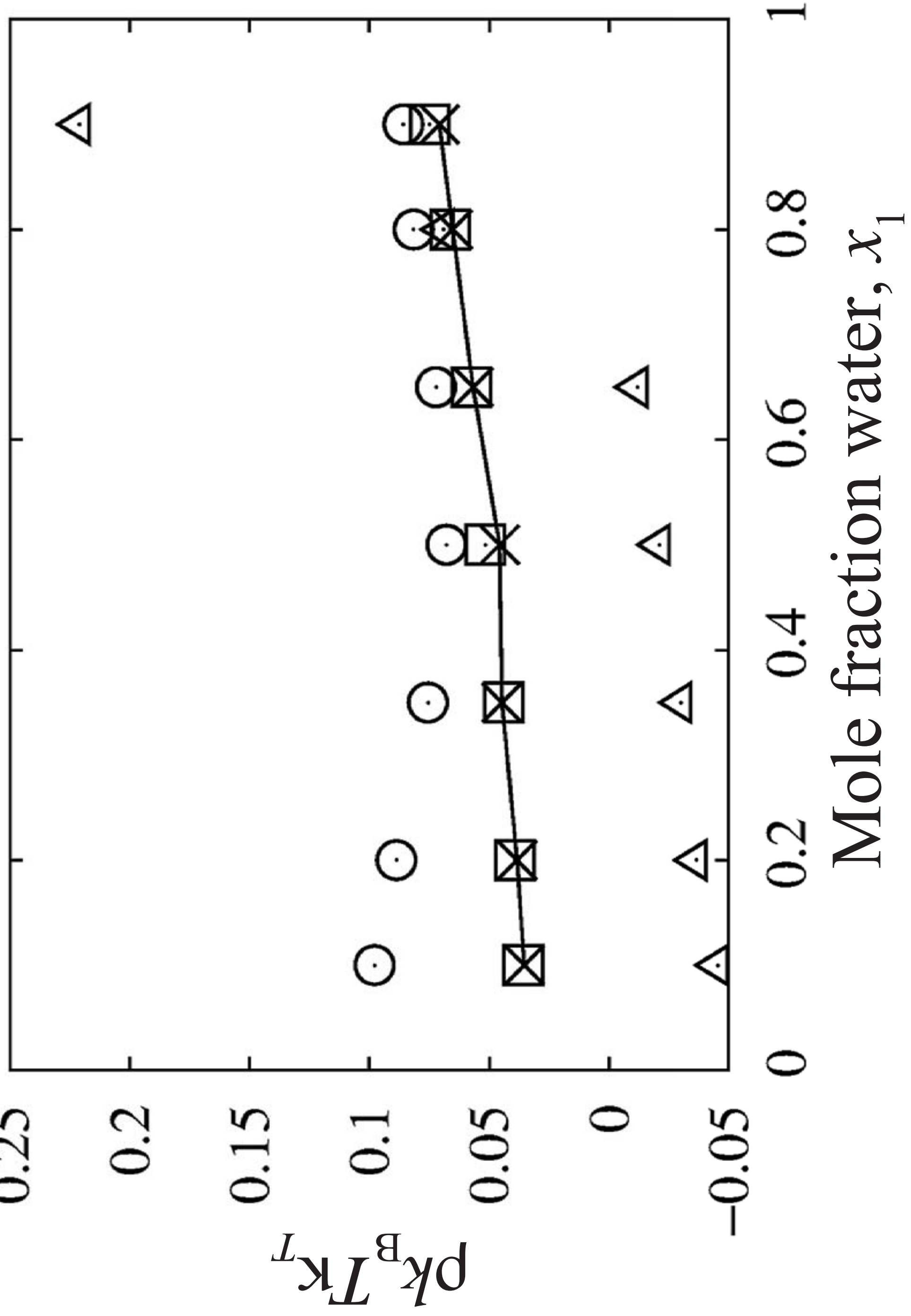




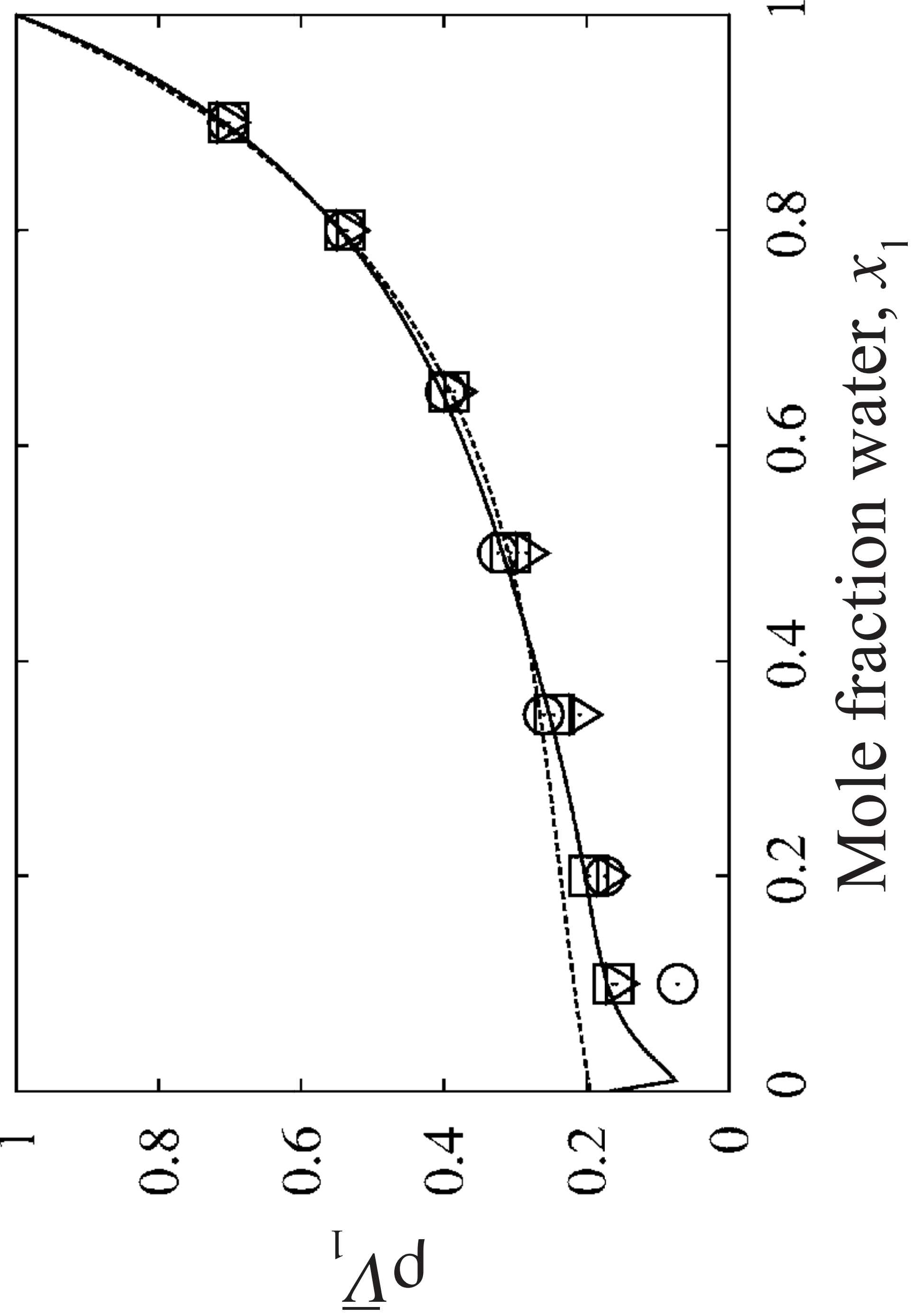




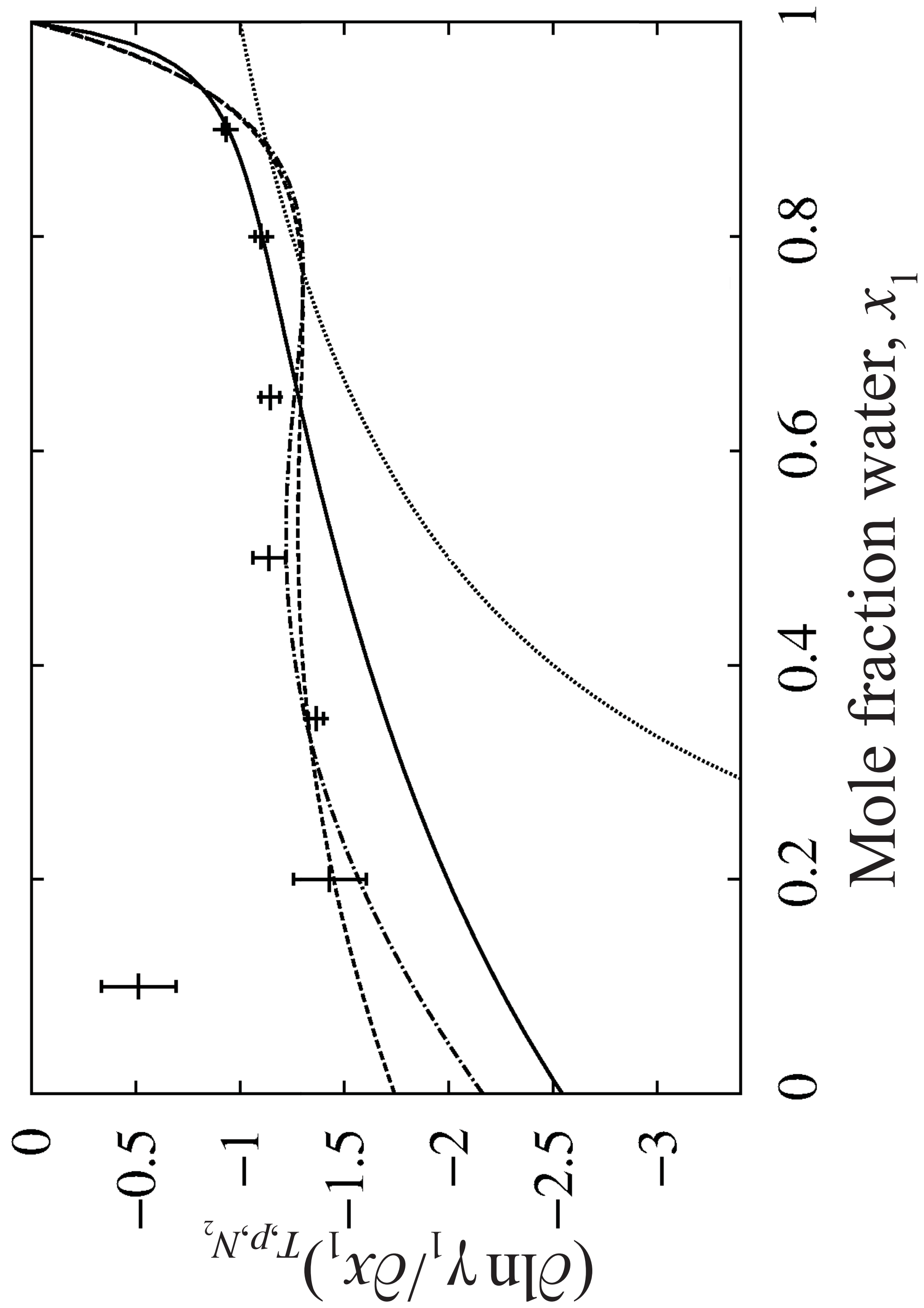



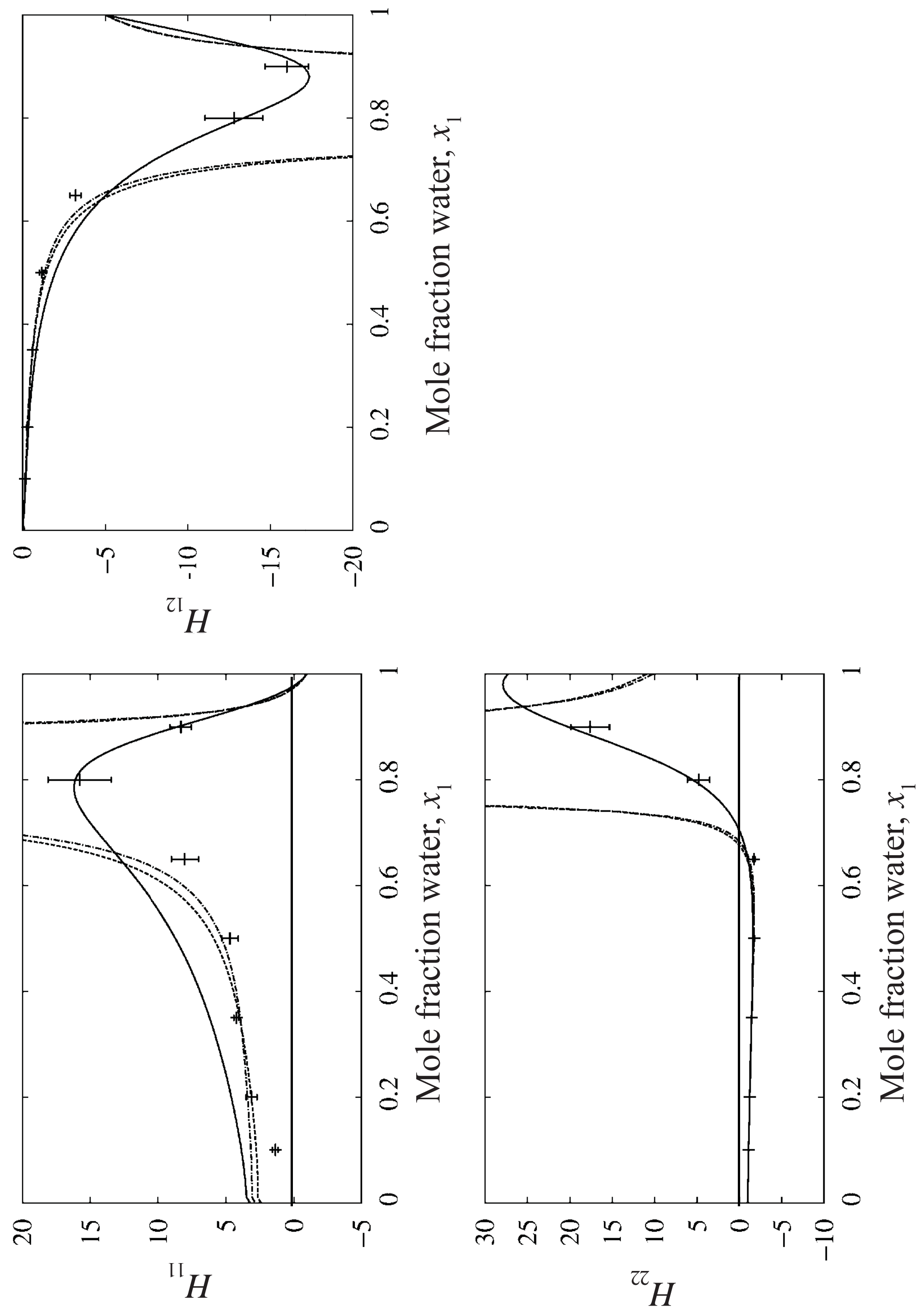


\section{Symbol Description}

\section{$\underline{\text { Greek }}$}

$\alpha_{p}$

Isobaric thermal expansion coefficient (Equation 1.6)

$\Gamma_{23}$

$\gamma_{ \pm}$

Preferential binding parameter (Equation 1.86)

$\gamma_{i}$

Mean ion molal activity coefficient (Equation 1.92)

$\gamma_{i}^{c}$

Lewis-Randall/rational/mole fraction activity coefficient (Equation 1.19)

Molar activity coefficient

$\gamma_{i}^{m} \quad$ Molal activity coefficient

$\Delta \quad$ Isothermal-isobaric partition function (Equation 1.28)

$\Delta G_{i j} \quad G_{i i}+G_{j j}-2 G_{i j}$ (Equation 1.93)

$\zeta_{2}$

$1+c_{i} G_{i i}+c_{j} G_{j j}+c_{i} c_{j}\left(G_{i i} G_{j j}-G_{i j}^{2}\right)$ (Equation 1.66)

$\eta_{12} \quad c_{i}+c_{j}+c_{i} c_{j}\left(G_{i i}+G_{j j}-2 G_{i j}\right)$ (Equation 1.66)

$\kappa_{T} \quad$ Isothermal compressibility (Equation 1.5)

$\Lambda_{i}$

Thermal de Broglie wavelength of specie $i$

$\lambda_{i}$

Absolute activity of $i$

$\mu_{i}$

Chemical potential of component $i$

$\mu_{i j}$

Chemical potential derivative (Equation 1.1)

$v \quad$ Number of cations/anions, $v=v_{+}+v_{-}$

$\Xi \quad$ Grand canonical partition function (Equation 1.28)

$\pi \quad$ Osmotic pressure

$\rho \quad$ Mass or total number density

$\rho_{\mathrm{i}} \quad$ Number density of $i,=N_{i} / V$, see also $c_{i}$

$\phi_{i} \quad$ Volume fraction of $i,=\rho_{i} \bar{V}_{i}$

$\varphi_{i} \quad$ Fugacity coefficient of $i$ (Equation 1.23)

$\Omega \quad$ Microcanonical partition function (Equation 1.28)

Mathematical

$<>$

$\{X\}$

1

$|\mathbf{A}|$

$\mathbf{A}^{\mathrm{ij}}$

A

I

$\delta_{i j}$

$\delta X_{i}$

$\left\langle(\delta X)^{2}>\right.$
Ensemble or time average

Set notation, $\left\{X_{1}, X_{2}, \ldots\right\}$

Unit matrix

Determinant of matrix A

Cofactor of matrix $\mathbf{A}$

Matrix with elements $A_{i j}$

Identity matrix

Kronecker delta

Instantaneous fluctuation, $X_{i}-\left\langle X_{i}\right\rangle$

Mean square fluctuation of a property $X$ 
$\underline{\text { Latin }}$

\begin{tabular}{|c|c|}
\hline+ & Cation \\
\hline - & Anion \\
\hline o & Pure \\
\hline$\infty$ & Infinitely dilute (limiting) \\
\hline 1 & Solvent \\
\hline $1 / k_{\mathrm{B}} T$ & $\beta$ \\
\hline 2 & Solute \\
\hline 3 & Cosolvent/cosolute/additive \\
\hline$\Delta_{\mathrm{r}} G$ & Reaction Gibbs energy (function) \\
\hline$\Delta_{\mathrm{r}} H$ & Reaction enthalpy \\
\hline$\Delta_{\mathrm{r}} S$ & Reaction entropy \\
\hline$\delta x_{j i}$ & Preferential solvation parameter ( $j$ surrounding $i$ ) \\
\hline$\delta x_{j i}^{\prime}$ & Corrected referential solvation parameter \\
\hline$\mu V T$ & Grand canonical ensemble \\
\hline$\hat{X}$ & Fourier transformed $X$ \\
\hline $\bar{X}_{i}$ & Partial molar property of $X$ \\
\hline$a_{ \pm}$ & Mean activity of electrolyte in solution \\
\hline$A$ & Helmholtz energy (function) \\
\hline $\mathrm{A}_{i}$ & Aggregate/Multimer of $i$ monomers \\
\hline$a_{i}$ & Activity of $i$ \\
\hline $\mathrm{aq}$ & Aqueous solution \\
\hline$c_{i}$ & Molarity of $i$, see also number density, $\rho_{i}$ \\
\hline$C_{i j}$ & $\rho \int c_{i j}(r) d r$, DCFI, elements of the $\boldsymbol{C}$ matrix (Equation 1.39) \\
\hline$c_{i j}(r)$ & Direct correlation function \\
\hline$C_{p}$ & Constant pressure heat capacity (Equation 1.7) \\
\hline$D$ & Activity derivative, concentration fluctuation term (Equation 1.73) \\
\hline$f_{i}$ & Fugacity of a substance $i$ in a gaseous mixture (Equation 1.21) \\
\hline$G$ & Gibbs energy (function) \\
\hline$g_{i j}$ & Radial (pair) distribution function, $\mathrm{RDF}$ \\
\hline$G_{i j}$ & Kirkwood-Buff integral, KBI \\
\hline$H$ & Enthalpy \\
\hline$h$ & Planck's constant \\
\hline$H_{i j}$ & $\rho \int h_{i j}(r) d r=\rho G_{i j}$, TCFI (see below Equation 1.38), or Henry's law constant \\
\hline$h_{i j}(r)$ & Total correlation function, TCF, $g_{i j}(r)-1$ \\
\hline & Ideal (mole fraction scale) \\
\hline$K$ & Equilibrium constant \\
\hline$k$ & Rate constant \\
\hline$k_{\mathrm{B}}$ & Boltzmann constant \\
\hline
\end{tabular}


$k_{\mathrm{H}}$

M

m

$m_{i}=c_{i} / c_{1}$

mix

$\mathrm{n}$

$n_{c}$

$N_{A}$

$N_{i}$

$N_{i j}$

NpT

NVE

NVT

$p$

$Q$

$r$

$R$

$R_{\text {cor }}$

$S$

$T$

$T_{\mathrm{m}}$

trs

U

V

$V_{\text {cor }}$

$X^{*}$

$X_{\mathrm{c}}$

$X^{\mathrm{E}}$

$X^{\mathrm{r}}$

$x_{i}$

$X_{\mathrm{m}}$

$y_{i}$

$z_{+/-}$

Acronyms

$\mathrm{COM}$

DCF

DCFI

EOS

FF
Henry's law constant, see also $H_{i j}$

Monomer

$m$-value for protein denaturation (see Equation 1.99)

(Dimensionless) molality

Mixing process

Number of monomers in an aggregate

Number of components in the system

Avogadro's number

Number of entities (usually molecules, atoms, or ions)

Excess coordination number

Isothermal-isobaric (Gibbs) ensemble

Microcanonical ensemble

Canonical ensemble

Pressure

Canonical partition function (Equation 1.28)

$\left|\boldsymbol{r}_{1}-\boldsymbol{r}_{2}\right|$, distance between COM of molecules

Gas constant

Correlation radius (see $V_{\text {cor }}$ )

Entropy

Temperature (thermodynamic)

Melting temperature

Transfer between two phases

Internal energy

Volume

Correlation volume (see Equation 1.81)

Reduced or characteristic quantity $X$

Critical $X$ ( $X$ is pressure or temperature)

Excess of $X$

Residual of quantity $X$

Liquid phase mole fraction composition

Molar quantity

Gas phase mole fraction composition, or solute solubility

Charge of cation/anion

Center of mass

Direct correlation function

Direct correlation function integral

Equation of state

Force Field 


\begin{tabular}{ll} 
FST & Fluctuation solution theory \\
FT & Fluctuation theory \\
GD & Gibbs-Duhem \\
IG & Ideal gas \\
KB & Kirkwood-Buff \\
KBFF & Kirkwood-Buff Force Field \\
KBI & Kirkwood-Buff integral \\
LJ & Lennard-Jones \\
MC & Monte Carlo \\
MD & Molecular Dynamics \\
MDF & Molecular Distribution Function \\
MM & McMillan-Mayer \\
MW & Molecular Weight \\
NRTL & Non-Random Two Liquid \\
OSA & Osmotic stress analysis \\
OZ & Ornstein-Zernike \\
PF & Partition function \\
PI & Preferential Interaction \\
PMF & Potential of mean force \\
PS & Preferential Solvation \\
PY & Percus-Yevick \\
RDF & Radial distribution function \\
RK & Redlich-Kister \\
RISM & Reference interaction-site model \\
SAFT & Statistical associated-fluid theory \\
SANS & Small-angle neutron scattering \\
SAXS & Small-angle X-ray scattering \\
SI & Symmetric ideal \\
SPT & Scaled particle theory \\
TCF & Total correlation function \\
TCFI & Total correlation function integral \\
UNIFAC & UNIversal Functional Activity Coefficient \\
UNIQUAC & UNIversal QUAsiChemical \\
VDW & van der Waals \\
\hline
\end{tabular}


Abernethy, G. M., and M. J. Gillan. 1980. New method of solving the HNC equation for ionic liquids. Molecular Physics. 39, 839.

Abildskov, J., M. D. Ellegaard, and J. P. O'Connell. 2009. Correlation of phase equilibria and liquid densities for gases with ionic liquids. Fluid Phase Equilibria. 286, 95.

Abildskov, J., M. D. Ellegaard, and J. P. O'Connell. 2010a. Densities and isothermal compressibilities of ionic liquids-modeling and application. Fluid Phase Equilibria. 295, 215.

Abildskov, J., M. D. Ellegaard, and J. P. O'Connell. 2010b. Phase behavior of mixtures of ionic liquids and organic solvents. Journal of Supercritical Fluids. 55, 833.

Abramowitz, M., and I. A. Stegun. 1970. Handbook of Mathematical Functions. New York: Dover Publications, Inc.

Acree Jr., W. E. 1984. Thermodynamic Properties of Nonelectrolyte Solutions. Orlando: Academic Press, Inc.

Adschiri, T., Y. W. Lee, M. Goto, and S. Takami. 2011. Green materials synthesis with supercritical water. Green Chemistry. 13, 1380.

Allison, J. R., M. Bergeler, N. Hansen, and W. F. van Gunsteren. 2011. Current computer modeling cannot explain why two highly similar sequences fold into different structures. Biochemistry. 50, 10965.

Allison, S. K., J. P. Fox, R. Hargreaves, and S. P. Bates. 2005. Clustering and microimmiscibility in alcohol-water mixtures: Evidence from molecular-dynamics simulations. Physical Review B. 71, 024201.

Almasy, L., G. Jancso, and L. Cser. 2002. Application of SANS to the determination of Kirkwood-Buff integrals in liquid mixtures. Applied Physics A-Materials Science and Processing. 74, S1376.

Alves, W. A., and P. S. Santos. 2007. Using Raman spectroscopy to investigate donor-acceptor reactions in the formamide/dimethylsulfoxide/acetonitrile system. Journal of Raman Spectroscopy. 38, 1332.

Andersen, H. C., and D. Chandler. 1972. Optimized cluster expansions for classical fluids. I. General theory and variational formulation of the mean spherical model and hard sphere Percus-Yevick equations. Journal of Chemical Physics. 57, 1918.

Anderson, C. F., E. S. Courtenay, and M. T. Record. 2002. Thermodynamic expressions relating different types of preferential interaction coefficients in solutions containing two solute components. Journal of Physical Chemistry B. 106, 418.

Anfinsen, C. B. 1973. Principles that govern the folding of protein chains. Science. 181, 223.

Aparicio, S., R. Alcalde, B. Garcia, and J. M. Leal. 2008. Structure-composition relationships in ternary solvents containing methylbenzoate. Journal of Physical Chemistry B. 112, 3420.

Aparicio, S., R. Alcalde, J. M. Leal, and B. García. 2005. Characterization and preferential solvation of the hexane/hexan-1-ol/methylbenzoate ternary solvent. Journal of Physical Chemistry B. 109, 6375.

Arakawa, T., R. Bhat, and S. N. Timasheff. 1990. Preferential interactions determine protein solubility in 3-component solutions - the $\mathrm{MgCl}_{2}$ system. Biochemistry. 29, 1914.

Arakawa, T., and S. N. Timasheff. 1982. Preferential interactions of proteins with salts in concentrated solutions. Biochemistry. 21, 6545.

Arakawa, T., and S. N. Timasheff. 1984. Mechanism of protein salting in and salting out by divalent-cation salts - Balance between hydration and salt binding. Biochemistry. 23, 5912. 
Arakawa, T., and S. N. Timasheff. 1985a. The stabilization of proteins by osmolytes. Biophysical Journal. 47, 411.

Arakawa, T., and S. N. Timasheff. 1985b. Theory of protein solubility. Methods in Enzymology. $114,49$.

Arakawa, T., and S. N. Timasheff. 1987. Abnormal solubility behavior of $\beta$-lactoglobulin salting-in by glycine and $\mathrm{NaCl}$. Biochemistry. 26, 5147.

Archer, A. J., and N. B. Wilding. 2007. Phase behavior of a fluid with competing attractive and repulsive interactions. Physical Review E. 76, 031501.

Attard, P. 1990. Integral-equations and closure relations for the bridge function and for the triplet correlation-function. Journal of Chemical Physics. 93, 7301.

Attard, P., D. R. Berard, C. P. Ursenbach, and G. N. Patey. 1991. Interaction free-energy between planar walls in dense fluids - An Ornstein-Zernike approach with results for hard-sphere, Lennard-Jones, and dipolar systems. Physical Review A. 44, 8224.

Auton, M., and D. W. Bolen. 2004. Additive transfer free energies of the peptide backbone unit that are independent of the model compound and the choice of concentration scale. Biochemistry. 43, 1329.

Auton, M., and D. W. Bolen. 2005. Predicting the energetics of osmolyte-induced protein folding/unfolding. Proceedings of the National Academy of Sciences of the United States of America. 102, 15065.

Auton, M., and D. W. Bolen. 2007. Application of the transfer model to understand how naturally occurring osmolytes affect protein stability. Methods in Enzymology. 428, 397.

Auton, M., D. W. Bolen, and J. Rösgen. 2008. Structural thermodynamics of protein preferential solvation: Osmolyte solvation of proteins, aminoacids, and peptides. Proteins: Structure, Function, and Bioinformatics. 73, 802.

Auton, M., L. M. F. Holthauzen, and D. W. Bolen. 2007. Anatomy of energetic changes accompanying urea-induced protein denaturation. Proceedings of the National Academy of Sciences of the United States of America. 104, 15317.

Auton, M., J. Rösgen, M. Sinev, L. M. F. Holthauzen, and D. W. Bolen. 2011. Osmolyte effects on protein stability and solubility: A balancing act between backbone and side-chains. Biophysical Chemistry. 159, 90.

Baldwin, R. L. 1996. How Hofmeister ion interactions affect protein stability. Biophysical Journal. 71, 2056.

Ball, P. 2008. Water - An enduring mystery. Nature. 452, 291.

Baynes, B. M., and B. L. Trout. 2003. Proteins in mixed solvents: A molecular-level perspective. Journal of Physical Chemistry B. 107, 14058.

Behera, R. 1998. On the calculation of thermodynamic properties of electrolyte solutions from Kirkwood-Buff theory. Journal of Chemical Physics. 108, 3373.

Ben-Naim, A. 1975. Solute and solvent effects on chemical-equilibria. Journal of Chemical Physics. 63, 2064.

Ben-Naim, A. 1977. Inversion of Kirkwood-Buff theory of solutions - Application to waterethanol system. Journal of Chemical Physics. 67, 4884.

Ben-Naim, A. 1987. Solvation Thermodynamics. New York: Plenum Press.

Ben-Naim, A. 1988. Theory of preferential solvation of nonelectrolytes. Cell Biophysics. 12, 255.

Ben-Naim, A. 1989. Preferential solvation in 2-component systems. Journal of Physical Chemistry. 93, 3809. 
Ben-Naim, A. 1990a. Inversion of Kirkwood-Buff theory of solutions and its applications. In Fluctuation Theory of Mixtures, Edited by E. Matteoli and G. A. Mansoori. New York: Taylor and Francis.

Ben-Naim, A. 1990b. Preferential solvation in 2-component and in 3-component systems. Pure and Applied Chemistry. 62, 25.

Ben-Naim, A. 1992. Statistical Thermodynamics for Chemists and Biochemists. New York: Plenum Press.

Ben-Naim, A. 2006. Molecular Theory of Solutions. New York: Oxford University Press.

Ben-Naim, A. 2007a. A critique of some recent suggestions to correct the Kirkwood-Buff integrals. Journal of Physical Chemistry B. 111, 2896.

Ben-Naim, A. 2007b. Reply to "Comment on 'A critique of some recent suggestions to correct the Kirkwood-Buff integrals"'. Journal of Physical Chemistry B. 111, 3072.

Ben-Naim, A. 2008. Comment on "The Kirkwood-Buff theory of solutions and the local composition of liquid mixtures". Journal of Physical Chemistry B. 112, 5874.

Ben-Naim, A. 2009. Molecular Theory of Water and Aqueous Solutions. Part 1: Understanding Water. Singapore: World Scientific Publishing Co.

Ben-Naim, A. 2011. Molecular Theory of Water and Aqueous Solutions. Part 2: The Role of Water in Protein Folding, Self-Assembly and Molecular Recognition. Singapore: World Scientific Publishing Co.

Ben-Naim, A., and A. Santos. 2009. Local and global properties of mixtures in one-dimensional systems. II. Exact results for the Kirkwood-Buff integrals. Journal of Chemical Physics. $131,164512$.

Bennion, B. J., and V. Daggett. 2003. The molecular basis for the chemical denaturation of proteins by urea. Proceedings of the National Academy of Sciences of the United States of America. 100, 5142.

Bentenitis, N., N. R. Cox, and P. E. Smith. 2009. A Kirkwood-Buff derived force field for thiols, sulfides, and disulfides. Journal of Physical Chemistry B. 113, 12306.

Berendsen, H. J. C., J. R. Grigera, and T. P. Straatsma. 1987. The missing term in effective pair potentials. Journal of Physical Chemistry. 91, 6269.

Berendsen, H. J. C., J. P. M. Postma, W. F. van Gunsteren, and J. Hermans. 1981. Interaction models for water in relation to protein hydration. In Intermolecular Forces, Edited by B. Pullman. Dordrecht: D. Reidel.

Beutler, T. C., A. E. Mark, R. C. van Schaik, P. R. Gerber, and W. F. van Gunsteren. 1994. Avoiding singularities and numerical instabilities in free-energy calculations based on molecular simulations. Chemical Physics Letters. 222, 529.

Biben, T., and J. P. Hansen. 1991. Phase-separation of asymmetric binary hard-sphere fluids. Physical Review Letters. 66, 2215.

Bjelkmar, P., P. Larsson, M. A. Cuendet, B. Hess, and E. Lindahl. 2010. Implementation of the CHARMM force field in GROMACS: Analysis of protein stability effects from correction maps, virtual interaction sites, and water models. Journal of Chemical Theory and Computation. 6, 459.

Blanco, M. A., E. Sahin, Y. Li, and C. J. Roberts. 2011. Reexamining protein-protein and protein-solvent interactions from Kirkwood-Buff analysis of light scattering in multicomponent solutions. Journal of Chemical Physics. 134, 225103.

Blum, L., and A. J. Torruella. 1972. Invariant expansion for 2-body correlations Thermodynamic functions, scattering, and Ornstein-Zernike equation. Journal of 
Chemical Physics. 56, 303.

Bolen, D. W. 2004. Effects of naturally occurring osmolytes on protein stability and solubility: Issues important in protein crystallization. Methods. 34, 312.

Bolen, D. W., and I. V. Baskakov. 2001. The osmophobic effect: Natural selection of a thermodynamic force in protein folding. Journal of Molecular Biology. 310, 955.

Bolen, D. W., and G. D. Rose. 2008. Structure and energetics of the hydrogen-bonded backbone in protein folding. Annual Review of Biochemistry. 77, 339.

Bondi, A. 1964. van der Waals volumes and radii. Journal of Physical Chemistry. 68, 441.

Bonnet, P., and R. A. Bryce. 2004. Molecular dynamics and free energy analysis of neuraminidase-ligand interactions. Protein Science. 13, 946.

Bouillot, B., S. Teychene, and B. Biscans. 2011. An evaluation of thermodynamic models for the prediction of drug and drug-like molecule solubility in organic solvents. Fluid Phase Equilibria. 309, 36.

Bowman, G. R., V. A. Voelz, and V. S. Pande. 2011. Taming the complexity of protein folding. Current Opinion in Structural Biology. 21, 4.

Branco, R. J. F., M. Graber, V. Denis, and J. Pleiss. 2009. Molecular mechanism of the hydration of Candida antarctica lipase B in the gas phase: Water adsorption isotherms and molecular dynamics simulations. ChemBioChem. 10, 2913.

Brelvi, S. W., and J. P. O'Connell. 1972. Corresponding states correlations for liquid compressibility and partial molal volumes of gases at infinite dilution in liquids. American Institute of Chemical Engineers Journal. 18, 1239.

Brelvi, S. W., and J. P. O'Connell. 1975a. Generalized isothermal equation of state for dense liquids. American Institute of Chemical Engineers Journal. 21, 171.

Brelvi, S. W., and J. P. O'Connell. 1975b. Generalized prediction of isothermal compressibilities and an isothermal equation of state for liquid-mixtures. American Institute of Chemical Engineers Journal. 21, 1024.

Brelvi, S. W., and J. P. O'Connell. 1975c. Prediction of unsymmetric convention liquid-phase activity-coefficients of hydrogen and methane. American Institute of Chemical Engineers Journal. 21, 157.

Brennecke, J. F. 1993. Spectroscopic investigation of reactions in supercritical fluids. A review. In Supercritical Fluid Engineering Science. Fundamentals and Applications, Edited by E. Kiran and J. F. Brennecke. Washington, DC: American Chemical Society.

Brennecke, J. F., P. G. Debenedetti, C. A. Eckert, and K. P. Johnston. 1990. Letter to the editor. American Institute of Chemical Engineers Journal. 36, 1927.

Brennecke, J. F., and C. A. Eckert. 1989. Phase-equilibria for supercritical fluid process design. American Institute of Chemical Engineers Journal. 35, 1409.

Brinkman, H. C., and J. J. Hermans. 1949. The effect of non-homogeneity of molecular weight on the scattering of light by high polymer solutions. Journal of Chemical Physics. 17, 574.

Broccio, M., D. Costa, Y. Liu, and S. H. Chen. 2006. The structural properties of a two-Yukawa fluid: Simulation and analytical results. Journal of Chemical Physics. 124, 084501.

Brooks, C. L., M. Karplus, and B. M. Pettitt. 1988. Proteins: A Theoretical Perspective of Dynamics, Structure and Thermodynamics. Volume 71, Advances in Chemical Physics: Wiley.

Brunner, G. 1983. Selectivity of supercritical compounds and entrainers with respect to model substances. Fluid Phase Equilibria. 10, 289. 
Brunner, G. 2005. Supercritical fluids: Technology and application to food processing. Journal of Food Engineering. 67, 21.

Brunner, G., Ed. 2004. Supercritical Fluids as Solvents and Reaction Media. Amsterdam: Elsevier B.V.

Bruno, T. J., and J. F. Ely. 1991. Supercritical Fluid Technology Reviews in Modern Theory Application. Boca Raton: CRC Press.

Bryngelson, J. D., J. N. Onuchic, N. D. Socci, and P. G. Wolynes. 1995. Funnels, pathways, and the energy landscape of protein folding: A synthesis. Proteins: Structure, Function, and Bioinformatics. 21, 167.

Buff, F. P., and R. Brout. 1955. Molecular formulation of thermodynamic functions encountered in solution theory. Journal of Chemical Physics. 23, 458.

Buff, F. P., and F. M. Schindler. 1958. Small perturbations in solution theory. Journal of Chemical Physics. 29, 1075.

Bustamante, C., and P. Bustamante. 1996. Nonlinear enthalpy-entropy compensation for the solubility of phenacetin in dioxane-water solvent mixtures. Journal of Pharmaceutical Sciences. 85, 1109.

Bustamante, P., B. Escalera, A. Martin, and E. Selles. 1993. A modification of the extended Hildebrand approach to predict the solubility of structurally related drugs in solvent mixtures. Journal of Pharmacy and Pharmacology. 45, 253.

Cabezas, H., and J. P. O'Connell. 1986. A fluctuation theory model of strong electrolytes. Fluid Phase Equilibria. 30, 213.

Cabezas, H., and J. P. O'Connell. 1993. Some uses and misuses of thermodynamic models for dilute liquid solutions. Industrial and Engineering Chemistry Research. 32, 2892.

Cagin, T., and B. M. Pettitt. 1991. Molecular-dynamics with a variable number of molecules. Molecular Physics. 72, 169.

Callen, H. B. 1962. Thermodynamics: An Introduction to the Physical Theories of Equilibrium Thermostatics and Irreversible Thermodynamics. New York: Wiley.

Campanella, E. A., P. M. Mathias, and J. P. O'Connell. 1987. Equilibrium properties of liquids containing supercritical substances. American Institute of Chemical Engineers Journal. 33, 2057.

Canchi, D. R., and A. E. Garcia. 2011. Backbone and side-chain contributions in protein denaturation by urea. Biophysical Journal. 100, 1526.

Carter, R. W. 1992. Ph.D. Thesis, University of Delaware.

Casassa, E. F., and H. Eisenberg. 1964. Thermodynamic analysis of multicomponent solutions. Advances in Protein Chemistry. 19, 287.

Case, F. H., J. Brennan, A. Chaka, K. D. Dobbs, D. G. Friend, D. Frurip, P. A. Gordon, J. Moore, R. D. Mountain, J. Olson, R. B. Ross, M. Schiller, and V. K. Shen. 2007. The third industrial fluid properties simulation challenge. Fluid Phase Equilibria. 260, 153.

Celinski, S. A., and J. M. Scholtz. 2002. Osmolyte effects on helix formation in peptides and the stability of coiled-coils. Protein Science. 11, 2048.

Ceperley, D. M., and G. V. Chester. 1977. Perturbation approach to classical one-component plasma. Physical Review A. 15, 756.

Chaikin, P. M., and T. C. Lubensky. 2000. Principles of Condensed Matter Physics. Cambridge, UK: Cambridge University Press.

Chalikian, T. V. 2003. Volumetric properties of proteins. Annual Review of Biophysics and Biomolecular Structure. 32, 207. 
Chalikian, T. V. 2011. Volumetric measurements in binary solvents: Theory to experiment. Biophysical Chemistry. 156, 3.

Chalikian, T. V., and R. Filfil. 2003. How large are the volume changes accompanying protein transitions and binding? Biophysical Chemistry. 104, 489.

Chandler, D. 2005. Interfaces and the driving force of hydrophobic assembly. Nature. 437, 640.

Chapman, D. L. 1913. Li. A contribution to the theory of electrocapillarity. Philisophical Magazine Series 6. 25, 475.

Cheatham, T. E., and B. R. Brooks. 1998. Recent advances in molecular dynamics simulation towards the realistic representation of biomolecules in solution. Theoretical Chemistry Accounts. 99, 279.

Chialvo, A. A. 1990a. An alternative approach to modeling excess Gibbs free energy in terms of Kirkwood-Buff integrals. In Fluctuation Theory of Mixtures, Edited by E. Matteoli and G. A. Mansoori. New York: Taylor and Francis.

Chialvo, A. A. 1990b. Determination of excess Gibbs free-energy from computer-simulation via the single charging-integral approach. I. Theory. Journal of Chemical Physics. 92, 673.

Chialvo, A. A. 1991. Excess properties of liquid-mixtures from computer-simulation - A coupling-parameter approach to the determination of their dependence on molecular asymmetry. Molecular Physics. 73, 127.

Chialvo, A. A. 1993a. Accurate calculation of excess thermal, infinite dilution, and related properties of liquid mixtures via molecular-based simulation. Fluid Phase Equilibria. 83, 23.

Chialvo, A. A. 1993b. Solute-solute and solute-solvent correlations in dilute near-critical ternary mixtures: Mixed-solute and entrainer effects. Journal of Physical Chemistry. 97, 2740.

Chialvo, A. A., S. Chialvo, J. M. Simonson, and Y. V. Kalyuzhnyi. 2008. Solvation phenomena in dilute multicomponent solutions. I. Formal results and molecular outlook. Journal of Chemical Physics. 128, 214512.

Chialvo, A. A., and P. T. Cummings. 1994. Solute-induced effects on the structure and the thermodynamics of infinitely dilute mixtures. American Institute of Chemical Engineers Journal. 40, 1558.

Chialvo, A. A., and P. T. Cummings. 1995. Comment on "Near critical phase behavior of dilute mixtures". Molecular Physics. 84, 41.

Chialvo, A. A., and P. T. Cummings. 1999. Molecular-based modeling of water and aqueous solutions at supercritical conditions. In Advances in Chemical Physics, Edited by S. A. Rice. New York: Wiley and Sons.

Chialvo, A. A., P. T. Cummings, and Y. V. Kalyuzhnyi. 1998. Solvation effect on kinetic rate constant of reactions in supercritical solvents. American Institute of Chemical Engineers Journal. 44, 667.

Chialvo, A. A., P. T. Cummings, J. M. Simonson, and R. E. Mesmer. 1999. Solvation in hightemperature electrolyte solutions. II. Some formal results. Journal of Chemical Physics. $110,1075$.

Chialvo, A. A., P. T. Cummings, J. M. Simonson, and R. E. Mesmer. 2000a. Solvation in hightemperature aqueous electrolyte solutions. Journal of Molecular Liquids. 87, 233.

Chialvo, A. A., and P. G. Debenedetti. 1992. Molecular dynamics study of solute-solute microstructure in attractive and repulsive supercritical mixtures. Industrial and Engineering Chemistry Research. 31, 1391.

Chialvo, A. A., Y. V. Kalyuzhnyi, and P. T. Cummings. 1996. Solvation thermodynamics of gas 
solubility at sub- and near-critical conditions. American Institute of Chemical Engineers Journal. 42, 571.

Chialvo, A. A., P. G. Kusalik, P. T. Cummings, and J. M. Simonson. 2001. Solvation in hightemperature electrolyte solutions. III. Integral equation calculations and interpretation of experimental data. Journal of Chemical Physics. 114, 3575.

Chialvo, A. A., P. G. Kusalik, P. T. Cummings, J. M. Simonson, and R. E. Mesmer. 2000b. Molecular approach to high-temperature solvation. Formal, integral equations, and experimental results. Journal of Physics-Condensed Matter. 12, 3585.

Chialvo, A. A., P. G. Kusalik, Y. V. Kalyuzhnyi, and P. T. Cummings. 2000c. Applications of integral equations calculations to high-temperature solvation phenomena. Journal of Statistical Physics. 100, 167.

Chiti, F., and C. M. Dobson. 2006. Protein misfolding, functional amyloid, and human disease. Annual Review of Biochemistry. 75, 333.

Chitra, R., and P. E. Smith. 2000. Molecular dynamics simulations of the properties of cosolvent solutions. Journal of Physical Chemistry B. 104, 5854.

Chitra, R., and P. E. Smith. 2001a. A comparison of the properties of 2,2,2-trifluoroethanol and 2,2,2-trifluoroethanol/water mixtures using different force fields. Journal of Chemical Physics. 115, 5521.

Chitra, R., and P. E. Smith. 2001b. Preferential interactions of cosolvents with hydrophobic solutes. Journal of Physical Chemistry B. 105, 11513.

Chitra, R., and P. E. Smith. 2001c. Properties of 2,2,2-trifluoroethanol and water mixtures. Journal of Chemical Physics. 114, 426.

Chitra, R., and P. E. Smith. 2002. Molecular association in solution: A Kirkwood-Buff analysis of sodium chloride, ammonium sulfate, guanidinium chloride, urea, and 2,2,2trifluoroethanol in water. Journal of Physical Chemistry B. 106, 1491.

Cho, S. S., Y. Levy, and P. G. Wolynes. 2009. Quantitative criteria for native energetic heterogeneity influences in the prediction of protein folding kinetics. 106, 434.

Choudhury, N. 2006. A molecular dynamics simulation study of buckyballs in water: Atomistic versus coarse-grained models of $\mathrm{C}_{60}$. Journal of Chemical Physics. 125, 034502.

Choudhury, N., and B. M. Pettitt. 2005a. Local density profiles are coupled to solute size and attractive potential for nanoscopic hydrophobic solutes. Molecular Simulation. 31, 457.

Choudhury, N., and B. M. Pettitt. 2005b. On the mechanism of hydrophobic association of nanoscopic solutes. Journal of the American Chemical Society. 127, 3556.

Choudhury, N., and B. M. Pettitt. 2006a. Enthalpy-entropy contributions to the potential of mean force of nanoscopic hydrophobic solutes. Journal of Physical Chemistry B. 110, 8459.

Choudhury, N., and B. M. Pettitt. 2006b. The role of attractive forces on the dewetting of large hydrophobic solutes. In Modelling Molecular Structure and Reactivity in Biological Systems, Edited by K. J. Naidoo. Cambridge, UK: Royal Society of Chemistry.

Choudhury, N., and B. M. Pettitt. 2007. The dewetting transition and the hydrophobic effect. Journal of the American Chemical Society. 129, 4847.

Christensen, S., G. H. Peters, F. Y. Hansen, and J. Abildskov. 2007a. Thermodynamic models from fluctuation solution theory analysis of molecular simulations. Fluid Phase Equilibria. 261, 185.

Christensen, S., G. H. Peters, F. Y. Hansen, J. P. O’Connell, and J. Abildskov. 2007b. Generation of thermodynamic data for organic liquid mixtures from molecular simulations. Molecular Simulation. 33, 449. 
Christensen, S., G. H. Peters, F. Y. Hansen, J. P. O'Connell, and J. Abildskov. 2007c. State conditions transferability of vapor-liquid equilibria via fluctuation solution theory with correlation function integrals from molecular dynamics simulation. Fluid Phase Equilibria. 260, 169.

Ciach, A., and W. T. Gozdz. 2001. Nonelectrolyte solutions exhibiting structure on the nanoscale. Annual Reports on the Progress of Chemistry, Section "C" (Physical Chemistry). 97, 269.

Clifford, A. A. 1999. Fundamentals of Supercritical Fluids. New York: Oxford University Press.

Clifford, A. A., K. Pople, W. J. Gaskill, K. D. Bartle, and C. M. Rayner. 1998. Potential tuning and reaction control in the Diels-Alder reaction between cyclopentadiene and methyl acrylate in supercritical carbon dioxide. Journal of the Chemical Society, Faraday Transactions. 94, 1451.

Cochran, H. D., L. L. Lee, and D. M. Pfund. 1990. Structure and properties of supercritical fluid mixtures from Kirkwood-Buff fluctuation theory and integral equation methods. In Fluctuation Theory of Mixtures, Edited by E. Matteoli and G. A. Mansoori. New York: Taylor and Francis.

Cohn, E. J., and J. T. Edsall. 1943. Proteins, amino acids and peptides as ions and dipolar ions. New York: Reinhold Publishing Corporation.

Conti, G., P. Gianni, L. Lepori, and E. Matteoli. 2003. Volumetric study of (2-methoxyethanol + tetrahydrofuran + cyclohexane) at 298.15 K. Journal of Chemical Thermodynamics. 35, 503.

Cooney, W. R., and J. P. O'Connell. 1987. Correlation of partial molar volumes at infinite dilution of salts in water. Chemical Engineering Communications. 56, 341.

Cornell, W. D., P. Cieplak, C. I. Bayly, I. R. Gould, K. M. Merz, D. M. Ferguson, D. C. Spellmeyer, T. Fox, J. W. Caldwell, and P. A. Kollman. 1995. A 2nd generation forcefield for the simulation of proteins, nucleic-acids, and organic-molecules. Journal of the American Chemical Society. 117, 5179.

Courtenay, E. S., M. W. Capp, C. F. Anderson, and M. T. Record. 2000. Vapor pressure osmometry studies of osmolyte-protein interactions: Implications for the action of osmoprotectants in vivo and for the interpretation of "osmotic stress" experiments in vitro. Biochemistry. 39, 4455.

Courtenay, E. S., M. W. Capp, and M. T. Record. 2001. Thermodynamics of interactions of urea and guanidinium salts with protein surface: Relationship between solute effects on protein processes and changes in water-accessible surface area. Protein Science. 10, 2485.

Coussaert, T., and M. Baus. 1997. Virial approach to hard-sphere demixing. Physical Review Letters. 79, 1881.

Curtiss, C. F., and R. B. Bird. 1999. Multicomponent diffusion. Industrial and Engineering Chemistry Research. 38, 2515.

D'Arrigo, G., R. Giordano, and J. Teixeira. 2009. Temperature and concentration dependence of SANS spectra of aqueous solutions of short-chain amphiphiles. European Physical Journal E. 29, 37.

Dai, S., S. Weerasinghe, and P. E. Smith. 2012. A Kirkwood-Buff derived force field for amines and carboxylic acids. In preparation.

Davidson, N. R. 1962. Statistical Mechanics. New York: McGraw-Hill.

Davis-Searles, P. R., A. J. Saunders, D. A. Erie, D. J. Winzor, and G. J. Pielak. 2001. 
Interpreting the effects of small uncharged solutes on protein-folding equilibria. Annual Review of Biophysics and Biomolecular Structure. 30, 271.

Davis, M. I. 1993. Thermodynamic and related studies of amphiphile plus water-systems. Chemical Society Reviews. 22, 127.

Day, R., D. Paschek, and A. E. Garcia. 2010. Microsecond simulations of the folding/unfolding thermodynamics of the Trp-cage miniprotein. Proteins: Structure, Function, and Bioinformatics. 78, 1889.

de Boer, J. 1940. Contribution to the theory of compressed gases. Ph.D. Thesis, University of Amsterdam, Amsterdam.

de Boer, J. 1949. Molecular distribution and equation of state of gases. Reports on Progress in Physics. 12, 305.

de Gennes, P. G. 1977. Microscopic Structure and Dynamics of Liquids. New York: Plenum Press.

Debenedetti, P. G. 1988. Fluctuation-based computer calculation of partial molar properties. 2. A numerically accurate method for the determination of partial molar energies and enthalpies. Journal of Chemical Physics. 88, 2681.

Debenedetti, P. G., and A. A. Chialvo. 1992. Solute-solute correlations in infinitely dilute supercritical mixtures. Journal of Chemical Physics. 97, 504.

Debenedetti, P. G., and S. K. Kumar. 1986. Infinite dilution fugacity coefficients and the general behavior of dilute binary systems. American Institute of Chemical Engineers Journal. 32, 1253.

Debenedetti, P. G., and S. K. Kumar. 1988. The molecular basis of temperature effects in supercritical extraction. American Institute of Chemical Engineers Journal. 34, 645.

Debenedetti, P. G., and R. S. Mohamed. 1989. Attractive, weakly attractive and repulsive nearcritical systems. Journal of Chemical Physics. 90, 4528.

Derr, E. L., and C. H. Deal, Jr. 1969. Analytical solutions of groups. Correlation of activity coefficients through structural group parameters. Paper read at Proceedings of the International Symposium on Distillation.

Dickhut, R. M., A. W. Andren, and D. E. Armstrong. 1989. Naphthalene solubility in selected organic solvent-water mixtures. Journal of Chemical and Engineering Data. 34, 438.

Diedrichs, A., and J. Gmehling. 2011. Solubility calculation of active pharmaceutical ingredients in alkanes, alcohols, water and their mixtures using various activity coefficient models. Industrial and Engineering Chemistry Research. 50, 1757.

Dill, K. A. 1990. Dominant forces in protein folding. Biochemistry. 29, 7133.

Dill, K. A., K. Ghosh, and J. D. Schmit. 2011. Physical limits of cells and proteomes. Proceedings of the National Academy of Sciences of the United States of America. 108, 17876.

Dixit, S., J. Crain, W. C. K. Poon, J. L. Finney, and A. K. Soper. 2002. Molecular segregation observed in a concentrated alcohol-water solution. Nature. 416, 829.

Dixon, M., and P. Hutchinson. 1977. Method for extrapolation of pair distribution functions. Molecular Physics. 33, 1663.

Dougan, L., S. P. Bates, R. Hargreaves, J. P. Fox, J. Crain, J. L. Finney, V. Reat, and A. K. Soper. 2004. Methanol-water solutions: A bi-percolating liquid mixture. Journal of Chemical Physics. 121, 6456.

Dyson, H. J., and P. E. Wright. 2002. Coupling of folding and binding for unstructured proteins. Current Opinion in Structural Biology. 12, 54. 
Dyson, H. J., and P. E. Wright. 2005. Intrinsically unstructured proteins and their functions. Nature Reviews Molecular Cell Biology. 6, 197.

Economou, I. G. 2002. Statistical Associating Fluid Theory: A successful model for the calculation of thermodynamic and phase equilibrium properties of complex fluid mixtures. Industrial and Engineering Chemistry Research. 41, 953.

Economou, I. G., and M. D. Donohue. 1990. Mean field calculation of thermodynamic properties of supercritical fluids. American Institute of Chemical Engineers Journal. 36, 1920.

Einstein, A. 1910. Theorie der opaleszenz von homogenen flüssigkeiten und flüssigkeitsgemischen in der nähe des kritischen zustandes. Annalen der Physik. 33, 1275 .

Eisenberg, H. 1976. Biological Macromolecules and Polyelectrolytes in Solution. Oxford: Clarendon Press.

Ellegaard, M. D. 2011. Molecular thermodynamics using fluctuation solution theory. Ph.D. Thesis, Department of Chemical and Biochemical Engineering, Technical University of Denmark.

Ellegaard, M. D., J. Abildskov, and J. P. O'Connell. 2010. Molecular thermodynamic modeling of mixed solvent solubility. Industrial and Engineering Chemistry Research. 49, 11620.

Ellegaard, M. D., J. Abildskov, and J. P. O'Connell. 2011. Solubilities of gases in ionic liquids using a corresponding-states approach to Kirkwood-Buff solution theory. Fluid Phase Equilibria. 302, 93.

Ellegaard, M. E., J. Abildskov, and J. P. O'Connell. 2009. Method for predicting solubilities of solids in mixed solvents. American Institute of Chemical Engineers Journal. 55, 1256.

Ellington, J. B., K. M. Park, and J. F. Brennecke. 1994. Effect of local composition enhancements on the esterification of phtalic-anhydride with methanol in supercritical carbon-dioxide. Industrial and Engineering Chemistry Research. 33, 965.

Enciso, E. 1985. Numerical-solution of the SSOZ equation by extension of Gillan method to nonhomonuclear molecular fluids. Molecular Physics. 56, 129.

Felitsky, D. J., and M. T. Record. 2004. Application of the local-bulk partitioning and competitive binding models to interpret preferential interactions of glycine betaine and urea with protein surface. Biochemistry. 43, 9276.

Feng, J. W. A., J. Kao, and G. R. Marshall. 2009. A second look at mini-protein stability: Analysis of FSD-1 using circular dichroism, differential scanning calorimetry, and simulations. Biophysical Journal. 97, 2803.

Ferrario, M., M. Haughney, I. R. McDonald, and M. L. Klein. 1990. Molecular-dynamics simulation of aqueous mixtures - Methanol, acetone, and ammonia. Journal of Chemical Physics. 93, 5156.

Fisher, M. E. 1964. Correlation functions + critical region of simple fluids. Journal of Mathematical Physics. 5, 944.

Foffi, G., C. de Michele, F. Sciortino, and P. Tartaglia. 2005. Arrested phase separation in a short-ranged attractive colloidal system: A numerical study. Journal of Chemical Physics. $122,224903$.

Foiles, S. M., N. W. Ashcroft, and L. Reatto. 1984. Structure factor and direct correlationfunction of a fluid from finite-range simulation data. Journal of Chemical Physics. 81, 6140.

Forsythe, E. L., R. A. Judge, and M. L. Pusey. 1999. Tetragonal chicken egg white lysozyme solubility in sodium chloride solutions. Journal of Chemical and Engineering Data. 44, 
637.

Fowler, R. H., and E. A. Guggenheim. 1939. Statistical Thermodynamics: A Version of Statistical Mechanics for Students of Physics and Chemistry. Cambridge, England: The University Press.

Frank, H. S., and F. Franks. 1968. Structural approach to solvent power of water for hydrocarbons - Urea as a structure breaker. Journal of Chemical Physics. 48, 4746.

Franks, F., and D. J. G. Ives. 1966. The structural properties of alcohol-water mixtures. Quarterly Reviews, Chemical Society. 20, 1.

Freddolino, P. L., C. B. Harrison, Y. X. Liu, and K. Schulten. 2010. Challenges in proteinfolding simulations. Nature Physics. 6, 751.

Fredenslund, A., J. Gmehling, and P. Rasmussen. 1977. Vapor-Liquid Equilibria Using UNIFAC: A Group-Contribution Method. Amsterdam: Elsevier.

Fredenslund, A., R. L. Jones, and J. M. Prausnitz. 1975. Group-contribution estimation of activity-coefficients in nonideal liquid-mixtures. American Institute of Chemical Engineers Journal. 21, 1086.

French, H. T. 1987. Vapour pressures and activity coefficients of (acetonitrile + water) at 308.15 K. Journal of Chemical Thermodynamics. 19, 1155.

Friedman, H. L. 1962. Ionic Solution Theory: Based on Cluster Expansion Methods, Monographs in Statistical Physics and Thermodynamics. New York: Interscience Publishers.

Friedman, H. L. 1986. Methods to determine structure in water and aqueous solutions. In Methods in Enzymology, Edited by P. Lester: Academic Press.

Friedman, H. L., and P. S. Ramanathan. 1970. Theory of mixed electrolyte solutions and application to a model for aqueous lithium chloride-cesium chloride. Journal of Physical Chemistry. 74, 3756.

Fries, P. H., and G. N. Patey. 1985. The solution of the hypernetted-chain approximation for fluids of nonspherical particles - A general-method with application to dipolar hardspheres. Journal of Chemical Physics. 82, 429.

Frisch, H. L., and J. L. Lebowitz. 1964. The Equilibrium Theory of Classical Fluids: A Lecture Note and Reprint Volume. Edited by H. L. Frisch and J. L. Lebowitz. New York: W. A. Benjamin.

Galam, S., and J. P. Hansen. 1976. Statistical-mechanics of dense ionized matter. 6. Electron screening corrections to thermodynamic properties of one-component plasma. Physical Review A. 14, 816.

García, B., S. Aparicio, R. Alcalde, and J. M. Leal. 2003. Preferential solvation in ternary solutions containing methylbenzoate. A Kirkwood-Buff fluctuation theory study. Journal of Physical Chemistry B. 107, 13478.

Gardas, R. L., M. G. Freire, P. J. Carvalho, I. M. Marrucho, I. M. A. Fonseca, A. G. M. Ferreira, and J. A. P. Coutinho. 2007. P $\rho$ T measurements of imidazolium-based ionic liquids. Journal of Chemical and Engineering Data. 52, 1881.

Gee, M. B. 2010. Computer simulation and theory of amino acid interactions in solution, Chemistry, Kansas State University, Manhattan, Kansas.

Gee, M. B., N. R. Cox, Y. Jiao, N. Bentenitis, S. Weerasinghe, and P. E. Smith. 2011. A Kirkwood-Buff derived force field for aqueous alkali halides. Journal of Chemical Theory and Computation. 7, 1369.

Gee, M. B., and P. E. Smith. 2009. Kirkwood-Buff theory of molecular and protein association, 
aggregation, and cellular crowding. Journal of Chemical Physics. 131, 165101.

Gee, M. B., and P. E. Smith. 2012. A Kirkwood-Buff derived force field for amine salts and carboxylates. In preparation.

Gekko, K., and S. N. Timasheff. 1981. Thermodynamic and kinetic examination of protein stabilization by glycerol. Biochemistry. 20, 4677.

Gianni, P., L. Lepori, and E. Matteoli. 2010. Excess Gibbs energies and volumes of the ternary system chloroform + tetrahydrofuran + cyclohexane at 298.15 K. Fluid Phase Equilibria. 297, 52.

Gibbs, J. W. 1902. Elementary Principles in Statistical Mechanics: Developed with Special Reference to the Rational Foundation of Thermodynamics. New York: Charles Scribner's Sons.

Gibbs, J. W. 1948. Elementary principles in statistical mechanics. In The Collected Works of J. Willard Gibbs. New Haven: Yale University Press.

Gillan, M. J. 1979. New method of solving the liquid structure integral-equations. Molecular Physics. 38, 1781.

Girardeau, M. D., and R. M. Mazo. 1973. Variational methods in statistical mechanics. In Advances in Chemical Physics, Edited by I. Prigogine and S. Rice: John Wiley and Sons, Inc.

Gmehling, J. 1995. From UNIFAC to modified UNIFAC to PSRK with the help of DDB. Fluid Phase Equilibria. 107, 1.

Gouy, M. 1910. Sur la constitution de la charge électrique à la surface d'un électrolyte. Journal de Physique Théorique et Appliquée. 9, 457.

Gray, C. G., and K. E. Gubbins. 1984. Theory of Molecular Fluids. Volume 1: Fundamentals. New York: Oxford University Press.

Greene, R. F., and C. N. Pace. 1974. Urea and guanidine-hydrochloride denaturation of ribonuclease, lysozyme, $\alpha$-chymotrypsin, and $\beta$-lactoglobulin. Journal of Biological Chemistry. 249, 5388.

Gross, J., and G. Sadowski. 2001. Perturbed-chain SAFT: An equation of state based on a perturbation theory for chain molecules. Industrial and Engineering Chemistry Research. 40, 1244.

Gross, J., and J. Vrabec. 2006. An equation-of-state contribution for polar components: Dipolar molecules. American Institute of Chemical Engineers Journal. 52, 1194.

Gruszkiewicz, M. S., and R. H. Wood. 1997. Conductance of dilute $\mathrm{LiCl}, \mathrm{NaCl}, \mathrm{NaBr}$, and $\mathrm{CsBr}$ solutions in supercritical water using a flow conductance cell. Journal of Physical Chemistry B. 101, 6549.

Gubbins, K. E., and J. P. O'Connell. 1974. Isothermal compressibility and partial molal volume for polyatomic liquids. Journal of Chemical Physics. 60, 3449.

Guo, B., S. Kao, H. McDonald, A. Asanov, L. L. Combs, and W. W. Wilson. 1999. Correlation of second virial coefficients and solubilities useful in protein crystal growth. Journal of Crystal Growth. 196, 424.

Guo, J. H., Y. Luo, A. Augustsson, S. Kashtanov, J. E. Rubensson, D. K. Shuh, H. Agren, and J. Nordgren. 2003. Molecular structure of alcohol-water mixtures. Physical Review Letters. $91,157401$.

Hall, D. G. 1971. Kirkwood-Buff theory of solutions - Alternative derivation of part of it and some applications. Transactions of the Faraday Society. 67, 2516.

Hall, D. G. 1983. Thermodynamics of micellar solutions. In Aggregation Processes in Solution, 
Edited by J. Gormally and E. Wyn-Jones. Amsterdam: Elsevier Scientific Publishing Co. Hamer, W. J., and Y.-C. Wu. 1972. Osmotic coefficients and mean activity coefficients of uniunivalent electrolytes in water at 25 degrees. Journal of Physical Chemistry Reference Data. 1, 1047.

Handa, Y. P., and G. C. Benson. 1979. Volume changes on mixing 2 liquids - Review of the experimental-techniques and the literature data. Fluid Phase Equilibria. 3, 185.

Hansen, J. P., and I. R. McDonald. 1986. Theory of Simple Liquids. 2nd. Ed. New York: Academic Press.

Hansen, J. P., and I. R. McDonald. 2006. Theory of Simple Liquids. 3rd. Ed. Amsterdam: Academic Press.

Henderson, D. 1974. Theory of simple mixtures. Annual Review of Physical Chemistry. 25, 461.

Henry, W. 1803. Experiments on the quantity of gases absorbed by water, at different temperatures, and under different pressures. Philosophical Transactions of the Royal Society of London. 93, 29.

Herczenik, E., and M. F. B. G. Gebbink. 2008. Molecular and cellular aspects of protein misfolding diseases. The FASEB Journal. 22, 2115.

Hess, B., C. Kutzner, D. van der Spoel, and E. Lindahl. 2008. GROMACS 4: Algorithms for highly efficient, load-balanced, and scalable molecular simulation. Journal of Chemical Theory and Computation. 4, 435.

Hess, B., and N. F. A. van der Vegt. 2009. Cation specific binding with protein surface charges. Proceedings of the National Academy of Sciences of the United States of America. 106, 13296.

Hildebrand, J. H. 1924. Solubility. New York: Chemical Catalog Company.

Hill, T. L. 1956. Statistical Mechanics: Principles and Selected Applications. New York: McGraw-Hill.

Hill, T. L. 1957. Theory of solutions. I. Journal of the American Chemical Society. 79, 4885.

Hill, T. L. 1959. Theory of solutions. II. Osmotic pressure virial expansion and light scattering in two component solutions. Journal of Chemical Physics. 30, 93.

Hnědkovský, L., V. Majer, and R. H. Wood. 1995. Volumes and heat-capacities of $\mathrm{H}_{3} \mathrm{BO}_{3}(a q)$ at temperatures from $298.15 \mathrm{~K}$ to $705 \mathrm{~K}$ and at pressures to $35 \mathrm{MPa}$. Journal of Chemical Thermodynamics. 27, 801.

Hnědkovský, L., R. H. Wood, and V. Majer. 1996. Volumes of aqueous solutions of $\mathrm{CH}_{4}, \mathrm{CO}_{2}$, $\mathrm{H}_{2} \mathrm{~S}$, and $\mathrm{NH}_{3}$ at temperatures from $298.15 \mathrm{~K}$ to $705 \mathrm{~K}$ and pressures to $35 \mathrm{MPa}$. Journal of Chemical Thermodynamics. 28, 125.

Horinek, D., and R. R. Netz. 2011. Can simulations quantitatively predict peptide transfer free energies to urea solutions? Thermodynamic concepts and force field limitations. Journal of Physical Chemistry A. 115, 6125.

Hornak, V., R. Abel, A. Okur, B. Strockbine, A. Roitberg, and C. Simmerling. 2006. Comparison of multiple Amber force fields and development of improved protein backbone parameters. Proteins: Structure, Function, and Bioinformatics. 65, 712.

Horta, B. A. C., P. F. J. Fuchs, W. F. van Gunsteren, and P. H. Hünenberger. 2011. New interaction parameters for oxygen compounds in the GROMOS force field: Improved pure-liquid and solvation properties for alcohols, ethers, aldehydes, ketones, carboxylic acids, and esters. Journal of Chemical Theory and Computation. 7, 1016.

Hu, C. Y., H. Kokubo, G. C. Lynch, D. W. Bolen, and B. M. Pettitt. 2010a. Backbone additivity in the transfer model of protein solvation. Protein Science. 19, 1011. 
Hu, C. Y., G. C. Lynch, H. Kokubo, and B. M. Pettitt. 2010b. Trimethylamine N-oxide influence on the backbone of proteins: An oligoglycine model. Proteins: Structure, Function, and Bioinformatics. 78, 695.

Hu, C. Y., B. M. Pettitt, and J. Rösgen. 2009. Osmolyte solutions and protein folding. F1000 Biology Reports. 1, 1.

Hu, Y. 1997. Fluctuation solution theory for strong electrolyte solutions. Ph.D. Thesis, University of Virginia.

Hua, L., R. Zhou, D. Thirumalai, and B. J. Berne. 2008. Urea denaturation by stronger dispersion interactions with proteins than water implies a 2-stage unfolding. Proceedings of the National Academy of Sciences of the United States of America. 105, 16928.

Huang, Y. H., and J. P. O'Connell. 1987. Corresponding states correlation for the volumetric properties of compressed liquids and liquid-mixtures. Fluid Phase Equilibria. 37, 75.

Hutchenson, K. W., A. M. Scurto, and B. Subramaniam, Eds. 2009. Gas-Expanded Liquids and Near-Critical Media: Green Chemistry and Engineering. Volume 1006, ACS symposium series.

Hynes, J. T. 1985. The theory of reactions in solution. In Theory of Chemical Reaction Dynamics, Edited by M. Baer. Boca Raton: CRC Press.

Jacquemin, J., P. Husson, V. Mayer, and I. Cibulka. 2007. High-pressure volumetric properties of imidazolium-based ionic liquids: Effect of the anion. Journal of Chemical and Engineering Data. 52, 2204.

Jagla, E. A. 1999. Core-softened potentials and the anomalous properties of water. Journal of Chemical Physics. 111, 8980.

Jakob, A., H. Grensemann, J. Lohmann, and J. Gmehling. 2006. Further development of modified UNIFAC (Dortmund): Revision and extension 5. Industrial and Engineering Chemistry Research. 45, 7924.

Janz, G. J., B. G. Oliver, G. R. Lakshmin, and G. E. Mayer. 1970. Electrical conductance, diffusion, viscosity, and density of sodium nitrate, sodium perchlorate, and sodium thiocyanate in concentrated aqueous solutions. Journal of Physical Chemistry. 74, 1285.

Jha, A. K., A. Colubri, M. H. Zaman, S. Koide, T. R. Sosnick, and K. F. Freed. 2005. Helix, sheet, and polyproline II frequencies and strong nearest neighbor effects in a restricted coil library. Biochemistry. 44, 9691.

Jiang, W., M. Hodoscek, and B. Roux. 2009. Computation of absolute hydration and binding free energy with free energy perturbation distributed replica-exchange molecular dynamics (FEP/REMD). Journal of Chemical Theory and Computation. 5, 2583.

Jiao, Y., F. Chen, S. Weerasinghe, and P. E. Smith. 2012. A Kirkwood-Buff derived force field for alchohols in water. In preparation.

Jiao, Y., and P. E. Smith. 2011. Fluctuation theory of molecular association and conformational equilibria. Journal of Chemical Physics. 135, 014502.

Jolly, D. L., and R. J. Bearman. 1980. Molecular-dynamics simulation of the mutual and selfdiffusion coefficients in Lennard-Jones liquid-mixtures. Molecular Physics. 41, 137.

Jolly, D. L., B. C. Freasier, and R. J. Bearman. 1976. Extension of simulation radial-distribution functions to an arbitrary range by Baxter's factorization technique. Chemical Physics. 15, 237.

Jonah, D. A. 1983. Investigation of binary-liquid mixtures via the study of infinitely dilutesolutions. Advances in Chemistry Series. 395.

Jonah, D. A. 1986. On a method of numerical differentiation and its application to the evaluation 
of limiting activity-coefficients and their 1st derivatives. Chemical Engineering Science. 41, 2261.

Jonah, D. A., and H. D. Cochran. 1994. Chemical-potentials in dilute, multicomponent solutions. Fluid Phase Equilibria. 92, 107.

Jorgensen, W. L., J. Chandrasekhar, J. D. Madura, R. W. Impey, and M. L. Klein. 1983. Comparison of simple potential functions for simulating liquid water. Journal of Chemical Physics. 79, 926.

Jorgensen, W. L., and J. Tirado-Rives. 2005. Potential energy functions for atomic-level simulations of water and organic and biomolecular systems. Proceedings of the National Academy of Sciences of the United States of America. 102, 6665.

Jorgensen, W. L., and J. Tirado-Rives. 1988. The OPLS potential functions for proteins - energy minimizations for crystals of cyclic-peptides and crambin. Journal of the American Chemical Society. 110, 1657.

Joung, I. S., and T. E. Cheatham, III. 2008. Determination of alkali and halide monovalent ion parameters for use in explicitly solvated biomolecular simulations. Journal of Physical Chemistry B. 112, 9020.

Joung, I. S., and T. E. Cheatham, III. 2009. Molecular dynamics simulations of the dynamic and energetic properties of alkali and halide ions using water-model-specific ion parameters. Journal of Physical Chemistry B. 113, 13279.

Jouyban-Gharamaleki, A., L. Valaee, M. Barzegar-Jalali, B. J. Clark, and W. E. Acree. 1999. Comparison of various cosolvency models for calculating solute solubility in watercosolvent mixtures. International Journal of Pharmaceutics. 177, 93.

Jouyban, A., S. Romero, H. K. Chan, B. J. Clark, and P. Bustamante. 2002. A cosolvency model to predict solubility of drugs at several temperatures from a limited number of solubility measurements. Chemical and Pharmaceutical Bulletin. 50, 594.

Juraszek, J., and P. G. Bolhuis. 2008. Rate constant and reaction coordinate of Trp-cage folding in explicit water. Biophysical Journal. 95, 4246.

Kaminski, G. A., R. A. Friesner, J. Tirado-Rives, and W. L. Jorgensen. 2001. Evaluation and reparametrization of the OPLS-AA force field for proteins via comparison with accurate quantum chemical calculations on peptides. Journal of Physical Chemistry B. 105, 6474.

Kan, A. T., and M. B. Tomson. 1996. UNIFAC prediction of aqueous and nonaqueous solubilities of chemicals with environmental interest. Environmental Science and Technology. 30, 1369.

Kang, M., and P. E. Smith. 2006. A Kirkwood-Buff derived force field for amides. Journal of Computational Chemistry. 27, 1477.

Kang, M., and P. E. Smith. 2007. Preferential interaction parameters in biological systems by Kirkwood-Buff theory and computer simulation. Fluid Phase Equilibria. 256, 14.

Kang, M., and P. E. Smith. 2008. Kirkwood-Buff theory of four and higher component mixtures. Journal of Chemical Physics. 128, 244511.

Karunaweera, S., M. B. Gee, S. Weerasinghe, and P. E. Smith. 2012. Theory and simulation of multicomponent osmotic systems. Journal of Chemical Theory and Computation. in press.

Kauzmann, W. 1959. Some factors in the interpretation of protein denaturation. In Advances in Protein Chemistry, Edited by C. B. Anfinsen, M. L. Anson, K. Bailey and J. T. Edsall. San Diego: Academic Press Inc.

Kežić, B., and A. Perera. 2011. Towards a more accurate reference interaction site model integral 
equation theory for molecular liquids. Journal of Chemical Physics. 135, 234104.

Kim, J. I. 1978. A critical study of the $\mathrm{Ph}_{4} \mathrm{AsPh}_{4} \mathrm{~B}$ assumption for single ion thermodynamics in amphiprotic and dipolar-aprotic solvents; evaluation of physical parameters relevant to theoretical consideration. Zeitschrift für Physikalische Chemie. 113, 129.

Kimura, Y., and Y. Yoshimura. 1992. Chemical-equilibrium in fluids from the gaseous to liquid states: Solvent density dependence of the dimerization equilibrium of 2-methyl-2nitrosopropane in carbon dioxide, chlorotrifluoromethane, and trifluoromethane. Journal of Chemical Physics. 96, 3085.

Kiran, E., P. G. Debenedetti, and C. J. Peters, Eds. 2000. Supercritical fluids. Fundamentals and applications. Volume E366, Nato asi. Dordrecht: Klüwer Academic Publishers.

Kiran, E., and J. M. H. Levelt Sengers. 1994. Supercritical fluids. Fundamentals for applications. Volume E273, Nato asi. Dordrecht: Klüwer Academic Publishers.

Kirkwood, J. G. 1934. Theory of solutions of molecules containing widely separated charges with special application to zwitterions. Journal of Chemical Physics. 2, 351.

Kirkwood, J. G. 1935. Statistical mechanics of fluid mixtures. Journal of Chemical Physics. 3, 300.

Kirkwood, J. G. 1936. Statistical mechanics of liquid solutions. Chemical Reviews. 19, 275.

Kirkwood, J. G. Privately circulated. Selected topics in statistical mechanics based on a series of lectures. Lectures delivered at Princeton University, Spring term of 1947. Notes by J. H. Irving.

Kirkwood, J. G., and F. P. Buff. 1951. The statistical mechanical theory of solutions. 1. Journal of Chemical Physics. 19, 774.

Kirkwood, J. G., and R. J. Goldberg. 1950. Light scattering arising from composition fluctuations in multi-component systems. Journal of Chemical Physics. 18, 54.

Klein-Seetharaman, J., M. Oikawa, S. B. Grimshaw, J. Wirmer, E. Duchardt, T. Ueda, T. Imoto, L. J. Smith, C. M. Dobson, and H. Schwalbe. 2002. Long-range interactions within a nonnative protein. Science. 295, 1719.

Knez, E. 2009. Enzymatic reactions in dense gases. Journal of Supercritical Fluids. 47, 357.

Koga, Y. 2007. Solution Thermodynamics and its Application to Aqueous Solutions Amsterdam: Elsevier.

Kojima, K., and K. Tochigi. 1979. Prediction of Vapor-Liquid Equilibria by the ASOG Method. Tokyo: Elsevier Scientific Publishing Company.

Kojima, K., S. J. Zhang, and T. Hiaki. 1997. Measuring methods of infinite dilution activity coefficients and a database for systems including water. Fluid Phase Equilibria. 131, 145.

Kokubo, H., C. Y. Hu, and B. M. Pettitt. 2011. Peptide conformational preferences in osmolyte solutions: Transfer free energies of decaalanine. Journal of the American Chemical Society. 133, 1849.

Kokubo, H., and B. Pettitt. 2007. Preferential solvation in urea solutions at different concentrations: Properties from simulation studies. Journal of Physical Chemistry B. 111, 5233.

Kokubo, H., J. Rösgen, D. W. Bolen, and B. M. Pettitt. 2007a. Physicochemical basis of nonideality in urea solutions by chemical potential calculations. Biophysical Journal. 642A.

Kokubo, H., J. Rösgen, D. W. Bolen, and B. M. Pettitt. 2007b. Molecular basis of the apparent near ideality of urea solutions. Biophysical Journal. 93, 3392.

Kontogeorgis, G. M., M. L. Michelsen, G. K. Folas, S. Derawi, N. von Solms, and E. H. Stenby. 
2006a. Ten years with the applications of cubic-plus-association EOS to pure organic compounds and self-associating system (cubic-plus-association) equation of state. Part 1. Pure compounds and self-associating systems. Industrial and Engineering Chemistry Research. 45, 4855.

Kontogeorgis, G. M., M. L. Michelsen, G. K. Folas, S. Derawi, N. von Solms, and E. H. Stenby. 2006b. Ten years with the CPA (cubic-plus-association) equation of state. Part 2. Crossassociating and multicomponent systems. Industrial and Engineering Chemistry Research. 45, 4869.

Kontogeorgis, G. M., E. C. Voutsas, I. V. Yakoumis, and D. P. Tassios. 1996. An equation of state for associating fluids. Industrial and Engineering Chemistry Research. 35, 4310.

Kornblatt, J. A., and M. J. Kornblatt. 2002. The effects of osmotic and hydrostatic pressures on macromolecular systems. Biochimica Et Biophysica Acta-Protein Structure and Molecular Enzymology. 1595, 30.

Krichevskii, I. R. 1937. Thermodynamics of an infinitely dilute solution in mixed solvents. I. The Henry coefficient in a mixed solvent behaving as an ideal solvent. Zhurnal Fizicheskoi Khimii. 9, 41.

Kruse, A., and E. Dinjus. 2007. Hot compressed water as reaction medium and reactant properties and synthesis reactions. Journal of Supercritical Fluids. 39, 362.

Kulkarni, A. M., and C. F. Zukoski. 2002. Nanoparticle crystal nucleation: Influence of solution conditions. Langmuir. 18, 3090.

Kumar, S. K., and K. P. Johnston. 1988. Modelling the solubility of solids in supercritical fluids with density as the independent variable. Journal of Supercritical Fluids. 1, 15.

Kumelan, J., A. P. S. Kamps, D. Tuma, and G. Maurer. 2006. Solubility of $\mathrm{H}_{2}$ in the ionic liquid [bmim] $\left[\mathrm{PF}_{6}\right]$. Journal of Chemical and Engineering Data. 51, 11.

Kuntz Jr., I. D., and W. Kauzmann. 1974. Hydration of proteins and polypeptides. Advances in Protein Chemistry. 28, 239.

Kurnik, R. T., and R. C. Reid. 1982. Solubility of solid mixtures in supercritical fluids. Fluid Phase Equilibria. 8, 93.

Kusalik, P. G., and G. N. Patey. 1987. The thermodynamic properties of electrolyte-solutions some formal results. Journal of Chemical Physics. 86, 5110.

Kusalik, P. G., and G. N. Patey. 1988. On the molecular theory of aqueous-electrolyte solutions .1. The solution of the RHNC approximation for models at finite concentration. Journal of Chemical Physics. 88, 7715.

Kwiatkowski, J., Z. Lisicki, and W. Majewski. 1984. An experimental-method for measuring solubilities of solids in supercritical fluids. Berichte der Bunsen-Gesellschaft-Physical Chemistry Chemical Physics. 88, 865.

Lado, F. 1964. Perturbation correction to radial distribution function. Physical Review A-General Physics. 135, 1013.

Lazaridis, T. 2002. Binding affinity and specificity from computational studies. Current Organic Chemistry. 6, 1319.

Lazaridis, T., A. Masunov, and F. Gandolfo. 2002. Contributions to the binding free energy of ligands to avidin and streptavidin. Proteins: Structure, Function, and Genetics. 47, 194.

Lebowitz, J. L., and J. K. Percus. 1961. Long-range correlations in a closed system with applications to nonuniform fluids. Physical Review. 122, 1675.

Lebowitz, J. L., and J. K. Percus. 1963. Asymptotic behavior of radial distribution function. Journal of Mathematical Physics. 4, 248. 
Lee, J. C., and S. N. Timasheff. 1981. The stabilization of proteins by sucrose. Journal of Biological Chemistry. 256, 7193.

Lee, M. E., and N. F. A. van der Vegt. 2005. A new force field for atomistic simulations of aqueous tertiary butanol solutions. Journal of Chemical Physics. 122, 114509.

Lepori, L., and E. Matteoli. 1997. Excess Gibbs energies of the ternary system ethanol + tetrahydrofuran + cyclohexane at 298.15 k. Fluid Phase Equilibria. 134, 113.

Lepori, L., and E. Matteoli. 1998. Excess volumes of the ternary system ethanol + tetrahydrofuran + cyclohexane at $298.15 \mathrm{k}$. Fluid Phase Equilibria. 145, 69.

Lepori, L., E. Matteoli, G. Conti, and P. Gianni. 1998. Excess Gibbs energies of the ternary system ethanol + N,N-dimethylformamide + cyclohexane at $298.15 \mathrm{k}$. Fluid Phase Equilibria. 153, 293.

Lepree, J. M., M. J. Mulski, and K. A. Connors. 1994. Solvent effects on chemical processes .6. The phenomenological model applied to the solubility of naphthalene and 4-nitroaniline in binary aqueous-organic solvent mixtures. Journal of the Chemical Society-Perkin Transactions 2, 1491.

Levelt Sengers, J. M. H. 1991. Solubility near the solvent's critical point. Journal of Supercritical Fluids. 4, 215.

Lewis, G. N. 1900a. A new conception of thermal pressure and a theory of solutions. Proceedings of the American Academy of Arts and Sciences. 36, 145.

Lewis, G. N. 1900b. A new view of the thermal pressure and theory of solutions. Zeitschrift für Physikalische Chemie. 35, 343.

Lewis, G. N. 1901. The law of physico-chemical change. Proceedings of the American Academy of Arts and Sciences. 37, 49.

Li, A., W. J. Doucette, and A. W. Andren. 1994. Estimation of aqueous solubility, octanol/water partition-coefficient, and Henry's law constant for polychlorinated-biphenyls using UNIFAC. Chemosphere. 29, 657.

Li, T. W., E. H. Chimowitz, and F. Munoz. 1995. First-order corrections to infinite dilution fugacity coefficients using computer-simulation. American Institute of Chemical Engineers Journal. 41, 2300.

Licence, P., and M. Poliakoff. 2008. An introduction to supercritical fluids: From bench scale to commercial plant. In New methodologies and techniques for a sustainable organic chemistry, Edited by A. Mordini and F. Faigl.

Lim, W. K., J. Rösgen, and S. W. Englander. 2009. Urea, but not guanidinium, destabilizes proteins by forming hydrogen bonds to the peptide group. Proceedings of the National Academy of Sciences of the United States of America. 106, 2595.

Lin, C.-L., and R. H. Wood. 1996. Prediction of the free energy of dilute aqueous methane, ethane, and propane at temperatures from 600 to 1200 degrees $\mathrm{C}$ and densities from 0 to $1 \mathrm{~g} \mathrm{~cm}^{-3}$ using molecular dynamics simulations. Journal of Physical Chemistry. 100, 16399.

Lin, T.-Y., and S. N. Timasheff. 1994. Why do some organisms use a urea-methylamine mixture as osmolyte? Thermodynamic compensation of urea and trimethylamine n-oxide interactions with protein. Biochemistry. 33, 12695.

Liu, H., and J. P. O'Connell. 1998. On the measurement of solute partial molar volumes in nearcritical fluids with supercritical fluid chromatography. Industrial and Engineering Chemistry Research. 37, 3323.

Liu, Y., and D. Bolen. 1995. The peptide backbone plays a dominant role in protein stabilization 
by naturally occurring osmolytes. Biochemistry. 34, 12884.

Longuet-Higgins, H. C. 1951. The statistical thermodynamics of multicomponent systems. Proceedings of the Royal Society of London. Series A. Mathematical and Physical Sciences. 205, 247.

Lupis, C. H. P. 1983. Chemical Thermodynamics of Materials. New York: North-Holland. Mackerell, A. D. 2004. Empirical force fields for biological macromolecules: Overview and issues. Journal of Computational Chemistry. 25, 1584.

Mackerell, A. D., D. Bashford, M. Bellott, R. L. Dunbrack, J. D. Evanseck, M. J. Field, S. Fischer, J. Gao, H. Guo, S. Ha, D. J. McCarthy, L. Kuchnir, K. Kuczera, F. T. K. Lau, C. Mattos, S. Michnick, T. Ngo, D. T. Nguyen, B. Prodhom, W. E. Reiher, B. Roux, M. Schlenkrich, J. C. Smith, R. Stote, J. Straub, M. Watanabe, J. Wiorkiewicz-Kuczera, D. Yin, and M. Karplus. 1998. All-atom empirical potential for molecular modeling and dynamics studies of proteins. Journal of Physical Chemistry B. 102, 3586.

Mackerell, A. D., M. Feig, and C. L. Brooks. 2004. Extending the treatment of backbone energetics in protein force fields: Limitations of gas-phase quantum mechanics in reproducing protein conformational distributions in molecular dynamics simulations. Journal of Computational Chemistry. 25, 1400.

Maerzke, K. A., N. E. Schultz, R. B. Ross, and J. I. Siepmann. 2009. TraPPE-UA force field for acrylates and monte carlo simulations for their mixtures with alkanes and alcohols. Journal of Physical Chemistry B. 113, 6415.

Majer, V., L. Hui, R. Crovetto, and R. H. Wood. 1991. Volumetric properties of aqueous 1-1 electrolyte-solutions near and above the critical-temperature of water. 1. Densities and apparent molar volumes of $\mathrm{NaCl}(a q)$ from $0.0025 \mathrm{~mol} \cdot \mathrm{kg}^{-1}$ to $3.1 \mathrm{~mol} \cdot \mathrm{kg}^{-1}, 604.4-\mathrm{K}$ to 725.5-K, and 18.5-MPa to 38.0-MPa. Journal of Chemical Thermodynamics. 23, 213.

Majer, V., J. Sedlbauer, and G. Bergin. 2008. Henry's law constant and related coefficients for aqueous hydrocarbons, $\mathrm{CO}_{2}$ and $\mathrm{H}_{2} \mathrm{~S}$ over a wide range of temperature and pressure. Fluid Phase Equilibria. 272, 65.

Mansoori, G. A., and J. F. Ely. 1985. Statistical mechanical theory of local compositions. Fluid Phase Equilibria. 22, 253.

Marcus, Y. 1983. A quasi-lattice quasi-chemical theory of preferential solvation of ions in mixed solvents. Australian Journal of Chemistry. 36, 1719.

Marcus, Y. 1989. Preferential solvation. Part 3. Binary solvent mixtures. Journal of the Chemical Society, Faraday Transactions 1: Physical Chemistry in Condensed Phases. 85, 381.

Marcus, Y. 1990. Preferential solvation in mixed solvents. Part 5. Binary mixtures of water and organic solvents. Journal of the Chemical Society, Faraday Transactions. 86, 2215.

Marcus, Y. 1991. Preferential solvation in mixed solvents. Part 6. Binary mixtures containing methanol, ethanol, acetone or triethylamine and another organic solvent. Journal of the Chemical Society, Faraday Transactions. 87, 1843.

Marcus, Y. 1995. Preferential solvation in mixed solvents. Part 7. Binary mixtures of water and alkanolamines. Journal of the Chemical Society, Faraday Transactions. 91, 427.

Marcus, Y. 1999. Preferential solvation in mixed solvents. Part 8. Aqueous methanol from subambient to elevated temperatures. Physical Chemistry Chemical Physics. 1, 2975.

Marcus, Y. 2001. Preferential solvation in mixed solvents. Part 10. Completely miscible aqueous co-solvent binary mixtures at 298.15 K. Monatshefte für Chemie. 132, 1387.

Marcus, Y. 2002a. Preferential solvation in mixed solvents. Part 11. Eight additional completely miscible aqueous co-solvent binary mixtures and the relationship between the volume- 
corrected preferential solvation parameters and the structures of the co-solvents. Physical Chemistry Chemical Physics. 4, 4462.

Marcus, Y. 2002b. Solvent Mixtures: Properties and selective Solvation. New York: Marcel Dekker, Inc.

Marcus, Y. 2003. Preferential solvation in mixed solvents. Part 12. Aqueous glycols. Journal of Molecular Liquids. 107, 109.

Marcus, Y. 2006a. Preferential solvation in mixed solvents. Part 13. Mixtures of tetrahydrofuran with organic solvents: Kirkwood-Buff. Journal of Solution Chemistry. 35, 251.

Marcus, Y. 2006b. Preferential solvation in mixed solvents. Part 14. Mixtures of 1,4-dioxane with organic solvents: Kirkwood-Buff integrals and volume-corrected preferential solvation parameters. Journal of Molecular Liquids. 128, 115.

Marcus, Y. 2008. Clustering in liquid mixtures of water and acetonitrile. In Solution Chemistry Research Progress, Edited by D. V. Bostrelli. New York: Nova Science Publishers, Inc.

Marcus, Y. 2011. Water structure enhancement in water-rich binary solvent mixtures. Journal of Molecular Liquids. 158, 23.

Marcus, Y. 2012. Water structure enhancement in water-rich binary solvent mixtures. Part 2. The excess partial molar heat capacity of the water. Journal of Molecular Liquids. 166, 62.

Marcus, Y., and Y. Migron. 1991. Polarity, hydrogen bonding, and structure of mixtures of water and cyanomethane. Journal of Physical Chemistry. 95, 400.

Marlow, G. E., and B. M. Pettitt. 1994. Studies of salt-peptide solutions: Theoretical and experimental approaches. In Advances in Computational Biology, Edited by H. O. Villar: Elsevier Science.

Martin, W., J. Baross, D. Kelley, and M. J. Russell. 2008. Hydrothermal vents and the origin of life. Nature Reviews Microbiology. 6, 805.

Mathias, P. M., and J. P. O'Connell. 1979. A predictive method for PVT and phase behavior of liquids containing supercritical components. In Equations of state in engineering and research: American Chemical Society.

Mathias, P. M., and J. P. O'Connell. 1981. Molecular thermodynamics of liquids containing supercritical compounds. Chemical Engineering Science. 36, 1123.

Matteoli, E. 1997. A study on Kirkwood-Buff integrals and preferential solvation in mixtures with small deviations from ideality and/or with size mismatch of components. Importance of a proper reference system. Journal of Physical Chemistry B. 101, 9800.

Matteoli, E., P. Gianni, and L. Lepori. 2010. Excess Gibbs energies of the ternary system 2methoxyethanol + tetrahydrofuran + cyclohexane and other relevant binaries at $298.15 \mathrm{~K}$. Journal of Chemical and Engineering Data. 55, 5441.

Matteoli, E., and L. Lepori. 1984. Solute solute interactions in water. 2. An analysis through the Kirkwood-Buff integrals for 14 organic solutes. Journal of Chemical Physics. 80, 2856.

Matteoli, E., and L. Lepori. 1990. The ternary system water + 1-propanol + urea at $298.15 \mathrm{~K}$. Activity coefficients, partial molal volumes and Kirkwood-Buff integrals. Journal of Molecular Liquids. 47, 89.

Matteoli, E., and L. Lepori. 1995. Kirkwood-Buff integrals and preferential solvation in ternary non-electrolyte mixtures. Journal of the Chemical Society, Faraday Transactions. 91, 431; Corrigendum: 91, 1885.

Matteoli, E., and L. Lepori. 2007. Comment on "A critique of some recent suggestions to correct the Kirkwood-Buff integrals". Journal of Physical Chemistry B. 111, 3069.

Matteoli, E., and L. Lepori. 2008. Reply to "Comment on 'The Kirkwood-Buff theory of 
solutions and the local composition of liquid mixtures'". Journal of Physical Chemistry B. $112,5878$.

Matteoli, E., and G. A. Mansoori. 1995. A simple expression for radial-distribution functions of pure fluids and mixtures. Journal of Chemical Physics. 103, 4672.

Matteoli, E., and G. A. Mansoori, Eds. 1990. Fluctuation Theory of Mixtures. Edited by G. A. Mansoori, Advances in Thermodynamics. New York: Taylor and Francis.

Mazo, R. M. 1958. Statistical mechanical theory of solutions. Journal of Chemical Physics. 29, 1122.

Mazo, R. M. 2006. A fluctuation theory analysis of the salting-out effect. Journal of Physical Chemistry B. 110, 24077.

Mazo, R. M. 2007. Salting out near the critical point. Journal of Physical Chemistry B. 111, 7288.

McGuigan, D. B., and P. A. Monson. 1990. Analysis of infinite dilution partial molar volumes using distribution function theory. Fluid Phase Equilibria. 57, 227.

McMillan, W. G., and J. E. Mayer. 1945. The statistical thermodynamics of multicomponent systems. Journal of Chemical Physics. 13, 276.

McNaught, A. D., and A. Wilkinson. 1997. IUPAC Compendium of Chemical Terminology: The Gold Book, $2^{\text {nd }}$ Ed.. Oxford: Blackwell Scienctific Publications.

Mecke, M., A. Muller, J. Winkelmann, J. Vrabec, J. Fischer, R. Span, and W. Wagner. 1996. An accurate van der Waals-type equation of state for the Lennard-Jones fluid. International Journal of Thermophysics. 17, 391.

Miyawaki, O. 2009. Thermodynamic analysis of protein unfolding in aqueous solutions as a multisite reaction of protein with water and solute molecules. Biophysical Chemistry. $144,46$.

Modell, M., and R. C. Reid. 1983. Thermodynamics and its Applications. 2nd Ed. Englewood Cliffs (New Jersey): Prentice Hall.

Morris, J. W., P. J. Mulvey, M. M. Abbott, and H. C. van Ness. 1975. Excess thermodynamic functions for ternary systems. I. Acetone-chloroform-methanol at 50 degrees. Journal of Chemical and Engineering Data. 20, 403.

Morris, K. R. 1988. Solubility of aromatic compounds in mixed solvents. Ph.D. Thesis, Pharmaceutical Sciences Graduate College, The University of Arizona.

Mota, F. L., A. J. Queimada, A. E. Andreatta, S. P. Pinho, and E. A. Macedo. 2012. Calculation of drug-like molecules solubility using predictive activity coefficient models. Fluid Phase Equilibria. 322, 48.

Mu, Y. G., D. S. Kosov, and G. Stock. 2003. Conformational dynamics of trialanine in water. 2. Comparison of Amber, CHARMM, GROMOS, and OPLS force fields to NMR and infrared experiments. Journal of Physical Chemistry B. 107, 5064.

Mukherji, D., N. F. A. van der Vegt, K. Kremer, and L. Delle Site. 2012. Kirkwood-Buff analysis of liquid mixtures in an open boundary simulation. Journal of Chemical Theory and Computation. 8, 375.

Muller, E. A., and K. E. Gubbins. 2001. Molecular-based equations of state for associating fluids: A review of saft and related approaches. Industrial and Engineering Chemistry Research. 40, 2193.

Munoz, F., and E. H. Chimowitz. 1993. Critical phenomena in mixtures. 2. Synergistic and other effects near mixture critical-points. Journal of Chemical Physics. 99, 5450.

Munoz, F., T. W. Li, and E. H. Chimowitz. 1995. Henry's law and synergism in dilute near- 
critical solutions - theory and simulation. American Institute of Chemical Engineers Journal. 41, 389.

Münster, A. 1969. Statistical Thermodynamics. Berlin: Springer-Verlag.

Münster, A. 1970. Classical Thermodynamics. London: Wiley-Interscience.

Myers, D. B., and R. L. Scott. 1963. Thermodynamic functions for nonelectrolyte solutions. Industrial and Engineering Chemistry. 55, 43.

Myers, J. K., C. N. Pace, and J. M. Scholtz. 1995. Denaturant $m$-values and heat-capacity changes - relation to changes in accessible surface-areas of protein unfolding. Protein Science. 4, 2138.

Nagata, I., and K. Miyazaki. 1992. Excess enthalpies of (aniline + propan-2-ol) and of (aniline + propan-2-ol + benzene) at the temperature $298.15 \mathrm{~K}$. Journal of Chemical Thermodynamics. 24, 1175.

Newman, K. E. 1994. Kirkwood-Buff solution theory - derivation and applications. Chemical Society Reviews. 23, 31.

Nichols, J. W., S. G. Moore, and D. R. Wheeler. 2009. Improved implementation of KirkwoodBuff solution theory in periodic molecular simulations. Physical Review E. 80, 051203.

Nikolova, P. V., S. J. B. Duff, P. Westh, et al. 2000. A thermodynamic study of aqueous acetonitrile: Excess chemical potentials, partial molar enthalpies, entropies and volumes, and fluctuations. Canadian Journal of Chemistry. 78, 1553.

Novák, J. P., J. Matouš, and J. Pick. 1987. Liquid-Liquid Equilibria. Amsterdam: Elsevier.

Nozaki, Y., and C. Tanford. 1963. The solubility of amino acids and related compounds in aqueous urea solutions. Journal of Biological Chemistry. 238, 4074.

Nymeyer, H. 2009. Energy landscape of the Trpzip2 peptide. Journal of Physical Chemistry B. $113,8288$.

O'Brien, E. P., G. Ziv, G. Haran, B. R. Brooks, and D. Thirumalai. 2008. Effects of denaturants and osmolytes on proteins are accurately predicted by the molecular transfer model. Proceedings of the National Academy of Sciences of the United States of America. 105, 13403.

O’Connell, J. P. 1971a. Molecular thermodynamics of gases in mixed solvents. American Institute of Chemical Engineers Journal. 17, 658.

O'Connell, J. P. 1971b. Thermodynamic properties of solutions based on correlation functions. Molecular Physics. 20, 27.

O'Connell, J. P. 1981. Thermodynamic properties of solutions and the theory of fluctuations. Fluid Phase Equilibria. 6, 21.

O'Connell, J. P. 1990. Thermodynamic properties of mixtures from fluctuation solution theory. In Fluctuation Theory of Mixtures, Edited by E. Matteoli and G. A. Mansoori. New York: Taylor and Francis.

O'Connell, J. P. 1993. Application of fluctuation solution theory to strong electrolyte-solutions. Fluid Phase Equilibria. 83, 233.

O'Connell, J. P. 1994. Thermodynamics and fluctuation solution theory with some applications to systems at near or supercritical conditions. In Part II: Fluctuations, crossover effects, transport properties. In Supercritical fluids: Fundamentals for Application, Edited by E. Kiran and J. M. H. Levelt Sengers. Dordrecht, The Netherlands: Klüwer Academic Publishers.

O'Connell, J. P. 1995. Application of fluctuation solution theory to thermodynamic properties of solutions. Fluid Phase Equilibria. 104, 21. 
O’Connell, J. P., and J. M. Haile. 2005. Thermodynamics: Fundamentals for Applications. New York: Cambridge University Press.

O’Connell, J. P., Y. Q. Hu, and K. A. Marshall. 1999. Aqueous strong electrolyte solution activity coefficients and densities from fluctuation solution theory. Fluid Phase Equilibria. 158, 583.

O'Connell, J. P., and H. Q. Liu. 1998. Thermodynamic modelling of near-critical solutions. Fluid Phase Equilibria. 144, 1.

O'Connell, J. P., and J. M. Prausnitz. 1964. Thermodynamics of gas solubility in mixed solvents. Industrial and Engineering Chemistry Fundamentals. 3, 347.

O'Connell, J. P., A. V. Sharygin, and R. H. Wood. 1996. Infinite dilution partial molar volumes of aqueous solutes over wide ranges of conditions. Industrial and Engineering Chemistry Research. 35, 2808.

O'Connell, J. P., and H. Q. Liu. 1998. Thermodynamic modelling of near-critical solutions. Fluid Phase Equilibria. 144, 1.

O'Connell, J. P., and R. Clairmont. 2010. Evaluation of equation of state combining and mixing rules with properties from fluctuation solution theory. Poster presented at the 12th international conference on properties and phase equilibria for product and process design. Suzhou, Jiangsu, China.

Oostenbrink, C., A. Villa, A. E. Mark, and W. F. van Gunsteren. 2004. A biomolecular force field based on the free enthalpy of hydration and solvation: The GROMOS force-field parameter sets 53a5 and 53a6. Journal of Computational Chemistry. 25, 1656.

Pace, C. N. 1986. Determination and analysis of urea and guanidine hydrochloride denaturation curves. In Methods in Enzymology. Enzyme Structure Part L, Edited by C. H. W. Hirs and S. N. Timasheff: Academic Press, Inc.

Pace, C. N., S. Trevino, E. Prabhakaran, and J. M. Scholtz. 2004. Protein structure, stability and solubility in water and other solvents. Philosophical Transactions of the Royal Society of London Series B-Biological Sciences. 359, 1225.

Paduszynski, K., and U. Domanska. 2012. A new group contribution method for prediction of density of pure ionic liquids over a wide range of temperature and pressure. Industrial and Engineering Chemistry Research. 51, 591.

Pappenberger, G., C. Saudan, M. Becker, A. E. Merbach, and T. Kiefhaber. 2000. Denaturantinduced movement of the transition state of protein folding revealed by high-pressure stopped-flow measurements. Proceedings of the National Academy of Sciences of the United States of America. 97, 17.

Parsegian, V. A., R. P. Rand, and D. C. Rau. 1995. Macromolecules and water: Probing with osmotic stress. Energetics of Biological Macromolecules. 259, 43.

Parsegian, V. A., R. P. Rand, and D. C. Rau. 2000. Osmotic stress, crowding, preferential hydration, and binding: A comparison of perspectives. Proceedings of the National Academy of Sciences of the United States of America. 97, 3987.

Paschek, D., R. Day, and A. E. Garcia. 2011. Influence of water-protein hydrogen bonding on the stability of Trp-cage miniprotein. A comparison between the TIP3P and TIP4P-Ew water models. Physical Chemistry Chemical Physics. 13, 19840.

Paschek, D., S. Hempel, and A. E. Garcia. 2008. Computing the stability diagram of the Trpcage miniprotein. Proceedings of the National Academy of Sciences of the United States of America. 105, 17754.

Paul, S., and G. Patey. 2007. Structure and interaction in aqueous urea-trimethylamine-N-oxide 
solutions. Journal of the American Chemical Society. 129, 4476.

Pauling, L., R. B. Corey, and H. R. Branson. 1951. The structure of proteins: Two hydrogenbonded helical configurations of the polypeptide chain. Proceedings of the National Academy of Sciences of the United States of America. 37, 205.

Pearson, F. J., and G. S. Rushbrooke. 1957. XX. On the theory of binary fluid mixtures. Proceedings of the Royal Society of Edinburgh, Section: A Mathematics. 64, 305.

Peng, D.-Y., and D. B. Robinson. 1976. A new two-constant equation of state. Industrial and Engineering Chemistry Fundamentals. 15, 59.

Perera, A. 2009. Bridge function and fundamental measure theory: A test in dimension one. Molecular Physics. 107, 2251.

Perera, A. 2011. On the microscopic structure of liquid water. Molecular Physics. 109, 2433.

Perera, A., B. Kežić, F. Sokolić, and L. Zoranić. 2012. Micro-heterogeneity in complex liquids. In Molecular Dynamics - Studies of Synthetic and Biological Macromolecules, Edited by L. Wang. Rijeka, Croatia: InTech.

Perera, A., R. Mazighi, and B. Kežić. 2012. Fluctuations and micro-heterogeneity in aqueous mixtures. Journal of Chemical Physics. 136, 174516.

Perera, A., and G. N. Patey. 1988. The solution of the hypernetted-chain and Percus-Yevick approximations for fluids of hard spherocylinders. Journal of Chemical Physics. 89, 5861.

Perera, A., and F. Sokolic. 2004. Modeling nonionic aqueous solutions: The acetone-water mixture. Journal of Chemical Physics. 121, 11272.

Perera, A., F. Sokolić, L. Almasy, and Y. Koga. 2006. Kirkwood-Buff integrals of aqueous alcohol binary mixtures. Journal of Chemical Physics. 124, 124515.

Perera, A., F. Sokolić, L. Almasy, P. Westh, and Y. Koga. 2005. On the evaluation of the Kirkwood-Buff integrals of aqueous acetone mixtures. Journal of Chemical Physics. 123, 024503.

Perera, A., L. Zoranić, F. Sokolić, and R. Mazighi. 2011. A comparative molecular dynamics study of water-methanol and acetone-methanol mixtures. Journal of Molecular Liquids. $159,52$.

Perkyns, J. S., Y. Wang, and B. M. Pettitt. 1996. Salting in peptides: Conformationally dependent solubilities and phase behavior of a tripeptide zwitterion in electrolyte solution. Journal of the American Chemical Society. 118, 1164.

Perry, R. L., H. Cabezas, and J. P. O'Connell. 1988. Fluctuation thermodynamic properties of strong electrolyte-solutions. Molecular Physics. 63, 189.

Perry, R. L., and J. P. O'Connell. 1984. Fluctuation thermodynamic properties of reactive components from species correlation-function integrals. Molecular Physics. 52, 137.

Perry, R. L., J. C. Telotte, and J. P. O'Connell. 1981. Solution thermodynamics for reactive components. Fluid Phase Equilibria. 5, 245.

Pettitt, B. M., and P. J. Rossky. 1986. Alkali halides in water: Ion-solvent correlations and ionion potentials of mean force at infinite dilution. Journal of Chemical Physics. 84, 5836.

Pfund, D. M., and H. D. Cochran. 1993. Chemical potentials in ternary supercritical fluid mixtures. In Supercritical Engineering Science. Fundamentals Studies and Applications, Edited by E. Kiran and J. F. Brennecke. Washington, DC: American Chemical Society.

Pierce, V., M. Kang, M. Aburi, S. Weerasinghe, and P. E. Smith. 2008. Recent applications of Kirkwood-Buff theory to biological systems. Cell Biochemistry and Biophysics. 50, 1.

Pitzer, K. S. 1995. Thermodynamics. New York: McGraw-Hill. 
Ploetz, E. A., N. Bentenitis, and P. E. Smith. 2010a. Developing force fields from the microscopic structure of solutions. Fluid Phase Equilibria. 290, 43.

Ploetz, E. A., N. Bentenitis, and P. E. Smith. 2010b. Kirkwood-Buff integrals for ideal solutions. Journal of Chemical Physics. 132, 164501.

Ploetz, E. A., and P. E. Smith. 2011a. A Kirkwood-Buff force field for the aromatic amino acids. Physical Chemistry Chemical Physics. 13, 18154.

Ploetz, E. A., and P. E. Smith. 2011b. Local fluctuations in solution mixtures. Journal of Chemical Physics. 135, 044506.

Plyasunov, A. V. 2011. Thermodynamics of $\mathrm{B}(\mathrm{OH})_{3}$ in the vapor phase of water: Vapor-liquid and Henry's constants, fugacity and second cross virial coefficients. Fluid Phase Equilibria. 305, 212.

Plyasunov, A. V., J. P. O'Connell, and R. H. Wood. 2000. Infinite dilution partial molar properties of aqueous solutions of nonelectrolytes. I. Equations for partial molar volumes at infinite dilution and standard thermodynamic functions of hydration of volatile nonelectrolytes over wide ranges of conditions. Geochimica et Cosmochimica Acta. 64, 495.

Plyasunov, A. V., J. P. O’Connell, R. H. Wood, and E. L. Shock. 2000. Infinite dilution partial molar properties of aqueous solutions of nonelectrolytes. II. Equations for the standard thermodynamic functions of hydration of volatile nonelectrolytes over wide ranges of conditions including subcritical temperatures. Geochimica et Cosmochimica Acta. 64, 2779.

Plyasunov, A. V., J. P. O'Connell, R. H. Wood, and E. L. Shock. 2001. Semiempirical equation of state for the infinite dilution thermodynamic functions of hydration of nonelectrolytes over wide ranges of temperature and pressure. Fluid Phase Equilibria. 183, 133.

Plyasunov, A. V., E. L. Shock, and J. P. O'Connell. 2006. Corresponding-states correlations for estimating partial molar volumes of nonelectrolytes at infinite dilution in water over extended temperature and pressure ranges. Fluid Phase Equilibria. 247, 18.

Pohorille, A., and L. R. Pratt. 1990. Cavities in molecular liquids and the theory of hydrophobic solubilities. Journal of the American Chemical Society. 112, 5066.

Poland, D. C., and H. A. Scheraga. 1965. Hydrophobic bonding and micelle stability. Journal of Physical Chemistry. 69, 2431.

Poling, B. E., J. M. Praunitz, and J. P. O'Connell. 2000. The Properties of Gases and Liquids. 5th Ed. New York: McGraw-Hill. Errata at http://www.che.virginia.edu/PGL5/.

Polishuk, I., and A. Mulero. 2011. The numerical challenges of SAFT EoS models. Reviews in Chemical Engineering. 27, 241.

Pratt, L. R., and D. Chandler. 1977. Theory of the hydrophobic effect. Journal of Chemical Physics. 67, 3683.

Prausnitz, J. M., R. N. Lichtenthaler, and E. Gomes de Azevedo. 1986. Molecular Thermodynamics of Fluid Phase Equilibria. 2nd. Ed. Englewood Cliffs: Prentice-Hall.

Prausnitz, J. M., R. N. Lichtenthaler, and E. Gomes de Azevedo. 1999. Molecular Thermodynamics of Fluid-Phase Equilibria. 3rd Ed., Prentice Hall International Series in the Physical and Chemical Engineering Sciences. Upper Saddle River, N.J.: PrenticeHall.

Press, W. H., S. A. Teukolsky, W. T. Vetterling, and B. P. Flannery. 1992. Numerical Recipes in C: The Art of Scientific Computing. 2nd Ed. Cambridge: Cambridge University Press.

Prigogine, I. with contributions from A. Bellemans and V. Mathot. 1957. The Molecular Theory 
of Solutions. Amsterdam: North-Holland Publishing Co.

Prigogine, I., and R. Dufay. 1954. Chemical Thermodynamics, Treatise on Thermodynamics. London; New York: Longmans, Green.

Puliti, G., S. Paolucci, and M. Sen. 2011. Thermodynamic properties of gold-water nanolayer mixtures using molecular dynamics. Journal of Nanoparticle Research. 13, 4277.

Qu, Y. X., C. L. Bolen, and D. W. Bolen. 1998. Osmolyte-driven contraction of a random coil protein. Proceedings of the National Academy of Sciences of the United States of America. 95, 9268.

Ramirez, R., M. Mareschal, and D. Borgis. 2005. Direct correlation functions and the density functional theory of polar solvents. Chemical Physics. 319, 261.

Raoult, F.-M. 1878. Vapour-tension and solidifying point of saline solutions. Comptes Rendus Hebdomadaires des Seances de l'Academie des Sciences. 87, 167.

Raoult, F.-M. 1882. Law of freezing of solvents. Comptes Rendus Hebdomadaires des Seances de l'Academie des Sciences. 95, 1030.

Raoult, F.-M. 1887. General law of the vapor pressure of solvents. Comptes Rendus Hebdomadaires des Seances de l'Academie des Sciences. 104, 1430.

Raoult, F.-M. 1888. Vapour-tensions of ethereal solutions. Zeitschrift für Physikalische Chemie, Stöchiometrie und Verwandtschaftslehre. 2, 353.

Rasaiah, J. C., and H. L. Friedman. 1968. Integral equation methods in the computation of equilibrium properties of ionic solutions. Journal of Chemical Physics. 48, 2742.

Reaves, J. T., and C. B. Roberts. 1999. Subcritical solvent effects on a parallel Diels-Alder reaction network. Industrial and Engineering Chemistry Research. 38, 855.

Record, M. T., W. T. Zhang, and C. F. Anderson. 1998. Analysis of effects of salts and uncharged solutes on protein and nucleic acid equilibria and processes: A practical guide to recognizing and interpreting polyelectrolyte effects, Hofmeister effects, and osmotic effects of salts. Advances in Protein Chemistry. 51, 281.

Redlich, O., and A. T. Kister. 1948. Thermodynamics of nonelectrolyte solutions $-x-y-T$ relations in a binary system. Industrial and Engineering Chemistry. 40, 341.

Ren, P. Y., C. J. Wu, and J. W. Ponder. 2011. Polarizable atomic multipole-based molecular mechanics for organic molecules. Journal of Chemical Theory and Computation. 7, 3143.

Retailleau, P., A. Ducruix, and M. Ries-Kautt. 2002. Importance of the nature of anions in lysozyme crystallisation correlated with protein net charge variation. Acta Crystallographica Section D-Biological Crystallography. 58, 1576.

Retailleau, P., M. Ries-Kautt, and A. Ducruix. 1997. No salting-in of lysozyme chloride observed at low ionic strength over a large range of pH. Biophysical Journal. 73, 2156.

Richards, J. P. 2011. Magmatic to hydrothermal metal fluxes in convergent and collided margins. Ore Geology Reviews. 40, 1.

Ries-Kautt, M. M., and A. F. Ducruix. 1989. Relative effectiveness of various ions on the solubility and crystal-growth of lysozyme. Journal of Biological Chemistry. 264, 745.

Roberts, C. B., J. F. Brennecke, and J. E. Chateauneuf. 1995. Solvation effects on reactions of triplet benzophenone in supercritical fluids. American Institute of Chemical Engineers Journal. 41, 1306.

Roberts, C. B., J. W. Zhang, J. E. Chateauneuf, and J. F. Brennecke. 1995. Laser flash-photolysis and integral-equation theory to investigate reactions of dilute solutes with oxygen in supercritical fluids. Journal of the American Chemical Society. 117, 6553.

Robinson, C. R., S. G. Sligar, M. L. Johnson, and G. K. Ackers. 1995. Hydrostatic and osmotic 
pressure as tools to study macromolecular recognition. Energetics of Biological Macromolecules. 259, 395.

Romankiw, L. A., and I. M. Chou. 1983. Densities of aqueous $\mathrm{NaCl}, \mathrm{KCl}, \mathrm{MgCl}_{2}$, and $\mathrm{CaCl}_{2}$ binary-solutions in the concentration range $0.5-6.1-\mathrm{m}$ at 25-degrees-C, 30-degrees-C, 35degrees-C, 40-degrees-C, and 45-degrees-C. Journal of Chemical and Engineering Data. 28,300 .

Romero, S., A. Reillo, B. Escalera, and P. Bustamante. 1996. The behavior of paracetamol in mixtures of amphiprotic and amphiprotic-aprotic solvents. Relationship of solubility curves to specific and nonspecific interactions. Chemical and Pharmaceutical Bulletin. 44, 1061.

Rose, G., P. Fleming, J. Banavar, and A. Maritan. 2006. A backbone-based theory of protein folding. Proceedings of the National Academy of Sciences of the United States of America. 103, 16623.

Rosenberg, R. M., and W. L. Peticolas. 2004. Henry's law: A retrospective. Journal of Chemical Education. 81, 1647.

Rösgen, J., B. M. Pettitt, and D. W. Bolen. 2004. Uncovering the basis for nonideal behavior of biological molecules. Biochemistry. 43, 14472.

Rösgen, J., B. M. Pettitt, and D. W. Bolen. 2005. Protein folding, stability, and solvation structure in osmolyte solutions. Biophysical journal. 89, 2988.

Rösgen, J., B. M. Pettitt, J. Perkyns, and D. W. Bolen. 2004. Statistical thermodynamic approach to the chemical activities in two-component solutions. Journal of Physical Chemistry B. $108,2048$.

Rossky, P. J. 2008. Protein denaturation by urea: Slash and bond. Proceedings of the National Academy of Sciences of the United States of America. 105, 16825.

Rowlinson, J. S., and F. L. Swinton. 1982. Liquids and Liquid Mixtures. 3rd Ed. London: Butterworth Scientific.

Ruckenstein, E., and I. Shulgin. 2002a. The solubility of solids in mixtures composed of a supercritical fluid and an entrainer. Fluid Phase Equilibria. 200, 53.

Ruckenstein, E., and I. L. Shulgin. 2001a. Effect of a third component on the interactions in a binary mixture determined from the fluctuation theory of solutions. Fluid Phase Equilibria. 180, 281.

Ruckenstein, E., and I. L. Shulgin. 2001b. Entrainer effect in supercritical mixtures. Fluid Phase Equilibria. 180, 345.

Ruckenstein, E., and I. L. Shulgin. 2002b. Salting-out or -in by fluctuation theory. Industrial and Engineering Chemistry Research. 41, 4674.

Ruckenstein, E., and I. L. Shulgin. 2003a. Ideal multicomponent liquid solution as a mixed solvent. Industrial and Engineering Chemistry Research. 42, 4406.

Ruckenstein, E., and I. L. Shulgin. 2003b. Solubility of drugs in aqueous solutions. Part 1: Ideal mixed solvent approximation. International Journal of Pharmaceutics. 258, 193.

Ruckenstein, E., and I. L. Shulgin. 2003c. Solubility of drugs in aqueous solutions. Part 2: Binary nonideal mixed solvent. International Journal of Pharmaceutics. 260, 283.

Ruckenstein, E., and I. L. Shulgin. 2003d. Solubility of drugs in aqueous solutions. Part 3: Multicomponent mixed solvent. International Journal of Pharmaceutics. 267, 121.

Ruckenstein, E., and I. L. Shulgin. 2004. Solubility of drugs in aqueous solutions. Part 4: Drug solubility by the dilute approximation. International Journal of Pharmaceutics. 278, 221.

Ruckenstein, E., and I. L. Shulgin. 2005. Solubility of hydrophobic organic pollutants in binary 
and multicomponent aqueous solvents. Environmental Science and Technology. 39, 1623. Ruckenstein, E., and I. L. Shulgin. 2006. Effect of salts and organic additives on the solubility of proteins in aqueous solutions. Advances in Colloid and Interface Science. 123, 97.

Ruckenstein, E., and I. L. Shulgin, Eds. 2009. Thermodynamics of Solutions: From Gases to Pharmaceutics to Proteins. Dordrecht: Springer.

Salacuse, J. J., A. R. Denton, and P. A. Egelstaff. 1996. Finite-size effects in molecular dynamics simulations: Static structure factor and compressibility. 1. Theoretical method. Physical Review E. 53, 2382.

Sasahara, K., M. Sakurai, and K. Nitta. 2001. Pressure effect on denaturant-induced unfolding of hen egg white lysozyme. Proteins: Structure, Function, and Genetics. 44, 180.

Sasahara, K., N. Sakurai, and K. Nitta. 1999. The volume and compressibility changes of lysozyme associated with guanidinium chloride and pressure-assisted unfolding. Journal of Molecular Biology. 291, 693.

Savage, P. E., S. Golapan, T. I. Mizan, C. J. Martino, and E. E. Brock. 1995. Reactions at supercritical conditions: Applications and fundamentals. American Institute of Chemical Engineers Journal. 41, 1723.

Schachman, H. K., and M. A. Lauffer. 1949. The hydration, size and shape of tobacco mosaic virus. Journal of the American Chemical Society. 71, 536.

Schellman, J. A. 1987. Selective binding and solvent denaturation. Biopolymers. 26, 549.

Schmid, B., and J. Gmehling. 2012. Revised parameters and typical results of the VTPR group contribution equation of state. Fluid Phase Equilibria. 317, 110.

Schmid, N., A. P. Eichenberger, A. Choutko, S. Riniker, M. Winger, A. E. Mark, and W. F. van Gunsteren. 2011. Definition and testing of the GROMOS force-field versions 54A7 and 54B7. European Biophysics Journal with Biophysics Letters. 40, 843.

Schnell, S. K., X. Liu, J.-M. Simon, A. Bardow, D. Bedeaux, T. J. H. Vlugt, and S. Kjelstrup. 2011. Calculating thermodynamic properties from fluctuations at small scales. Journal of Physical Chemistry B. 115, 10911.

Schoen, M., and C. Hoheisel. 1984. The mutual diffusion coefficient- $D_{12}$ in binary-liquid model mixtures - molecular-dynamics calculations based on Lennard-Jones (12-6) potentials. 1. The method of determination. Molecular Physics. 52, 33.

Sedlbauer, J., J. P. O'Connell, and R. H. Wood. 2000. A new equation of state for correlation and prediction of standard molal thermodynamic properties of aqueous species at high temperatures and pressures. Chemical Geology. 163, 43.

Sedlbauer, J., E. M. Yezdimer, and R. H. Wood. 1998. Partial molar volumes at infinite dilution in aqueous solutions of $\mathrm{NaCl}, \mathrm{LiCl}, \mathrm{NaBr}$, and $\mathrm{CsBr}$ at temperatures from $550 \mathrm{~K}$ to 725 K. Journal of Chemical Thermodynamics. 30, 3.

Shimizu, S. 2004. Estimating hydration changes upon biomolecular reactions from osmotic stress, high pressure, and preferential hydration experiments. Proceedings of the National Academy of Sciences of the United States of America. 101, 1195.

Shimizu, S. 2011. Molecular origin of the cosolvent-induced changes in the thermal stability of proteins. Chemical Physics Letters. 514, 156.

Shimizu, S., and C. L. Boon. 2004. The Kirkwood-Buff theory and the effect of cosolvents on biochemical reactions. Journal of Chemical Physics. 121, 9147.

Shimizu, S., and N. Matubayasi. 2006. Preferential hydration of proteins: A Kirkwood-Buff approach. Chemical Physics Letters. 420, 518.

Shimizu, S., W. M. McLaren, and N. Matubayasi. 2006. The Hofmeister series and protein-salt 
interactions. Journal of Chemical Physics. 124, 234905.

Shukla, D., and B. L. Trout. 2011. Understanding the synergistic effect of arginine and glutamic acid mixtures on protein solubility. Journal of Physical Chemistry B. 115, 11831.

Shulgin, I., and E. Ruckenstein. 2002a. The solubility of binary mixed gases by the fluctuation theory. Industrial and Engineering Chemistry Research. 41, 6279.

Shulgin, I. L., and E. Ruckenstein. 2002b. Henry's constant in mixed solvents from binary data. Industrial and Engineering Chemistry Research. 41, 1689.

Shulgin, I. L., and E. Ruckenstein. 2003. Prediction of gas solubility in binary polymer plus solvent mixtures. Polymer. 44, 901.

Shulgin, I. L., and E. Ruckenstein. 2005a. A protein molecule in an aqueous mixed solvent: Fluctuation theory outlook. Journal of Chemical Physics. 123, 054909.

Shulgin, I. L., and E. Ruckenstein. 2005b. Relationship between preferential interaction of a protein in an aqueous mixed solvent and its solubility. Biophysical Chemistry. 118, 128.

Shulgin, I. L., and E. Ruckenstein. 2006a. The Kirkwood-Buff theory of solutions and the local composition of liquid mixtures. Journal of Physical Chemistry B. 110, 12707.

Shulgin, I. L., and E. Ruckenstein. 2006b. Preferential hydration and solubility of proteins in aqueous solutions of polyethylene glycol. Biophysical Chemistry. 120, 188.

Shulgin, I. L., and E. Ruckenstein. 2008a. Excess around a central molecule with application to binary mixtures. Physical Chemistry Chemical Physics. 10, 1097.

Shulgin, I. L., and E. Ruckenstein. 2008b. Reply to "Comment on 'The Kirkwood-Buff theory of solutions and the local composition of liquid mixtures"'. Journal of Physical Chemistry B. $112,5876$.

Simnick, J. J., H. M. Sebastian, H. M. Lin, and K. C. Chao. 1979a. Gas-liquid equilibrium in mixtures of methane+m-xylene, and methane-meta-cresol. Fluid Phase Equilibria. 3, 145.

Simnick, J. J., H. M. Sebastian, H. M. Lin, and K. C. Chao. 1979b. Vapor-liquid-equilibrium in methane + quinoline mixtures at elevated-temperatures and pressures. Journal of Chemical and Engineering Data. 24, 239.

Smit, B. 1992. Phase-diagrams of Lennard-Jones fluids. Journal of Chemical Physics. 96, 8639.

Smith, P. E. 2004. Cosolvent interactions with biomolecules: Relating computer simulation data to experimental thermodynamic data. Journal of Physical Chemistry B. 108, 18716.

Smith, P. E. 2006a. Chemical potential derivatives and preferential interaction parameters in biological systems from Kirkwood-Buff theory. Biophysical Journal. 91, 849.

Smith, P. E. 2006b. Equilibrium dialysis data and the relationships between preferential interaction parameters for biological systems in terms of Kirkwood-Buff integrals. Journal of Physical Chemistry B. 110, 2862.

Smith, P. E. 2008. On the Kirkwood-Buff inversion procedure. Journal of Chemical Physics. 129, 124509.

Smith, P. E., G. E. Marlow, and B. M. Pettitt. 1993. Peptides in ionic-solutions - A simulation study of a bis(penicillamine) enkephalin in sodium-acetate solution. Journal of the American Chemical Society. 115, 7493.

Smith, P. E., and R. M. Mazo. 2008. On the theory of solute solubility in mixed solvents. Journal of Physical Chemistry B. 112, 7875.

Smith, P. E., and B. M. Pettitt. 1991. Effects of salt on the structure and dynamics of the bis(penicillamine) enkephalin zwitterion - a simulation study. Journal of the American Chemical Society. 113, 6029. 
Smith, P. E., and B. M. Pettitt. 1992. Amino-acid side-chain populations in aqueous and saline solution: bis-penicillamine enkephalin. Biopolymers. 32, 1623.

Soper, A. K., L. Dougan, J. Crain, and J. L. Finney. 2006. Excess entropy in alcohol-water solutions: A simple clustering explanation. Journal of Physical Chemistry B. 110, 3472.

Staples, B. R., and R. L. Nuttall. 1977. Activity and osmotic coefficients of aqueous calciumchloride at 298.15-K. Journal of Physical and Chemical Reference Data. 6, 385.

Steinfeld, J. I., J. S. Francisco, and W. L. Hase. 1989. Chemical Kinetics and Dynamics. Englewood Cliffs: Prentice Hall.

Stell, G., G. N. Patey, and J. S. Høye. 1981. Dielectric constants of fluid models: Statistical mechanical theory and its quantitative implementation. Advances in Chemical Physics. $48,183$.

Stockmayer, W. H. 1950. Light scattering in multi-component systems. Journal of Chemical Physics. 18, 58.

Stradner, A., H. Sedgwick, F. Cardinaux, W. C. K. Poon, S. U. Egelhaaf, and P. Schurtenberger. 2004. Equilibrium cluster formation in concentrated protein solutions and colloids. Nature. 432, 492.

Tanford, C. 1964. Isothermal unfolding of globular proteins in aqueous urea solutions. Journal of American Chemical Society. 86, 2050.

Tanford, C. 1974. Thermodynamics of micelle formation: Prediction of micelle size and size distribution. Proceedings of the National Academy of Sciences. 71, 1811.

Tanford, C. 1997. How protein chemists learned about the hydrophobic factor. Protein Science. 6, 1358.

Teubner, M., and R. Strey. 1987. Origin of the scattering peak in microemulsions. Journal of Chemical Physics. 87, 3195.

Teufel, D. P., C. M. Johnson, J. K. Lum, and H. Neuweiler. 2011. Backbone-driven collapse in unfolded protein chains. Journal of Molecular Biology. 409, 250.

Theodorou, D. N., and U. W. Suter. 1985. Geometrical considerations in model systems with periodic boundaries. Journal of Chemical Physics. 82, 955.

Timasheff, S. N. 1992. A physicochemical basis for the selection of osmolytes by nature. In Water and Life: Comparative Analysis of Water Relationships at the Organismic, Cellular, and Molecular Levels Edited by G. N. Somero, C. B. Osmond and C. L. Bolis. Berlin: Springer-Verlag.

Timasheff, S. N. 1993. The control of protein stability and association by weak-interactions with water - how do solvents affect these processes? Annual Review of Biophysics and Biomolecular Structure. 22, 67.

Timasheff, S. N. 1998a. Control of protein stability and reactions by weakly interacting cosolvents: The simplicity of the complicated. Advances in Protein Chemistry. 51, 355.

Timasheff, S. N. 1998b. In disperse solution, "osmotic stress" is a restricted case of preferential interactions. Proceedings of the National Academy of Sciences of the United States of America. 95, 7363.

Timasheff, S. N. 2002a. Protein-solvent preferential interactions, protein hydration, and the modulation of biochemical reactions by solvent components. Proceedings of the National Academy of Sciences of the United States of America. 99, 9721.

Timasheff, S. N. 2002b. Protein hydration, thermodynamic binding, and preferential hydration. Biochemistry. 41, 13473.

Timasheff, S. N., and T. Arakawa. 1988. Mechanism of protein precipitation and stabilization by 
co-solvents. Journal of Crystal Growth. 90, 39.

Timasheff, S. N., and T. Arakawa. 1989. Stabilization of protein structure by solvents. In Protein Structure: A Practical Approach, Edited by T. E. Creighton. Oxford: IRL Press at Oxford University Press.

Timasheff, S. N., and G. F. Xie. 2003. Preferential interactions of urea with lysozyme and their linkage to protein denaturation. Biophysical Chemistry. 105, 421.

Tokunaga, J. 1975. Solubilities of oxygen, nitrogen, and carbon-dioxide in aqueous alcohol solutions. Journal of Chemical and Engineering Data. 20, 41.

Tolmachev, V. V. 1960. Relationship between the statistic variation principle and the method of forming partial sums for diagrams in the thermodynamic perturbation theory for a modified statement of the problem of bose-einstein non-ideal system. Doklady Akademii Nauk USSR. 134, 1324.

Tran, H. T., A. Mao, and R. V. Pappu. 2008. Role of backbone-solvent interactions in determining conformational equilibria of intrinsically disordered proteins. Journal of the American Chemical Society. 130, 7380.

Treece, J. M., R. S. Sheinson, and T. L. McMeekin. 1964. Solubilities of $\beta$-lactoglobulins A, B, and AB. Archives of Biochemistry and Biophysics. 108, 99.

Treiner, C., P. Tzias, M. Chemla, and G. M. Poltoratskii. 1976. Solvation of tetrabutylammonium bromide in water + acetonitrile mixtures at $298.15 \mathrm{~K}$ from vapour pressure measurements of dilute solutions. Journal of the Chemical Society, Faraday Transactions 1: Physical Chemistry in Condensed Phases. 72, 2007.

Treszczanowicz, T., A. J. Treszczanowicz, T. Kasprzycka-Guttman, and A. Kulesza. 2001. Solubility of $\beta$-carotene in binary solvents formed by some hydrocarbons with ketones. Journal of Chemical and Engineering Data. 46, 792.

Uversky, V. N., C. J. Oldfield, and A. K. Dunker. 2005. Showing your ID: Intrinsic disorder as an ID for recognition, regulation and cell signaling. Journal of Molecular Recognition. $18,343$.

Valdeavella, C. V., J. S. Perkyns, and B. M. Pettitt. 1994. Investigations into the common ion effect. Journal of Chemical Physics. 101, 5093.

van't Hoff, J. H. 1887. Die rolle des osmotischen druckes in der analogie zwischen lösungen und gasen. Zeitschrift für Physikalische Chemie, Stöchiometrie und Verwandtschaftslehre. 1, 481.

van't Hoff, J. H. 1894. How the theory of solutions arose. Berichte der Deutschen Chemischen Gesellschaft. 27, 6.

van Alsten, J. G., and C. A. Eckert. 1993. Effect of entrainers and of solute size and polarity in supercritical-fluid solutions. Journal of Chemical and Engineering Data. 38, 605.

van Ness, H. C. 1995. Thermodynamics in the treatment of vapor/liquid equilibrium (vle) data. Pure and Applied Chemistry. 67, 859.

van Ness, H. C., and M. M. Abbott. 1982. Classical Thermodynamics of Nonelectrolyte Solutions: With Applications to Phase Equilibria. New York: McGraw Hill.

Vergara, A., L. Paduano, F. Capuano, and R. Sartorio. 2002. Kirkwood-Buff integrals for polymer-solvent mixtures. Preferential solvation and volumetric analysis in aqueous peg solutions. Physical Chemistry Chemical Physics. 4, 4716.

Verlet, L. 1968. Computer experiments on classical fluids. 2. Equilibrium correlation functions. Physical Review. 165, 201.

Vlcek, L., A. A. Chialvo, and D. R. Cole. 2011. Optimized unlike-pair interactions for water- 
carbon dioxide mixtures described by the SPC/E and EPM2 models. Journal of Physical Chemistry B. 115, 8775.

Wallas, S. M. 1985. Phase Equilibria in Chemical Engineering. Boston: ButterworthHeinemann.

Wang, J. M., P. Cieplak, and P. A. Kollman. 2000. How well does a restrained electrostatic potential (RESP) model perform in calculating conformational energies of organic and biological molecules? Journal of Computational Chemistry. 21, 1049.

Wang, S. S., C. G. Gray, P. A. Egelstaff, and K. E. Gubbins. 1973. Monte-Carlo study of pair correlation-function for a liquid with non-central forces. Chemical Physics Letters. 21, 123.

Wang, W., O. Donini, C. M. Reyes, and P. A. Kollman. 2001. Biomolecular simulations: Recent developments in force fields, simulations of enzyme catalysis, protein-ligand, proteinprotein, and protein-nucleic acid noncovalent interactions. Annual Review of Biophysics and Biomolecular Structure. 30, 211.

Wedberg, N. H. R. I. 2011. Molecular modeling of enzyme dynamics towards understanding solvent effects. Ph.D. Thesis, DTU Chemical Engineering, Technical University of Denmark, Kongens Lyngby.

Wedberg, R., J. Abildskov, and G. H. Peters. 2012. Protein dynamics in organic media at varying water activity studied by molecular dynamics simulation. Journal of Physical Chemistry B. 116, 2575.

Wedberg, R., J. P. O’Connell, G. H. Peters, and J. Abildskov. 2010. Accurate Kirkwood-Buff integrals from molecular simulations. Molecular Simulation. 36, 1243.

Wedberg, R., J. P. O'Connell, G. H. Peters, and J. Abildskov. 2011a. Pair correlation function integrals: Computation and use. Journal of Chemical Physics. 135, 084113.

Wedberg, R., J. P. O'Connell, G. H. Peters, and J. Abildskov. 2011b. Total and direct correlation function integrals from molecular simulation of binary systems. Fluid Phase Equilibria. $302,32$.

Wedberg, R., G. H. Peters, and J. Abildskov. 2008. Total correlation function integrals and isothermal compressibilities from molecular simulations. Fluid Phase Equilibria. 273, 1.

Weerasinghe, S., M. B. Gee, M. Kang, N. Bentenitis, and P. E. Smith. 2010. Developing force fields from the microscopic structure of solutions: The Kirkwood-Buff approach. In Modeling solvent environments: Wiley-VCH Verlag GmbH and Co. KGaA.

Weerasinghe, S., and B. M. Pettitt. 1994. Ideal chemical-potential contribution in moleculardynamics simulations of the grand-canonical ensemble. Molecular Physics. 82, 897.

Weerasinghe, S., and P. E. Smith. 2003a. Cavity formation and preferential interactions in urea solutions: Dependence on urea aggregation. Journal of Chemical Physics. 118, 5901.

Weerasinghe, S., and P. E. Smith. 2003b. Kirkwood-Buff derived force field for mixtures of acetone and water. Journal of Chemical Physics. 118, 10663.

Weerasinghe, S., and P. E. Smith. 2003c. A Kirkwood-Buff derived force field for mixtures of urea and water. Journal of Physical Chemistry B. 107, 3891.

Weerasinghe, S., and P. E. Smith. 2003d. A Kirkwood-Buff derived force field for sodium chloride in water. Journal of Chemical Physics. 119, 11342.

Weerasinghe, S., and P. E. Smith. 2004. A Kirkwood-Buff derived force field for the simulation of aqueous guanidinium chloride solutions. Journal of Chemical Physics. 121, 2180.

Weerasinghe, S., and P. E. Smith. 2005. A Kirkwood-Buff derived force field for methanol and aqueous methanol solutions. Journal of Physical Chemistry B. 109, 15080. 
Weinreb, P. H., W. Zhen, A. Poon, K. A. Conway, and P. T. Lansbury. 1996. NACP, a protein implicated in Alzheimer's disease and learning, is natively unfolded. Biochemistry. 35, 13709.

Weinstein, R. D., A. R. Renslo, R. L. Danheiser, J. G. Harris, and J. W. Tester. 1996. Kinetic correlation of Diels-Alder reactions in supercritical carbon dioxide. Journal of Physical Chemistry. 100, 12337.

Wen, X.-G. 2004. Quantum Field Theory of Many-Body Systems: From the Origin of Sound to an Origin of Light and Electrons. Oxford: Oxford University Press.

Wheeler, D. R., and J. Newman. 2004a. Molecular dynamics simulations of multicomponent diffusion. 1. Equilibrium method. Journal of Physical Chemistry B. 108, 18353.

Wheeler, D. R., and J. Newman. 2004b. Molecular dynamics simulations of multicomponent diffusion. 2. Nonequilibrium method. Journal of Physical Chemistry B. 108, 18362.

Widom, B. 1963. Some topics in the theory of fluids. Journal of Chemical Physics. 39, 2808.

Wienke, G., and J. Gmehling. 1998. Prediction of octanol-water partition coefficients, Henry coefficients, and water solubilities using UNIFAC. Toxicological and Environmental Chemistry. 65, 57.

Wiggins, P. 2008. Life depends upon two kinds of water. PLoS One. 3, e1406.

Wilczek-Vera, G., and J. H. Vera. 2011. The activity of individual ions. A conceptual discussion of the relation between the theory and the experimentally measured values. Fluid Phase Equilibria. 312, 79.

Wilhelm, E., R. Battino, and R. J. Wilcock. 1977. Low-pressure solubility of gases in liquid water. Chemical Reviews. 77, 219.

Williams, J. R., and A. A. Clifford, Eds. 2000. Supercritical fluid methods and protocols. Edited by J. M. Waker, Methods in Biotechnology. Totowa, New Jersey, USA: Humana Press Inc.

Wilson, G. M. 1964. Vapor-liquid equilibrium. XI. A new expression for the excess free energy of mixing. Journal of the American Chemical Society. 86, 127.

Wong, D. S. H., and S. I. Sandler. 1992. A theoretically correct mixing rule for cubic equations of state. American Institute of Chemical Engineers Journal. 38, 671.

Wooley, R. J., and J. P. O'Connell. 1991. A database of fluctuation thermodynamic properties and molecular correlation-function integrals for a variety of binary liquids. Fluid Phase Equilibria. 66, 233.

Wrabl, J., and D. Shortle. 1999. A model of the changes in denatured state structure underlying m value effects in staphylococcal nuclease. Nature Structural Biology. 6, 876.

Wright, P. E., and H. J. Dyson. 1999 Intrinsically unstructured proteins: Re-assessing the protein structure-function paradigm. Journal of Molecular Biology. 293, 321.

Wyman, J. 1964. Linked functions and reciprocal effects in hemoglobin - A 2nd look. Advances in Protein Chemistry. 19, 223.

Yalkowsky, S. H., and T. J. Roseman. 1981. Solubilization of drugs by cosolvents. In Techniques of Solubilization of Drugs, Edited by S. H. Yalkowsky. New York: Marcel Dekker.

Yancey, P., M. Clark, S. Hand, R. Bowlus, and G. Somero. 1982. Living with water stress: Evolution of osmolyte systems. Science. 217, 1214.

Yesodharan, S. 2002. Supercritical water oxidation: An environmentally safe method for the disposal of organic wastes. Current Science. 82, 1112.

Zeck, S., and H. Knapp. 1985. Solubilities of ethylene, ethane, and carbon-dioxide in mixed- 
solvents consisting of methanol, acetone, and water. International Journal of Thermophysics. 6, 643.

Zhang, C., and J. P. Ma. 2010. Enhanced sampling and applications in protein folding in explicit solvent. Journal of Chemical Physics. 132, 16.

Zhang, W. T., M. W. Capp, J. P. Bond, C. F. Anderson, and M. T. Record. 1996.

Thermodynamic characterization of interactions of native bovine serum albumin with highly excluded (glycine betaine) and moderately accumulated (urea) solutes by a novel application of vapor pressure osmometry. Biochemistry. 35, 10506.

Zhong, Y., and S. Patel. 2010. Nonadditive empirical force fields for short-chain linear alcohols: Methanol to butanol. Hydration free energetics and Kirkwood-Buff analysis using charge equilibration models. Journal of Physical Chemistry B. 114, 11076.

Zhu, X., P. E. M. Lopes, and A. D. Mackerell, Jr. 2012. Recent developments and applications of the CHARMM force fields. Wiley Interdisciplinary Reviews-Computational Molecular Science. 2, 167.

Zielkiewicz, J. 1995a. Kirkwood-Buff integrals in the binary and ternary mixtures containing heptane and aliphatic alcohol. Journal of Physical Chemistry. 99, 3357.

Zielkiewicz, J. 1995b. Solvation of DMF in the $N, N$-dimethylformamide + alcohol + water mixtures investigated by means of the Kirkwood-Buff integrals. Journal of Physical Chemistry. 99, 4787.

Zoranić, L., R. Mazighi, F. Sokolić, and A. Perera. 2009. Concentration fluctuations and microheterogeneity in aqueous amide mixtures. Journal of Chemical Physics. 130, 124315.

Zou, Q., B. J. Bennion, V. Daggett, and K. P. Murphy. 2002. The molecular mechanism of stabilization of proteins by TMAO and its ability to counteract the effects of urea. Journal of the American Chemical Society. 124, 1192. 